Portland State University

PDXScholar

\title{
Women's Work: a Feminist Standpoint Theory Study of Scholarship, Voice, and Resistance in the Academic Generation of Knowledge
}

Linnea Angelica Spitzer

Portland State University

Follow this and additional works at: https://pdxscholar.library.pdx.edu/open_access_etds

Part of the Publishing Commons, and the Women's Studies Commons

Let us know how access to this document benefits you.

\section{Recommended Citation}

Spitzer, Linnea Angelica, "Women's Work: a Feminist Standpoint Theory Study of Scholarship, Voice, and Resistance in the Academic Generation of Knowledge" (2021). Dissertations and Theses. Paper 5752. https://doi.org/10.15760/etd.7623

This Dissertation is brought to you for free and open access. It has been accepted for inclusion in Dissertations and Theses by an authorized administrator of PDXScholar. Please contact us if we can make this document more accessible: pdxscholar@pdx.edu. 


\title{
Women's Work: A Feminist Standpoint Theory Study of Scholarship, Voice, and Resistance in the Academic Generation of Knowledge
}

\section{by}

\section{Linnea Angelica Spitzer}

A dissertation submitted in partial fulfillment of the requirements for the degree of

\section{Doctor of Education}

in

Educational Leadership: Postsecondary Education

\author{
Dissertation Committee: \\ Karen Haley, Chair \\ Erin Flynn \\ Priya Kapoor \\ Annie Knepler
}

Portland State University

2021 


\begin{abstract}
More women than ever are earning doctoral degrees and are taking research or teaching positions at universities. However, the number of tenured women in full professorships have not yet achieved parity with the number of men in similar positions. Of the many reasons proposed for the disproportionate representation of women in the higher ranks of academia, one of the most commonly cited is the lower rates of publication by women in scholarly journals, an important criterion for promotion and tenure. However, women faculty are not unproductive. As scholars, they produce research and publish their findings in mainstream academic journals. In their teaching and advising roles, women faculty also mentor novice scholars in how to participate in research and publication practices. The question is, what role do women play in perpetuating or subverting the androcentric expectations of academic scholarship in their research and mentoring practices? Through the lens of Feminist Standpoint Theory, this qualitative in-depth interview study explores the research, publication, and mentoring experiences of women professors in order to understand the different ways in which women successfully participate in the academic generation of knowledge. Results suggest that women both reproduce and subvert many androcentric expectations of academic publication in their own research and in their mentoring practices. Based on these results, this dissertation argues for changing the lens through which women's publication practices are viewed, in order to move away from a deficit frame to one that fully celebrates the depth and complexity that women scholars bring to the generation of knowledge.
\end{abstract}




\section{ACKNOWLEDGEMENTS}

I would like to thank my family, friends, Ed.D. cohort, colleagues, students, and community members who have supported me and who continue to support me through this educational journey. In particular, I would like to thank my husband, Eric Bagdonas and my parents, Rosalind and Richard Spitzer for putting up with me and supporting me in unquantifiable ways. I would like to thank my aunt and uncle, Sue and Steve Appelo, for collectively having more degrees than I can count, and for their unyielding support of their nieces and nephews' educational journeys. My educational journey has also been supported by a network of intelligent, loving friends. A special thank you to Bethany Potts, my four-year-EdD-writing partner and motivator extraordinaire; Denise Harron, who always remembers to check up on me and who holds the unique honor of being the only person in the known universe aside from my committee to have read my dissertation end-to-end; and Amy Hofer for pandemic walks, cookies, and wide-ranging emotional support. This dissertation would not have been possible without the generous participation of the women I interviewed, and I will be forever grateful for their time and their candidness. Last, but certainly not least, I would like to thank my advisor, Karen Haley, for her kindness, her responsiveness, and her eagle eye, as well as my committee for their time and invaluable feedback. 
Abstract

\section{TABLE OF CONTENTS}

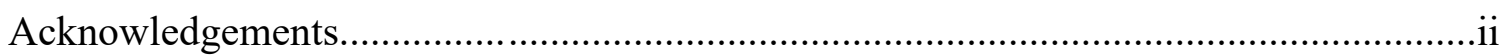

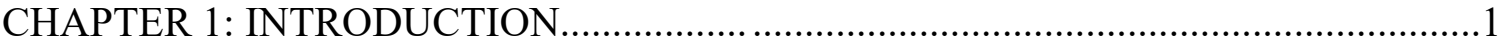

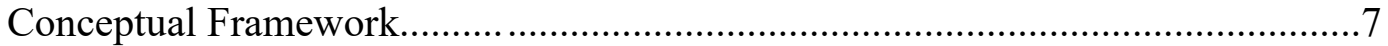

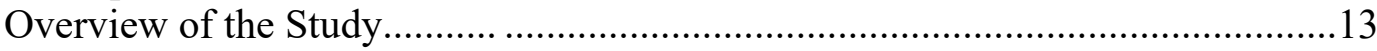

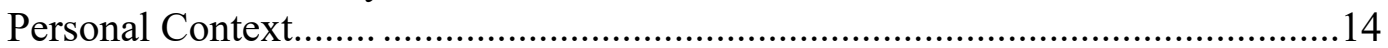

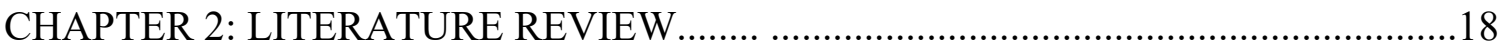

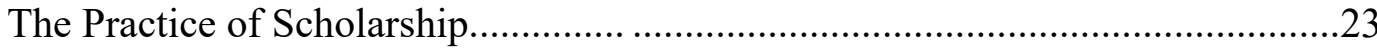

The Practice of Scholarly Writing............................................................19

The Practice of Scholarly Research............................................................22

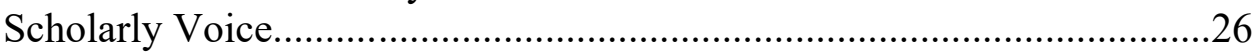

Gatekeepers in Academic Publication.......................................................32

Socialization: Alignment of Academic Scholarship and Identity............................35

Community of Practice........................................................................... 37

Social Reproduction in Academia..........................................................40

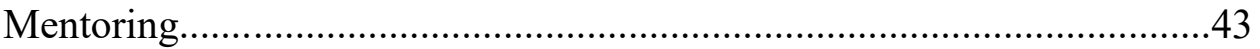

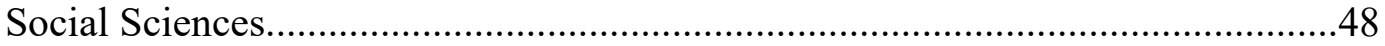

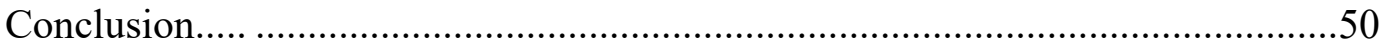

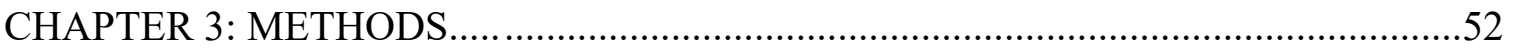

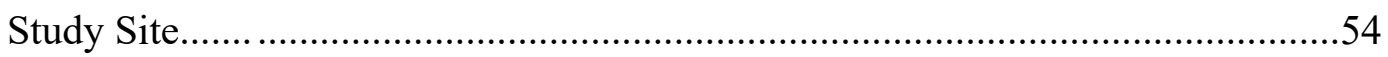

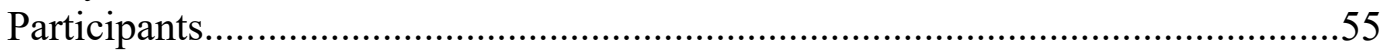

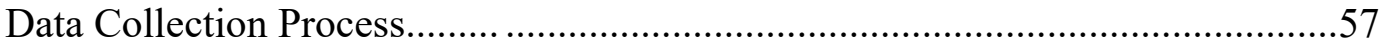

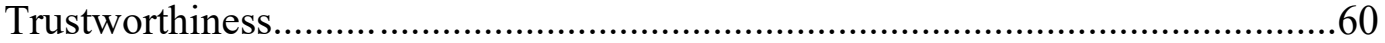

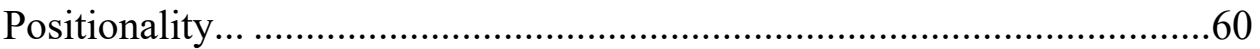

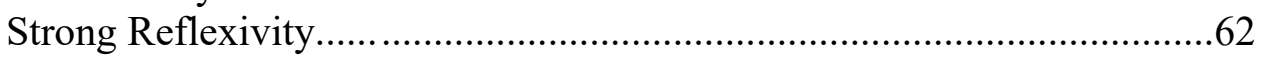

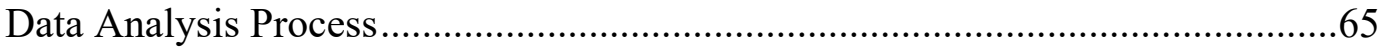

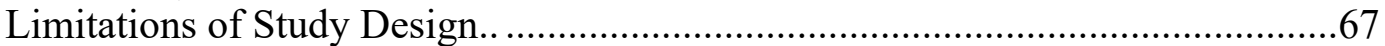

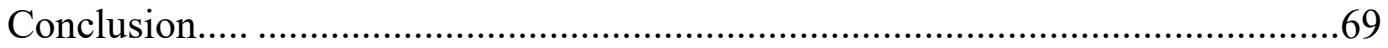

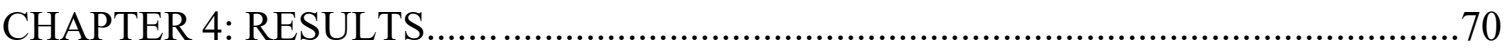

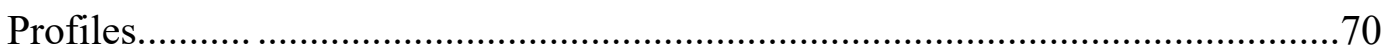

Angela: The Manifesto Writer................................................................71

Catherine: A Surgeon with a Scalpel......................................................

Lisa: The Historical View.....................................................................72

Lucy: Simultaneously, However................................................................73

Oksana: Not One for Packaging...........................................................74

Rene: Lawyering ...............................................................................74

Sara: Meticulously Proving Them Wrong................................................75

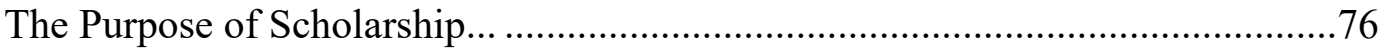

To Generate Understanding of Complex, Meaningful Phenomena............78

Choosing Complex Research Topics ............................................79

Writing Complex Research Topics................................................

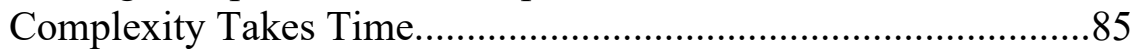

To Communicate, to Participate in a Conversation....................................87 
The Influence of Audience on Communicative Choices. .87

The Influence of Tenure Requirements on Communicative Choices

The Process of Becoming a Scholar..

Socialization

Mentors and Advisors.

The Culture of Graduate School...............................................103

Early Experiences with Publication........................................108

Reviewer Feedback.................................................109

Publication Support from Senior Scholars .....................111

Professional Evolution

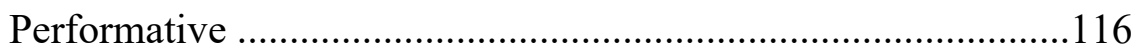

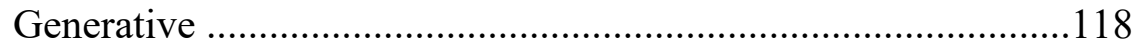

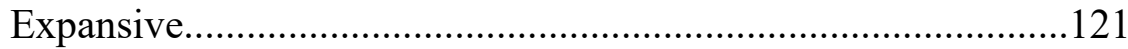

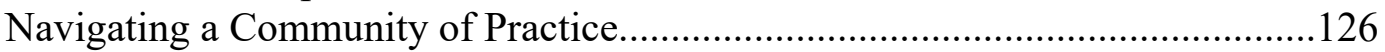

Navigating the Conversation of Scholarship. ......................................126

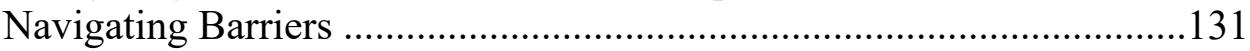

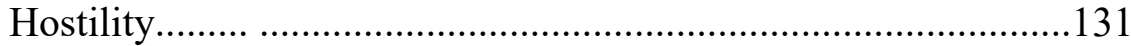

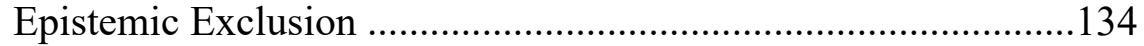

Gendered Defaults..................................................................135

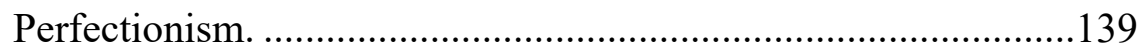

Finding Resilience................................................................142

Navigating Scholarly Reproduction........................................................ 145

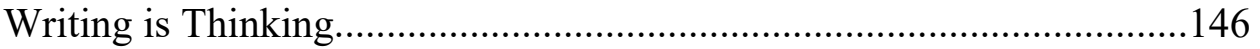

The Practice of Mentoring.........................................................151

Reciprocal Mentoring .........................................................151

Intersections of Race and Gender in Mentoring.......................143

Conclusion.

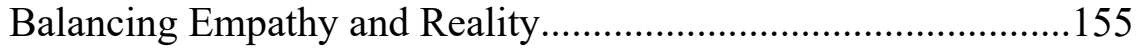

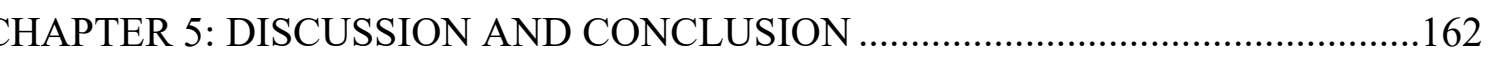

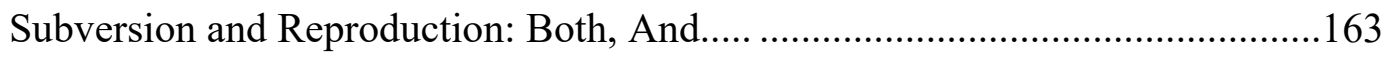

Subversion of Disciplinary Boundaries...............................................164

Subversion of Boundaries between Personal and Professional ..............165

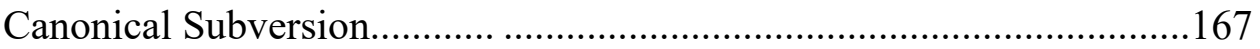

Subversion of Time.....................................................................170

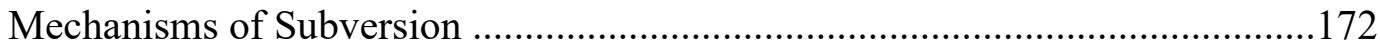

Perfectionism as a Mechanism of Subversion ....................................173

Using the Master's Tools for Subversion ............................................177

Teaching Participatory Practices through Mentoring .....................................180

Social Reproduction in Mentoring..................................................... 180

Explicit vs. Implicit Communication of Norms ................................. 185

The Importance of Relational Networks .......................................................190

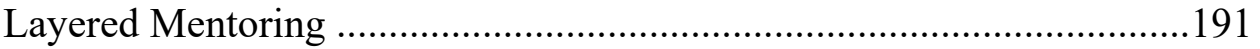

Reciprocal Mentoring ...............................................................193 
WOMEN'S WORK $\quad$ v

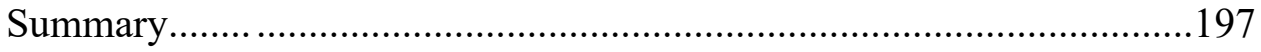

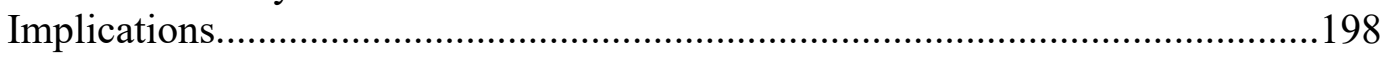

Myth \#1: Women's Research Practices Should Emulate those of Men..198

Myth \#2: Women are Stymied by the Written Style of Academic

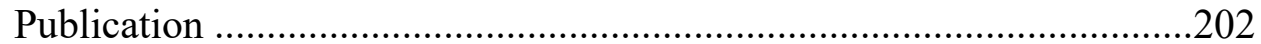

Myth \#3: Perfectionism is a Pathology .............................................206

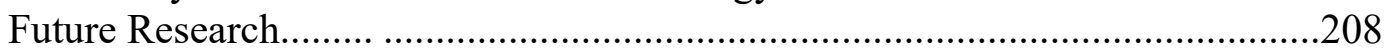

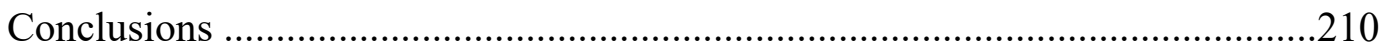

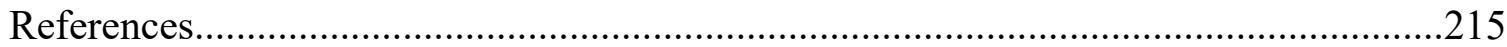

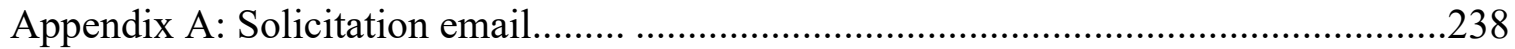

Appendix B: Solicitation email attachment... .............................................................239

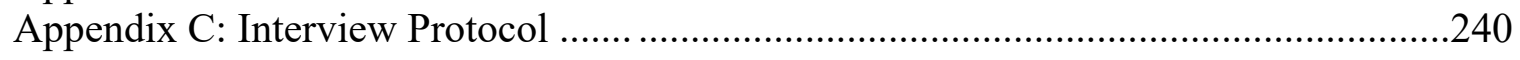




\section{CHAPTER 1: INTRODUCTION}

More women than ever are earning doctoral degrees and are taking research or teaching positions at universities. However, despite a three-fold increase in the number of women earning college degrees over the past 75 years, the percentage of women in faculty positions at American universities has not increased at a similar rate (Kelly, 2019). Although women now hold nearly half of all faculty positions, the vast majority of women working in higher education fill the ranks of non-tenure track instructors or lecturers. In 2017, women held 56\% of instructor and lecturer positions in American universities, $52 \%$ of the assistant professor positions, $45 \%$ of the associate professor positions, and only 33\% of the full professorships (McFarland et al., 2017). These numbers point to a rather persistent problem: women are entering the professoriate at similar rates as men, but their numbers have not yet achieved parity in the upper levels of the academic hierarchy (Box-Steffensmeier et al., 2015; Ginther \& Kahn, 2006; Kelly, 2019). Lack of promotion is a problem for all women, but while the numbers of white women faculty in assistant, associate, and full professor ranks have shown steady growth in many departments, the numbers of women with multiple intersecting marginalized identities, such as race, nation, and class, are still disappointingly low (Kelly, 2019; Kelly \& McCann, 2014). In 2017, for example, 2\% of full professors in American universities identified as black women and only 1.5\% identified as Latina (McFarland et al., 2017), a number which has increased by less than half a percentage point for both groups since 2007 (Planty et al., 2009). 
The lack of women in higher positions of academia is problematic because universities are a primary location for the generation of knowledge (Sprague, 2016). As professors generate and share knowledge through research, teaching, and publication, students learn to engage with both dominant and subversive ideas about how the world works. A professoriate that predominately consists of Anglo-European men ensures that the knowledge created and shared at universities will arise from the experiences of an elite class of individuals and will likely not represent the lived experiences of an increasingly diverse student body (Gonzales, 2018; Sprague, 2016). The entrenchment of androcentric perspectives leads to a number of concerns regarding the prevalence of diverse voices in the generation of knowledge and the education of the next generation of scholars. On the one hand, if perspectives that challenge the status quo are put forth from those in non-dominant positions, then how will these perspectives be valued? On the other hand, it is worthwhile asking whether women holding less prestige and security would be willing to risk tenure and further promotion in order to engage in and promote such subversive practices.

Research on women in academia has reported on a variety of reasons why women tend to be found primarily at the lower rungs of the academic ladder. One reason is that women may leave academia because they feel unwelcomed or out of place. Some research has suggested that faculty who are not white, heteronormative men continue to face a persistently "chilly" climate of sexism, racism, and homophobia in academia (Stockdill \& Danico, 2012). This chilly climate can take a variety of forms for women faculty, including difficulty making meaningful mentoring connections with more senior 
men in their departments (Bagilhole, 1994), spending less time in professional conversations with other faculty members (O’Meara et al., 2017), or being treated as second-class citizens, particularly for women of multiple marginalized racial or sexual identities (O’Meara et al., 2017; Souto-Manning \& Ray, 2007). Other research suggests that women tend to struggle with the timing of the tenure clock. This has been shown to be particularly challenging for women with children, who are often faced with the expectation of being a primary caregiver both at home and at work, resulting in the need to balance care for one's career with care for others in her circle (Box-Steffensmeier et al., 2015; Ginther \& Kahn, 2006; Guarino \& Borden, 2017).

Another possible reason for the absence of women in higher positions of academia is that women tend to produce fewer research-based publications than men, an important criterion for promotion and tenure (Gómez Cama et al., 2016; Gonzales, 2018; O’Meara et al., 2017; Sefcovic \& Bifano, 2004; Vandrick, 2003). On average, women spend nearly six hours fewer per week on research, compared to men of similar rank and nearly double the amount of time on teaching-related tasks (such as reading dissertations or comps papers) (O’Meara et al., 2017). This lack of time spent on scholarship has very real consequences. Since the publication of research is the primary mode of communication in academia, less time spent on communication can mean less visibility for one's research agenda. The visibility of publication is also a vital source of professional legitimacy for scholars (Gonzales \& Terosky, 2016; Mato, 2011; Webb, 1992) and, by extension, a defining factor in their job security (Hyland, 2015). Because researchers promote their expertise and engage in academic discourse through 
publication, an academic's reputation, and thus job and funding opportunities, is often based on measures of productivity that include the appearance of articles in highly ranked journals (Buchanan, 2020; Canagarajah, 2002; Hyland, 2016; Mato, 2011; Paasi, 2005).

The pressure to publish has only increased in recent years, as has the pressure to produce money-generating research (in the form of grants), since state funding has decreased and federal funding has remained largely flat for American public universities over the past 20 years (Hyland, 2015; Two Decades of Change in Federal and State Higher Education Funding: Recent Trends across Levels of Government, 2019). Many institutions have therefore sought to increase their competitiveness and funding potential by either forcing out non-research faculty or requiring teaching faculty to produce published research (Hyland, 2015). However, it is not easy to engage in research without the privilege of being well-funded. To fund research, it is often necessary to procure grants from public and private institutions, but selection for these grants is often based on the applicant's existing research record (Hyland, 2015). Without publications to prove that a scholar can do the work or that a topic is researchable, it can be hard to convince a funding organization to devote money to a project. Without grant money, it can be challenging for a scholar to hire graduate students to assist with research and publication, as well as fund travel and research expenses necessary for producing new work. This cycle benefits those whose research focus is already intrinsically valued by those in charge of the production of knowledge and excludes those who seek to disrupt the status quo or present innovative ideas. 
A number of reasons have been proposed for the lower rates of publication for women. One commonly cited reason is that women tend to be saddled with a relatively high burden of service, including both heavy mentoring loads and a disproportionate amount of committee work, in comparison to men of similar ranks (Gómez Cama et al., 2016; Guarino \& Borden, 2017). For example, female graduate students are often steered to or voluntarily seek out mentoring from same gender or race faculty. Considering the smaller proportion of women in the professoriate, the increasing number of female students results in a unbalanced mentoring load for women faculty and especially women of color (Humble et al., 2006; Sandler \& Hall, 1986). In addition to mentoring work, women have been shown to perform a higher amount of departmental and university service work than men, both in terms of the number of activities and the time spent on these activities (Guarino \& Borden, 2017). The time spent on "taking care of the academic family" (Guarino \& Borden, 2017, p.19) may end up disadvantaging women in terms of available time to spend on research and publication. To illustrate, O'Meara et al. (2017) found that female faculty were significantly more likely than men to have spent time on internal service duties, like chairing masters' theses or undergraduate capstone projects. Men, on the other hand, were more likely to have served as an editor of a journal and to have at least one journal article submission under review. One takeaway from this comparison is that women's work at a university appears to be largely focused on internal responsibilities, whereas the work of men is more externally facing, allowing them to have a broader professional network and therefore more exposure to a scholarly community. Since publication is also externally facing, in that its goal is to disseminate 
knowledge, opportunities for research would also gravitate towards men, both from their connections and the assumption that their interests are more research-oriented than those of women.

Another barrier to publication that women reportedly face is the difficulty of reconciling their identities with the expectations of androcentric modes of communication and research practices in academic scholarship. As the leaders of academic institutions and primary generators of knowledge, upper-class Western men have had an over-sized influence on shaping the way that academic thought is generated and disseminated (Collins, 1990; Delgado Bernal \& Villalpando, 2002; Gonzales, 2018; Hilário et al., 2018; Mato, 2011; Sprague, 2016). These gatekeepers have dictated both the types of acceptable research practices and the language that can be used to communicate these practices in academic publication, to the exclusion of many other ways of knowing and communicating. Those whose work adheres to the long-standing communicative norms of academic scholarship are rewarded by having their work published in sanctioned venues while those working from the margins often face exclusion and dismissal (Buchanan, 2020; Canagarajah, 2002; Delgado Bernal \& Villalpando, 2002; Gray, 2017; hooks, 1994; Settles et al., 2020).

Despite all of these barriers, women do publish. In order to do so, they adhere to norms in some instances yet subvert them in others through both their research practices and their written voice. Knowing when and how to apply or ignore the rules of the academic game requires a sophisticated understanding of where and how boundaries can be pushed (Casanave, 2002), and while research on women scholars has shown that 
mentoring helps with publication (Dua, 2007; Holmes et al., 2007; Sánchez-Martín \& Seloni, 2019; Terosky, 2019), it is unclear whether this mentoring helps women subvert or "mind the boundaries" of academic publication (Gonzales, 2018). Do women, in their teaching and learning practice, perpetuate expectations of the androcentric academic establishment, or do they explicate (for themselves and others) a scholarly practice that pushes back and carves out new paths for future women scholars? In attempt to answer this question, I investigated how women serve as agents for the very norms that discredit and undermine their work.

\section{Conceptual Framework}

In order to center the voices of women in this exploration of research and publication practices in academia, I am using Feminist Standpoint Theory as my conceptual framework for this dissertation. Originating in the work of Hartstock (1983), Collins (1986,1990), and Smith (1987), Feminist Standpoint theorists argue that researchers generate knowledge based on how they understand the world, pursuing questions and research methods that align with their social values (Harding, 1991; HesseBiber et al., 2004; Sprague, 2016). However, because the primary modes of knowledge generation and dissemination have been historically controlled by upper-class Western men, many mainstream theories for interpreting social phenomena are based on the cultural assumptions of this relatively small subset of the population (Harding, 1991; Hartstock, 1983; Smith, 1987). The locus of knowledge is, therefore, the standpoint of a dominant group, which has traditionally been promoted as authoritative, value-free, and objective (Bhavnani, 2004; Harding, 1991; Sprague, 2016). The problem is that this 
perspective is based on subjective assumptions that have discounted and marginalized the lived experiences of those in non-dominant positions, leaving large gaps in the way the world is understood. In order to generate knowledge that is truly representative, Feminist Standpoint theorists pursue questions that are "rooted in women's lives," centering the subjects of research as knowers and their lived experiences as authoritative sources of knowledge (Hesse-Biber et al., 2004, p. 15).

In the development of Standpoint Theory, black feminist scholars have been particularly instrumental in calling for research that considers the multiple intersecting and conflicting identities that originate from the social communities to which women belong (Collins, 1986, 1990; Crenshaw, 1989; hooks, 1984). The consideration of "interlocking systems of oppression" is in contrast to the view of identities such as race, class, gender, and sexuality as binary opposites (white/non-white, man/woman, heterosexual/ homosexual), which is common feature of Western androcentric research practices (Collins, 1986, p.19). This oppositional framework creates "ranked dichotomies" used by dominant groups to create hierarchical designations of preference (Weber, 2004), implying that some groups are superior than others, a belief that reinforces existing systems of domination and subordination (Bhavnani, 2004; Collins, 1986; Le Guin, 1986/1989; Weber, 2004).

According to Standpoint Theory, the hierarchical position of the upper-class Western male has obscured his ability to be an objective generator of knowledge, resulting in a precedent of scientific assumptions that are based on andro- and Eurocentric biases (Bhavnani, 2004; Collins, 1986, 1990; Harding, 1991; Hesse-Biber et 
al., 2004). To illustrate, Harding (1991) describes how dominant groups refuse to be responsible for tasks associated with the drudgery of daily life (such as housekeeping, cooking, and childcare), leaving this area of care to those in non-dominant positions. The requirements for fulfilling these tasks are not based on innate preferences, but are rather socially determined by a variety of conditions that have surrounded the lives of dominant white men and the non-dominant position of women (and particularly, women of multiple marginalized identities, like race, class, sexuality, and/or nation) (Collins, 1990; Harding, 1991; Sprague, 2016; Weber, 2004). This uneven distribution of power and responsibility has influenced not only who has the time and space to be a legitimate creator of knowledge, but also what kind of knowledge they choose to create (Sprague, 2016). Liberated from the responsibility of daily care-taking duties, elite Western men have been largely free to spend their days contemplating the "perfect motions of abstract, isolated bodies" (Harding, 2001, p.27) rather than the imperfect collisions of human ones.

Due to the long exclusion of female perspectives from scientific research, the expectations for research practices reflect the privilege of the dominant male position. For one, the lack of responsibility for tasks associated with physical caretaking tasks have led to a preference for research that is based in abstraction and removed from the concrete world of meeting people's needs (Sprague, 2016). According to these preferences, research should yield findings that are broadly generalizable rather locally applicable, and should aim for developing grand theory, described using language that is "highly abstract, difficult to read, and containing obscure references" (hooks, 1994, p.64) over recommendations for practice. Androcentric research also requires the elimination 
of human, relational elements from the communication of findings. For example, the authors of scientific manuscripts are obscured through the use of passive voice and oblique references to "the researcher," and subjects are held at a distance through highly structured interview protocols and meticulously designed surveys (Gray, 2017; Mitchell, 2017; Sprague, 2016; Sprague \& Kobrynowicz, 2004). In another example of scientific distance, many researchers view the removal of subjects from outside influences as a mark of a strong piece of research. According to Sprague (2016), the removal of a subject from her natural environment reflects values of individualism through the belief that a subject can only be truly understood when she is examined in isolation from her community and her natural environment. Although researchers use this practice to eliminate variables, Sprague criticizes such individuation in research as a specifically white male value, existing in contrast to the experience of women, who find value in the embedded, concreate relationships of place and community.

An additional feature of masculine dominance in the generation of knowledge can be seen in the use of research as a tool to enforce existing structures of hierarchy (Collins, 1986; Sprague, 2016; Sprague \& Kobrynowicz, 2004). From preserving distance in the researcher-subject relationship in scientific studies to dividing the world into binary, oppositional categories, androcentric research has been highly effective at delineating knowledge from opinion and acceptable behavior from deviance. The distance between researcher and subject prevents the subject from participating in the generation of knowledge that might directly influence her lived experience. For example, Smith (1987) describes the dismantling of midwifery in England and the United States through the 
influence of the Western medical establishment, which sought to control and standardize the practice of childbearing. This system creates a hierarchy between the doctor and the patient, designating one as the knower and the other as the passive recipient of the knower's expertise. The professionalization of gynecology and the systematic exclusion of women from the medical profession has, according to Smith, silenced the experiential knowledge of women in an area where they should have the strongest voice.

In terms of oppositional categorization, black feminists have written at length how the multiple marginalizations of race, class, sexuality, and gender have rendered them invisible in the struggles for racial and gender equality. bell hooks (1984), for example, relates how she is often asked whether her black or her female identity is more important to her work, a question which asks her to separate into two distinct parts an identity that is wholly comprised of both elements. According to Collins (1986), Western discourse holds that these two halves do not enhance, but instead oppose each other, forcing those who hold multiple subjugated identities further onto the margins of their respective groups. As Audre Lorde (1977/2007) writes, “even in the women's movement, we have had to fight, and still do, for that very visibility that renders us most vulnerable, our blackness" (p.42). Through the portrayal of dichotomous, rather than intersecting identity, individuals are bifurcated into distinct categories, divided and alone, and buried under multiple levels of subjugated selves. These practices can be seen in the failure to both account for intersectionality in research practices and acknowledge the unique contributions of intersectional researchers in their disciplines (Harding, 1991; Sprague, 2016; Sprague \& Kobrynowicz, 2004). 
In order to counter the historical subjectivity originating from Euro- and androcentric biases, Sprague (2016) proposes that researchers work from a Feminist Standpoint based on the following guidelines:

- Work from the standpoint of the disadvantaged;

- Ground interpretations in interests and experience;

- Maintain strategically diverse discourse;

- Create knowledge that empowers the disadvantaged (p.140). Questions about marginalized groups tend to focus on deficiencies. It is important for feminist researchers to reframe questions to focus on interrogating social structures and empowering marginalized voices (p.14).

Despite the persistent challenges facing female academics, I believe, as bell hooks (1994) has written, that higher education has the potential to be truly liberatory, provided that marginalized voices are included in scholarly conversations. Unfortunately, the female voice has been remarkably absent in the academy. As the writer Ursula Le Guin (1986/1989) explained, it is the "father tongue" that has been the language of "works of law, philosophy, social thought, and science" (p.149). While this language has been immensely productive in the generation of knowledge, it has achieved its dominance through the subjugation of others. In contrast, Le Guin describes the mother tongue as a language that is "always on the verge of silence and often on the verge of song" (Le Guin, 1986/1989, p. 148), one that seeks relationships and exchange over dominance. In some writing, the female voice is readily observable in a personal anecdote or a joyful remark. In others, it is hidden, where a word or a turn of phrase leaves a mark as subtle as 
a thumbprint on an otherwise spotless glass window. In uncovering these voices, I am seeking to celebrate them, to showcase the ingenuity and perseverance of those who are navigating the imperfect landscape of another's voice. It is, therefore, from Sprague's guidelines above that I begin my dissertation research.

\section{Overview of the Study}

The purpose of this study is to explore how women understand, describe, and produce scholarly work. More specifically, this study will explore how women faculty have learned and interpreted the norms of academic communication, and how they either perpetuate or subvert these norms through their academic work and through their mentoring practices.

To explore this topic, I conducted a qualitative interview study of women assistant and associate professors in the social sciences at a large regional comprehensive university, using Feminist Standpoint Theory as my conceptual framework. Through a series of three in-depth semi-structured interviews, I asked my participants to report on their experiences in learning to write for their disciplines, whether/how they found ways of inserting their voice into their scholarship, and how they described values of scholarly writing to their mentees. Through these interviews, I explored how these women acted both as purveyors of androcentric norms of communication and as subverters of these norms. The findings from this study highlight the work that women do in order to successfully participate in the generation of knowledge.

In light of the above discussion regarding binaries favoring androcentric power structures, it is important to note that feminist research is not limited to exploring only 
one side of a binary gender categorization. Many of the challenges described by womenidentified scholars may also be experienced by men from underrepresented groups, from non-binary or non-gender conforming scholars, or even from white Anglophone men who value more nuanced modes of communication. The tenets of Feminist Standpoint Theory suggest that it is important to consider and accept the presence of many feminisms, as well as many ways of being female (Hesse-Biber et al., 2004)

For the purposes of this study, I focused on the experiences of self-identified women, with a full awareness of the contested nature of binary gender categorizations. My use of the term "woman" or "women" is an attempt to move past cis-gendered dichotomies, to also include "variously positioned self-identified women," (Linabary \& Hamel, 2017, p. 98) in my understanding of the experiences of women scholars.

\section{Personal Context}

I have worked in higher education for over ten years, as a non-tenure track faculty member in an intensive English language program. I teach advanced academic writing and therefore, commonly work with multilingual graduate students and professionals on their scholarship, coaching them on the format and structure their academic manuscripts. I have presented at conferences, participated in research projects, and conducted workshops, but until this past year, I had not published. This grated on me. I felt embarrassed talking with students and colleagues about writing because my own writing skills had not been legitimated by the professional establishment. There are reasons why it took me so long to publish empirical research, many of which line up with the research cited above. As a full-time non-tenure track instructor, I have a heavy teaching load, 
which requires most of my workday to be spent on planning lessons, teaching, grading, and meeting with students. I also spend a good deal of time in service work, as I belong to several departmental and university-wide committees, a compulsion which is probably driven by a desire to prove my worthiness to the institution as a non-tenure track faculty member.

Apart from issues of time, I have also struggled with aligning my research interests with my scholarly voice. Prior to my doctorate, my research training was in a branch of Applied Linguistics that adheres quite firmly to quantitative, positivist frameworks, despite the field's broader focus on communicative language practices. Because of this training, combined with my upbringing as a white, middle-class English speaker, the voice I am comfortable using in my writing reflects these positivist values. Nominalizations and dense, impersonal sentences roll off my fingertips much more easily than personal narratives like this. However, I have never been able to connect with the research topics that might be reported in such a voice, as I am drawn to topics that are deep and extensive in nature, ones that may require a more in-touch, personal writing style. In the few (unsuccessful) publications I attempted earlier in my career, I believe this internal conflict resulted in a writing style that was "intermittently disordered and an authorial voice that [is] inconsistently empowered" (Leggatt-Cook, 2011, p.394).

I am fortunate for many reasons. I grew up in white Anglophone middle-class family, where the majority of my relatives have received some form of post-secondary education, and a large portion has earned graduate degrees. This experience gave me the foundation to intuit the norms and expectations inherent in academic communication. I 
am now on my third college degree and have therefore had quite a bit of practice writing according to these conventions. Also, I am uniquely privileged because I have spent my professional career teaching writing to multilingual students, who have taught me about different cultural values in communication, and to whom I have learned to explicate the implicit values of writing American academic prose. In having the experience of explicitly communicating the norms of academic writing practice to multilingual writers, I have come to realize how rare this type of instruction is once American students have completed their undergraduate degrees. Despite the highly professionalized expectations of writing in graduate school, most novice scholars are expected to learn to write as I have, by intuiting the rules of academic prose based on knowledge of cultural expectations and norms. It is possible to learn the norms of academic communication in this way, but a scholar has to develop a certain amount of agency and understanding of these rules if she intends to use them in order to express her authentic voice. In my case, I feel this agency in my writing, but until recently, not in my research practice. I believe that such agency in both research and in the means of sharing the research is necessary for those of us who wish to participate in the generation of knowledge. We need a certain degree of ownership, or capital as Bourdieu (1987) would call it, over these means of knowledge production if we are to truly make it our own. In order to develop such ownership, however, it is important to understand the mechanisms through which ownership of knowledge has traditionally been denied to non-dominant groups.

In the section that follows, I will expand on how the conventions of academic writing have evolved to privilege certain voices over others and how these conventions 
can clash with the identities of women and others from non-dominant groups. I will also explore how these norms are often subverted by those seeking to disseminate knowledge from their own authentic positions. 


\section{CHAPTER 2: LITERATURE REVIEW}

Despite the increased diversity of university faculty (especially at the lower ranks), the reins of knowledge creation are still firmly held by an elite few. The gendered nature of the academy has prevented women from full participation in the publication of research, contributing to uneven promotion rates for women professors. Research suggests that there are a number of factors for why women do not publish as frequently as men, ranging from lack of time after teaching and service obligations to lack of support by the establishment. In addition to these factors, research on women scholars often discusses the challenges that women face in reconciling their identities with dominant practices of scholarship within the academy, including the ways in which research is conducted and disseminated. In order to better understand how the practice of scholarship in academia clashes with women's identities, this chapter describes how current research practices have been established, maintained, and reproduced in generations of academics. I explore research that discusses how women have both subverted and perpetuated these norms, and how these acts of subversion or perpetuation might support or hinder the development of future generations of women scholars.

This chapter further elaborates on these themes by exploring how dominant practices of scholarship might serve as a barrier for women's participation in the academic generation of knowledge. In the following sections, I first describe how the research and writing preferences of Anglo-European men have led to the establishment of scholarship practice in academia that is remarkably effective in excluding non-dominant voices. Next, I discuss how novice academics are socialized into the practice of 
scholarship, and how women and others from non-dominant groups tend clash with established norms as they are asked to rework their identities to better fit with the expectations of the academy. Finally, I explore how social science disciplines are a unique location for the exploration of these themes, as the increasing number of women graduate students in these fields has not been met with an equal degree of change in terms of who is in charge of knowledge generation and how this generation of knowledge is practiced.

\section{The Practice of Scholarship}

Many women have been able to successfully work within established boundaries and produce scholarship that is highly regarded by the mainstream academy; however, many others report challenges in communicating their scholarship in ways that are recognized by a system of knowledge production that has not been designed to accommodate their worldviews (Collins 1986; Gonzales, 2018; Harding, 2001; Fleischman, 1998; Sefcovic \& Bifano, 2004; Sprague, 2016). Such challenges result from the fact that while publishing academic research in peer-reviewed journals has become a global practice, the ways in which the construction of knowledge is practiced and shared have quite local origins (Mato, 2011). The particularities of these origins can be seen in the practices of both scholarly writing and scholarly research that are valued by the academic establishment. In the sections below, I elaborate on the androcentric origins and current expectations inherent in the practices of scholarship by first discussing practices of writing and then, by discussing the practices of research. Finally, I describe how these 
expectations result in a particular voice that academics are expected to impart on their readers and how the gatekeepers of academic publication enforce these standards.

\section{The Practice of Scholarly Writing}

The rhetorical structure and language used to communicate research in academic texts evolved primarily out of British and French scholarly publications, such as Philosophical Transactions, a journal published by the Royal Society of London, which began publication in 1665 (Williams, 2011). Featured in this journal were prominent scientists, such as Sir Isaac Newton, who developed structures of explication and argumentation designed to preempt attacks on their research by competing scholars (Bazerman, 1988; Lillis \& Turner, 2001). This structure of argumentation continues to play out in the ways that modern day academics are expected to present their research. For example, strong academic texts are often seen as those that seek to aggressively dominate their reader by using strategies such as attacking opponents and pre-emptively defending one's own arguments (Bazerman, 1988; Mitchell, 2017). Such strategies are reflected not only in the language used, but also in the location of the argument. Fleischman (1998) describes how the male preference for stating conclusions at the beginning of a texts (for example, in thesis statements or topic sentences) has dominated American composition practices. This is in contrast how women have been socialized to communicate, by building relationships and connections before launching into an assertion. As a result of these socialized tendencies, Fleischman (1998) asserts that women are often more comfortable beginning a text with personal experience and then setting up a line of reasoning that leads to a conclusion. In the end, it is the 
communicative practices more valued by Western men that have achieved prominence in current styles of academic argumentation, whereas the more relational or reflexive writing commonly valued by women and other non-dominant groups is seen as weak or biased (Canagarajah, 2002; Fleischman, 1998; Gray, 2017; Li, 2008; Mitchell, 2017).

The practice of aggressive argumentation was later supplemented by the $19^{\text {th }}$ century European positivist movement, which brought expectations for research to be value-neutral, replicable, and based on the objective analysis of observable phenomena in the pursuit of "Truth" (Hyland, 2015, p. 3). These values resulted in a writing style that prioritized a detached and impersonal authorial voice and a tendency towards abstraction rather than concreteness in theory and in language (Harding, 1991; Hilário et al., 2018; Sefcovic \& Bifano, 2004; Sprague, 2016). This style manifests in current academic preferences such as the avoidance of the first person (I/me/we/us) and the heavy use of nominalizations (nouns like avoidance, instead of verbs like avoid) in academic prose (Biber et al., 1999; Fleischman, 1998). In using such structures in writing, the author's presence is removed from the text and the actions become abstractions. This style of writing is so engrained in our expectations for written texts that it might feel jarring if I suddenly enter this text, breaking what is commonly described in theater as the "fourth wall" and talk to you, my reader, directly. You might feel as though I am being indiscrete, too personal, too exposed. I'm sorry. I'll go back behind the wall now.

The writing style originating in Philosophical Transactions and the positivist movement has continued to influence views on what constitutes scholarly argumentation, largely due to the continued dominance of the Anglo-European Western male. To this 
day, the Western world controls the majority of publication outlets for academic scholarship. Out of the top-ranked 500 journals in the world, only $16 \%$ are based in nonAnglophone countries, and only one is based in a non-Western country (China) (Scimago Journal \& Country Rank, 2020). This number actually represents a decrease in diversity since this literature review was initially drafted. In $2017,20 \%$ of journals were in nonAnglophone countries and three were in non-Western Countries (Scimago Journal \& Country Rank, 2017). In addition to the limited geographic range of scholarly journals, many of the editorships of these journals fall to older, white, Anglophone men holding tenured positions at their universities (Tardy \& Matsuda, 2009). These gatekeepers have been shown to be particularly challenged in accepting modes of communication or ideas that do not fit within their established worldview (Hyland, 2015; Nelson \& Castelló, 2012; Tardy \& Matsuda, 2009) and have a vested interest in maintaining the "historical, and thus familiar arrangements of a field" (Gonzales \& Terosky, 2016, p. 4). The entrenchment of the gatekeepers of academic communication has been widely observed across the disciplinary spectrum, with many expressing sentiments similar to those written by the political commentator and literary critic, Edward Said (2001), Writing is not free, nor is it performed uniquely by a sovereign writer who writes more or less as he or she pleases. Writing belongs to a system of utterances that has all sorts of affiliative, often constricting relationships... One can see this most clearly in scholarly writing...in which the individual writer is born on very heavily by institutions, rituals, exclusions, prohibitions, and a highly particularized, even tyrannical conception of truth and the desire for truth. (p.24) 
Indeed, the voice in which an academic is expected to communicate her research is very rarely her own, but rather an amalgamation of expectations dictated by scientific and disciplinary conventions. In learning to speak the academic tongue, scholars demonstrate their allegiance not only to their disciplines, but also to a lineage of white Anglophone male argumentation.

\section{The Practice of Scholarly Research}

In addition to the restrictive nature of academic communication, the practices of constructing knowledge can serve as barriers to women publishing their research in mainstream journals. Although positivist epistemologies have been challenged in recent decades, assumptions of best practices in research that have been based on these beliefs are still prevalent in the expectations of the mainstream academic press (Hesse-Biber et al., 2004; Mitchell, 2017). According to this worldview, reality is external to the researcher and rests patiently in the shadows, waiting to be elucidated by an unbiased seeker (Mitchell, 2017). The continued dominance of positivist values has led to the prioritization of research topics that are singularly focused, broadly generalizable, and hierarchical in terms of relationships between the seeker and the subject (Bazerman, 1988; Fleischman, 1998; Gonzales, 2018; Harding, 1991; Sprague, 2016; Sprague \& Kobrynowicz, 2004).

One of the hallmarks of academic research is a deep, singular focus on a particular topic and the subsequent extension of this topic to produce grand theories about the world. Students of academic writing are told to narrow their topics, and the research questions that frame journal articles are limited to the investigation of a meticulously 
delineated query. Yet, tests of statistical significance drawn from such limited investigations are often used to infer generalizability to a much wider population. This trend appears to emulate the tendency of androcentric research to generalize findings drawn from the perspectives of white upper-class men under the assumption that what is true for men is true for women, and what is true for whites is true for people of color (for discussions of such overgeneralization, see Collins, 1986, 1990; Crenshaw, 1989; Harding, 2004; hooks, 1984; Mato, 2011; Sprague, 2016). In contrast to this perspective, many researchers working from non-dominant epistemologies argue that all knowledge is locally derived and that our understanding of the world arises from a person's position within their particular society (Hesse-Biber et al., 2004; Mato, 2011; Sprague, 2016). Women researchers, for example, often draw from the cultural and social capital (see Bourdieu, 1979, 1987) that originates from their communities and therefore tend to research themes that are interdisciplinary, practice-oriented, and arise from their lived experiences (Gonzales, 2018). From the androcentric perspective, such research is less rigorous, more biased, and less generalizable to the general public (Delgado Bernal \& Villalpando, 2002; hooks, 1994; Huber, 2009), and therefore, holds less value than research that deeply explores a single uniting truth about the state of humanity.

The Western locus of scholarship has also worked to maintain and perpetuate existing hierarchies. One way scholarship does so is by promoting the hierarchy of the individual, where the knower, or the researcher, is separate from the subjects of study (Hesse-Biber et al., 2004; Sprague \& Kobrynowicz, 2004). In research of this nature, participants in studies are not seen as holders of knowledge, but rather as sites for 
researchers to uncover truths through careful study and observation of an "other." According to Sprague (2016), such research tends to compare differences between hierarchical groups (whites vs. People of Color; Western vs. "traditional societies") rather than comparing within-group differences or hierarchical similarities. Western androcentric research also maintains hierarchical relationships between dominant and marginalized groups by asking different questions when researching hierarchically differentiated groups. For example, it would be more common to ask why women tend to lack self-confidence than to ask why men tend to lack modesty (Sprague, 2016, p. 14). Such research questions problematize the social tendencies of non-dominant groups and normalize the behaviors of the dominant. Through this lens, some groups are labeled as deviant, and others are left unexamined. This practice essentially works to preserve existing systems of dominance and to dismiss or minimalize the knowledge of others while promoting and codifying the discoveries of established elite (Delgado Bernal \& Villalpando, 2002; Hesse-Biber et al., 2004; Mato, 2011; Mohanty, 2003).

The preference for such research, according to feminist standpoint theorists, originates from privilege. When an individual achieves a position of power, his daily needs are taken care of, and therefore he is free to gaze upon humanity from a "godlike" position, distant and hidden from view (Haraway, 1988). The primacy of research that adheres to these norms results in what Delgado Bernal and Villalpando (2002) call an apartheid of knowledge, referring to the exclusion of culturally-based ways of knowing and the subjugation of epistemological perspectives that do not adhere to Euro and androcentric preferences. Because of the dominance of these preferences, the ideas of 
marginalized groups are often seen as less legitimate and less publishable by the academic establishment (Casanave \& Vandrick, 2003; Delgado Bernal \& Villalpando, 2002; Mato, 2011). Because of the perception that their work is lower quality, less important and less theoretical than that produced by the dominant elite, BIPOC (black, Indigenous, People of Color) researchers are often systematically excluded from the scholarly canon of knowledge production, as they are passed over in hiring committees, rejected for tenure, and are not seen as viable candidates for awards and fellowships (Settles et al., 2020). Settles et al. (2020) describe this experience as epistemic exclusion, which "is theorized to be an experience in which faculty of color are deemed illegitimate members of the academy" (p.1). Because of "interlocking systems of oppression" (Collins, 1986, p.19) the devaluation of work produced by women scholars of color can have a crippling effect on their academic careers (Buchanan, 2020), as both their bodies and their minds are regularly delegitimized and dismissed.

\section{Scholarly Voice}

The combination of these research practices and writing styles result in a particular tone, or voice, that many will easily recognizable as "scholarly." Although pretentions of neutrality in academic communication practices may assert that scholarly writing conveys information, rather than an author's positionality, it is clear that this style of communicating information has originated from the values of a particular demographic. This preference for one style of voice over all others is a well-examined topic in feminist critiques of academic communication (Bhavnani, 2004; Fine, 1992; Fleischman, 1998; Mitchell, 2017; Sefcovic \& Bifano, 2004; Sprague, 2016; Webb, 
1992). According to Mitchell (2017), voice is, "a representation of authorial presence and/or identity within written text and that presence contributes to our way of knowing" (p.2). The argument here is that language can impose certain parameters that determine which thoughts can or cannot be fully expressed. Anyone who has learned another language has experienced the phenomenon of untranslatable words and expressions that have arisen out of a shared cultural understanding that is present in one language group, but not another.

As mentioned earlier in this literature review, the way that scholarship is written reflects an understanding of the world as defined by Western androcentric research practices. For example, in most disciplines, pretentions toward objectivity dictate that research should be written in a distant, impersonal voice, as many mainstream research publications consider authorial visibility as distracting from the subject of study (Nelson \& Castelló, 2012). In this tradition, the author is assumed to be voiceless, and the writing should be a mere vessel for communicating important academic findings (Mitchell, 2017). The problem is that "voiceless" writing is still heavily accented with the cultural values of its origins. In the same way that "male" is gender and "white" is race, cultural constructs around scholarly writing are not neutral, despite their cultural dominance. Nowhere is this more apparent than in instances when authors endeavor to break the long-established cultural rules of voice in their scholarly writing. Suresh Canagarajah (2002), for instance, cites several reviewer comments on an article he had submitted for publication. In a variety of ways, the reviewers had all criticized the impassioned tone of Canagarajah's writing and requested for the revision to be more subdued and "objective" 
(p.23). While many experienced writers, such as Canagarajah, eventually learn how to negotiate such feedback, junior scholars may find themselves completely sacrificing their voice and vision for a publishers' requirements, resulting in voice that is no longer authentically their own (for example, see Hyland, 2015; Kubota, 2003).

In describing their entrance to academic scholarship, novice scholars (both men and women) have often remarked on the experience of losing their authentic voices in their written work (Ackerman, 1995; Kubota, 2003; Leggatt-Cook, 2011; Potgieter \& Smit, 2009). In their well-known study of "Nate," Berkenkotter et al. (1988) tracked the progress of a doctoral student in Rhetoric as he struggled to trade his tendencies toward hyperbole and personal voice for a more measured, academic tone. In the example texts, it is clear that Nate was wrestling with his ability to express himself: the excerpts move from a fluid, expressive prose to a stilted voice that lurches from one idea to the next. In a memo to a professor, Nate claimed to have lost his voice or to have "never had it from the start" (p.23). Although the article shows Nate developing some fluidity in his academic voice by the end of the study (it was later revealed that he was also a co-author for the article), it is clear that he had needed to relinquish a part of himself in order to adopt a new persona as an academic.

The challenge of reconciling one's voice with the requirements of academic prose becomes even more pronounced as writers move from their graduate work to the professional world of research and publication. As Potgieter and Smit (2009) write, after having completed our $\mathrm{PhDs}$, we soon understood that attempting to claim our academic voices and hallmarking our academic signatures is not only 
extremely challenging and complicated, but that such attempts are also frequently adjudicated by (peer) reviewers to be inadequate and, sometimes, even derisory or inappropriate. (p.218)

In an illustrative example, Kubota (2003) writes of her early experiences with publishing during which she found herself regularly sacrificing her authentic voice in response to publisher demands. She describes the frustration of being left with a rejected paper she barely recognized after multiple revisions that did not manage to meet the expectations of the reviewers. A second journal also rejected this heavily revised draft, but accepted the original, with a few minor changes. As a more experienced writer, Kubota reflected on her growing confidence in publication, her willingness to push back on reviewer suggestions, and her emerging confidence with her ability to communicate her authentic voice in her scholarship. However, it is clear from these examples that learning how to effectively participate in the generation of knowledge is lifelong journey for many women academics, one that cannot be easily solved through a unidirectional process of assimilation (Kim, 2015).

The above examples raise the question of how novice researchers learn to navigate the divide between their internal (personal) and external (scholarly) voices. Some feminist scholars assert that language of androcentric scholarship may simply not have the capacity to describe work that is deeply connected to personal experiences and concerns (Fleischman, 1998). However, recent studies have shown that even novice academics do not simply replicate the discourse practices of their more senior colleagues. According to Kim (2015), graduate student writers actively "reinforce, resist, appropriate, 
and re-appropriate diverse voices" in their academic prose (p.252). It is not only graduate students who find ways of subverting academic communicative norms; more established scholars may do so as well. Women professors of color have been found to be especially subversive in their publication practices, meaning that they intentionally seek out ways of practicing and publishing research that does not conform to dominant androcentric expectations (Gonzales, 2018). These subversive practices include, but are not limited to challenges of linguistic norms (Evans-Winters \& Esposito, 2018); they also challenge research practices in a variety of ways, including breaking down barriers between the researcher and the participants, applying new methodologies and ways of narrating the generation of knowledge, and pursuing subjects that are interdisciplinary, and are focused on understanding the lived experiences of marginalized groups (Buchanan, 2020; Gonzales, 2018; Huber, 2009; Meyerson \& Tompkins, 2007). Meyerson and Tompkins (2007) assert that innovation often comes from those at the "margins of organizations because actors are less aligned with and are disadvantaged by dominant interests, have less at stake when they challenge prevailing arrangements or experiment with new ones, and, importantly, are more likely to be exposed to institutional contradictions" (p.310). Because women of color often exist on the margins of their institutions, they are already exposed to the contradictory and exclusionary nature of dominant interests and are therefore more likely to challenge the norms that do not work in their interests.

In seeking out venues that support and accept innovative research practices, women of color will frequently publish in non-mainstream journals, where topics of race, class, and gender can be more deeply explored (Delgado Bernal \& Villalpando, 2002; 
Gonzales, 2018). Publication in journals that are more open to non-dominant modes of communication can be a welcome respite for many women scholars. When writing for a smaller, more specialized audience, women may be able to avoid what Dotson (2011) calls testimonial smothering, where scholars need to "truncate" their arguments in order to make them more palatable or more comprehensible to an audience that finds their work "unintelligible" (p.244). For example, when writing for a mainstream academic publication where the editors are primarily older white men, a researcher who focuses on the lived experiences of marginalized groups may need to refrain from overtly challenging the authority of the affinity group to which these editors belong. In contrast, if this same researcher publishes her work in a scholarly journal that specializes in exploring the lived experiences of marginalized groups, she can begin her work from baseline of shared understanding that allows her to explore her topic in more nuance. Mott and Cockayne (2017) describe such a situation in their rationale for placing their article in the specialized journal, Gender, Place, \& Culture, by writing, We were conscious that we would be writing for an audience that was already likely to agree with our argument, yet we reasoned that as a starting point for a broader conversation, this journal's readership likely shared the epistemological position that we advocate. (p.957)

Unfortunately, for many women on the tenure track, the practice of publishing one's work in non-mainstream or in disciplinary-adjacent journals may not be a luxury that they can afford (Lillis \& Curry, 2018). In such cases, it may be necessary to submit to the 
will of the dominant class in order to attain the stature that will support a more radical research agenda.

It is apparent from these examples that women are not merely passive adopters of norms; they act with agency in the ways that they represent their work and scholarly interests. Although the language and research practices of academic scholarship do not suit the needs of many women researchers, they may not consider themselves bound to blind adherence of these practices in their scholarly work. Still, the gates of academic legitimacy are strong, tall, and heavily guarded by a cadre of elites who do not abide the practices of transgressors.

\section{Gatekeepers in Academic Publication}

Since research is one of the hallmarks of legitimacy for academics, it is imperative that women publish in order to be recognized as legitimate scholars by their peers and institutions (Gopaul, 2015). In some disciplines, academic discourse has evolved to allow for a broader range of research topics and more relational forms of expression, with academic fields like sociology, education, and psychology engaging in lengthy public discussions on the role of the researcher in generating knowledge that is meaningful for a particular community (see for example, Campbell \& Wasco, 2000; Fine, 1992; Sprague, 2016). However, the academy as a whole has been rather slow to accept such change, and those who push the boundaries of what has commonly been accepted may face challenges in getting their research published in top-tier journals. This may be partially due to what Paasi (2005) sees as the "homogenization of publication practices" driven by forces of academic capitalism (p.773). Since many American and international 
universities require a record of publication in top-tier English language journals not just for promotion and tenure, but also for new hires, the competition for a spot in these journals has greatly increased in recent years (Hyland, 2015). This increase in competition has resulted in a greater degree of conformity in the research and publication practices of many producers of knowledge (Paasi, 2005), thereby limiting publication opportunities for non-standard voices and research practices.

With rejection rates of $90-95 \%$ for many top-tier journals (Sefcovic \& Bifano, 2004), editors have grown even more conservative in the topics and style of writing they accept, regularly rejecting articles that stray too far from the norm (Nelson \& Castelló, 2012; Tardy \& Matsuda, 2009). Non-conformity in voice or in research topic is regularly ignored or punished by the gate-keepers of academic norms, and is often seen as a furtive attempt to hide "inferiority or sub-standard work" (hooks, 1994, p. 5). A stark example of such punishment can be seen in the recent case of two female scientists who received the following excerpt from an anonymous reviewer in a rejection letter for their article, "It would probably...be beneficial to find one or two male biologists to work with (or at least obtain internal peer review from, but better yet as active co-authors)," in order to prevent the manuscript from "drifting too far away from empirical evidence into ideologically biased assumptions" (Gray, 2017, p. 186). It is unclear whether the article, which investigated gender bias in the transition of students from $\mathrm{PhD}$ to post-doctoral positions in the life sciences, specifically referred to the gender of the authors, but it is clear that either the topic of the article or the language employed to investigate the topic was associated with feminine subjectivity in a blind review. Although this comment generated 
such a firestorm that the reviewer was eventually dismissed from the journal (Bernstein, 2015), it speaks to the entrenchment of bias against women and the prevalence of assumptions tying authorial presence to sub-standard work.

In response to the entrenchment of academic norms in the generation of knowledge, women scholars need to either play by established androcentric rules or find avenues to showcase their research outside the purview mainstream academic journals (Sefcovic \& Bifano, 2004). For those who wish to remain in academia, the latter may not be an option, as tenure committees often prioritize highly ranked journals in their evaluation of portfolios (Hyland, 2015). Such priorities may be commonly associated with the pressures of working at research universities, but women in a variety of types of academic institutions may also experience similar expectations for their published work. Because colleges and universities "consistently strive to reposition themselves" in the academic hierarchy (Gonzales, 2014, p. 193), pressures to produce high-profile research can be found at colleges and universities that have traditionally been classified as access or teaching-focused institutions. The drive to increase competitiveness through what O’Meara (2007) calls a "pursuit of prestige" typifies a struggle facing many institutions that are caught in the middle of the academic hierarchy. For institutions that are neither elite research universities nor community-serving junior or community colleges, there is a strong temptation to "strive" for a higher level of prestige through the pursuit of researchheavy agendas (Gardner, 2013; Gonzales, 2014; O’Meara, 2007). According to Gardner (2013), the cultures in these "striving institutions" lead to environments that favor male dominance by emphasizing self-advancement and competition, rather than collaboration. 
In such institutions, the gendered nature of academia is exacerbated, with women taking on the majority of service and teaching roles, and men pursuing their research agendas from more senior positions of power (Gardner, 2013).

In addition to external expectations for publication from departments and tenure committees, faculty are often driven to publish by pressures to legitimate their academic work. In their study of 50 faculty at institutions ranging from community and liberal arts colleges to comprehensive and research universities, Gonzales and Terosky (2016) found that, regardless of institutional type, faculty viewed research and publication as an indicator of legitimate participation in academia. Those working at community colleges reported feeling as though their academic work was not valued by their colleagues in four-year institutions because they had not published in reputable journals; liberal arts faculty reported that an increased pressure to publish conflicted with their more traditional teaching-focused roles; and faculty at regional comprehensive institutions explicitly cited research and publication as markers of academic legitimacy. In order to demonstrate legitimacy in their academic work for tenure committees and disciplinary peers, women may feel additional pressure find ways reconciling their research agendas, voices, and identities with the requirements of publication in their disciplines.

\section{Socialization: Alignment of Academic Scholarship and Identity}

Like many professional communities, academia operates based on both explicitly stated and implicitly understood norms (Casanave, 2002, 2008; Curry, 2016; Hedgecock, 2008; Jones, 2016). Unlike many other professions, however, these norms are not communicated through explicit training modules or handbooks; rather, academics 
become members of their communities through more of an apprenticeship model, where novices (typically graduate students or post-docs) work under the guidance of a senior advisor to learn academic communication and research practices through the production of course papers, lab reports, or dissertations (Austin, 2002; Casanave, 1990, 2002; Duff, 2010; Jones, 2016). It is widely believed that the practice of producing such written work is a mechanism through which novice academics not only learn the disciplinary expectations of their fields, but also begin to craft their own identities as disciplinary insiders (Casanave, 2002; Fujioka, 2008; Ivanič, 1998; Prior \& Bilbro, 2012; Spray \& Hunt, 2015). For novice academics, this enculturation commonly begins with graduate student participation in sheltered disciplinary practices, like dissertations or term papers (Casanave, 2002). By producing such writing and receiving feedback from advisors or professors, graduate students are gradually socialized into to what Lave and Wenger (1991) call a community of practice (see also Berkenkotter, Huckin, \& Ackerman, 1988; Casanave, 2002; Casanave \& Vandrick, 2003; Curry, 2016; Dressen-Hammouda, 2008; Duff, 2010). The following section explores how academic socialization practices work to reproduce existing norms and hierarchies. The section begins by describing the notion of academia as a community of practice, then explores how these communities contribute to the reproduction of academic norms. The section concludes with an exploration of how women participate in academic mentoring practices that socialize the next generation of scholars. 


\section{Community of Practice}

A community of practice is defined as a social group that involves not just membership, but also engagement; in other words, the participants in communities of practice assert their membership through their involvement in the activities associated with the group (Lave \& Wenger, 1991; Wenger, 1998). Communities of practice can be convened in a variety of locations, from work to social groups, and it is common to be simultaneously involved in several intersecting and conflicting communities of practice at a time (Casanave \& Vandrick, 2003). While academics often participate in a general scholarly community of practice, where norms and expectations about what it means to be an academic are shared through interdepartmental collaborations and faculty governance, it is perhaps the disciplinary communities of practice that hold the most sway over modes of communication and legitimation of knowledge (Casanave, 1990).

The concept of communities of practice has been widely used to describe how graduate students and novice academics are socialized into their disciplines (Canagarajah, 2002, 2003; Casanave, 2002, 2008; Casanave \& Vandrick, 2003; Fujioka, 2008; Prior \& Bilbro, 2012; Teeuwsen et al., 2014). Much of this research has also adopted Lave and Wenger's (1991) notion of legitimate peripheral participation in order to understand how graduate students move from novice academics to scholars (Casanave, 2008; Fujioka, 2008; Prior \& Bilbro, 2012). Legitimate peripheral participation refers to the way in which newcomers gain entry into a community of practice (Lave \& Wenger, 1991; Wenger, 1998). These novices are allowed into the position of peripheral participants by senior community members and work their way into full participation through a series of 
established steps. In reference to this process of social enculturation, Lave and Wenger (1991) assert that learning how to participate in one's community of practice basically involves becoming a different person with "respect to the possibilities enacted by these systems of relations" (p.53). In aligning with the expectations of their communities of practice, these novices are asked to redefine who they are, to shed their previous identities and develop ones that fit within their discipline.

Although the concepts of communities of practice and legitimate peripheral participation are useful for understanding the apprenticeship-like nature of academic socialization, these theories have also been criticized for a lack of consideration for the complexity of power and conflict in the socialization process (Fujioka, 2008; Ivanič, 1998; Kim, 2015; Kubota, 2003). In order to participate in a disciplinary community of practice, an academic must learn how to produce prose that demonstrates competency in the field, contributes to the construction of knowledge in her discipline and participates in the academic conversation (Hedgecock, 2008; Tardy, 2005). Learning how to do so can serve as an admission ticket to the group, as those in positions of power assess how well the indoctrinee is reproducing the values of the group she seeks to join (Bourdieu, 1988). According to Hyland (2015), “... it is through the published work of their members that disciplines authenticate knowledge, establish their hierarchies, and manage their reward systems. It is also how they maintain their cultural authority in society more widely" (p.4). In this sense, the teaching, adoption, and eventual assimilation of norms helps maintain the continuity of the academic establishment. 
According to Ivanič (1998), the process of socialized assimilation is a conflictual one, as both academic writing and identity are socially constructed, born of lived experiences and social positions. She argues that the production of a text involves a "three-way interplay between the writer's life experience, their sense of self, and the reality they are constructing through their writing" (p.16). This reality that writers construct in their prose needs to be expressed in a voice that is comprehensible for an academic audience, yet, as a mode of communication, it also needs to be an authentic representation of the author's message (Nelson \& Castelló, 2012). A text can therefore serve as the front line in a conflict between the academic and the personal, leading many writers to feel a gap between their written work and their authentic selves (Casanave, 2003; Leggatt-Cook, 2011; Potgieter \& Smit, 2009). Such gaps are not only found in the voice used for scholarship, as discussed earlier in this chapter; they can also be found in expectations around what kinds of topics are appropriate for academic research. This can be problematic for women, especially women of marginalized identities, who report that their lived experiences and personal identities are major determiners in the type of research they pursue (Gonzales, 2018; Gonzales \& Terosky, 2020). When the personal is so connected with one's scholarship, it may feel insincere to write in a way that obscures the author or hides the passion that drives her work. Thus, for some women, it can be a challenge to authentically represent their research without acknowledging the personal influences on their work (Blanton, 2003; Mitchell, 2017; Webb, 1992).

Another problem can arise when women do seek socialization but are denied entry to their communities of practice because of dominant perceptions of their 
legitimacy to participate in the field. The concept of legitimate peripheral participation assumes that once a novice is accepted into an apprenticeship track, her participation is legitimized and supported by her sponsors (Lave \& Wenger, 1991). Unfortunately, white women and women of color are often seen as interlopers in many fields that are still heavily dominated by white men. If women are denied opportunities to participate, or if their experience is routinely delegitimized, they may not be able to effectively contribute to their scholarly communities of practice (Buchanan, 2020; Dotson, 2011; Settles et al., 2020). Such challenges in socialization have been reported to be a major reason why doctoral students from non-dominant groups leave graduate school before completing their degrees (Bancroft, 2013; Casanave, 2002; Golde, 2000) and why women of color leave tenure-track posts (Kelly \& McCann, 2014). As the number of women from a variety of racial, class, and sexual identities in graduate school continues to increase, challenges to established epistemologies of knowledge generation may become more commonplace. Despite the possibility for expansion in ways of knowing, I have shown earlier in this literature review that norms of academic communication and views of who should legitimately participate in the generation of knowledge have proven to be remarkably tenacious. One of the reasons for this tenacity is the way that these social norms are reproduced across generations of academics.

\section{Social Reproduction in Academia}

As professional academics are socialized into the norms and expectations of their disciplinary communities, they, in turn, bring these norms home to the departments in which they work. Not only do professors produce writing, but they are also deeply 
engaged in socializing the next set of indoctrinees into disciplinarity, or disciplinary practices of their fields (Prior, 1998). This socialization can originate from an advisor (someone officially designated by the department to provide academic support) or from a mentor (someone who may or may not be an advisor, but on whom a graduate student or new faculty member can rely for academic or emotional support) (Austin \& Wulff, 2004; Esposito et al., 2017; Gopaul, 2015). This apprenticeship model of academic enculturation becomes increasingly important as students move up the academic ladder. At the doctoral level, students are trained as future academics by working under the care of an advisor who provides guidance in the production of an original piece of research that conforms to the expectations of their fields (Austin, 2002; Prior \& Bilbro, 2012). In such relationships, norms are usually not explicitly taught, but rather implied through feedback on drafts and in models of professional academic communication, such as journal articles (Ackerman, 1995; Berkenkotter et al., 1988; Casanave, 2008; Hedgecock, 2008; Jones, 2016).

According to Bourdieu and Passeron (1977/1990), it is the implicit communication of norms that maintains existing systems of dominance and hierarchy, as those who come equipped with the right kind of social connections and cultural knowledge of how the system works (social and cultural capital) are the ones most likely to find academia a natural fit for their research agendas. Bourdieu and Passeron argue that the social norms perpetuated by educational institutions not only reflect the arbitrary preferences of the elite, but also are executed using symbolic violence against nondominant epistemologies. According to the authors, symbolic violence refers to a 
dominant group's use of power in order to assert the legitimacy of its ideas and meanings over all others, while, at the same time, denying or concealing the power relations that make this assertion possible. Examples of symbolic violence can be clearly seen in the narratives of women scholars, who write of having their work delegitimized by advisors, colleagues, reviewers, and editors because it strayed too far from an approved line of reasoning (Fleischman, 1998; Gray, 2017; Harding, 1991; hooks, 1994; Mitchell, 2017; Webb, 1992).

The process of academic reproduction results in a closed-loop system, where the doctoral student is trained in the research and communication practices of her field by an advisor who has, in turn, been socialized by a senior member of her disciplinary community. Upon graduation, this doctoral student will be further conditioned by the disciplinary expectations of publishers and editors, expectations which she will likely later impose on her students and advisees. Through this process of socialization, universities serve as institutions for the "reproduction of legitimate culture," where the means of knowledge creation are dictated by generations of academic elites (Bourdieu and Passaron, 1977/1990, p.101). As established earlier in this literature review, those holding the keys of legitimacy in the disciplines are often older white male professors, who are widely published and therefore, deeply committed to maintaining the status quo. Although academic advisors and mentors certainly play a role in the perpetuation of academic norms, they can also serve as guides in helping novice academics assert their research agendas and express their authentic voices in their scholarship. By helping non- 
dominant voices find avenues for expression, the right advisor may act more as a subverter of academic norms than a tool of disciplinary enculturation.

\section{Mentoring}

The presence of a mentor is vital for the success of graduate students and new faculty on the tenure track, as the "complexity of the requirements of membership as set by the gatekeepers of science can rarely be navigated alone" (Bancroft, 2013, p. 14). For novice women, having a supportive mentor appears to be especially important as a predictor of persistence as a graduate student (Dua, 2007; Humble et al., 2006) and in the success of publishing academic work as a new scholar (Dua, 2007; Holmes et al., 2007; Shvidko \& Atkinson, 2019; Terosky, 2019). Mentors help novices in a variety of ways, from academic to emotional support. In terms of academic development, mentors can introduce students and novice faculty to the practices and disciplinary conventions of their fields (Welton et al., 2014). This includes learning certain research practices that are commonly taught in graduate school, such as which research methods are disciplinarily acceptable, how a proposition should be argued, and which scholars should be cited in a literature review (Casanave, 2008; Hedgecock, 2008). Mentors can also help novices learn to navigate the "occluded genres" of scholarship (Swales, 1996) that surround the publication process, but are rarely explicitly discussed, such as cover letters for journal article submissions and correspondence with reviewers. Reciprocal mentoring relationships, where a senior member of a disciplinary community co-publishes with a junior member can be especially helpful in helping novices adapt to the many unspoken norms of academic publication (Thein \& Beach, 2010). 
In terms of emotional support, mentoring relationships can provide a safe space for novices to process their emotions and come to terms with the fear, vulnerability, and frustration that comes the process of academic socialization (Esposito et al., 2017). Feelings of inadequacy and self-doubt are common for women in their doctoral programs and in positions as new faculty members, as is the feeling that they do not belong, otherwise known as the imposter syndrome (Dua, 2007; Kelly \& McCann, 2014). Many women faculty, especially women of color faculty, also must deal with the emotional toll of tokenism, where they are hired for the sake of outward appearances, but are not valued for their work or intellectual contributions to the field (Buchanan, 2020; Kelly \& McCann, 2014). Mentors can care for women as they navigate these emotionally taxing experiences by protecting them from hostility or criticism, by serving as role models, and by providing positive, encouraging feedback on their work (Buchanan, 2020; Dua, 2007; Kelly \& McCann, 2014; Terosky, 2019). When women faculty have strong mentoring relationships that provide both academic and emotional support, they are reported to be more assertive in their needs and have higher levels of self-efficacy in their paths to tenure (Kelly \& McCann, 2014). It is hard to work alone; the path to disciplinary becoming is dark and treacherous with snares. Guides who provide company, sympathy, and expertise to women as they stumble along this occluded path can help them find a more secure footing in their academic practices.

Although mentoring relationships are clearly beneficial when it comes to helping women find a sense of belonging in their academic communities of practice, it can be challenging for women to establish mentoring relationships both as doctoral students and 
later, as faculty. In a survey of 78 graduate students at a variety of institutions, Welton et al. (2014) found that women graduate students had less access to both mentors and academic advisors than men, and that men were more likely to have been connected to mentors and assigned academic advisors within their programs. The men in this survey also reported meeting more regularly and developing closer relationships with their mentors than the women. It is not just a challenge for graduate students to find mentors; novice women faculty also struggle to find adequate support for their professional work in their academic careers (Farkas et al., 2019; Guarino \& Borden, 2017; Kelly \& McCann, 2014). This is represented both in the failure of departments to assign appropriate mentors to new women faculty (Farkas et al., 2019; Kelly \& McCann, 2014) and in the disproportionate amount of time that men and women spend engaged in professional conversations with departmental colleagues. In a survey of faculty, Guarino and Borden (2017) found that men spend twice the amount of time in professional conversations with their academic peers as women.

Women of color are often particularly challenged in finding supportive mentors in their academic practice. Because of persistent epistemic exclusion practiced by their white colleagues and because they are often the only person of color in their department, it is not easy to find a supportive senior mentor who understands the trauma of constant exclusions and microaggressions (Buchanan, 2020; Kelly \& McCann, 2014). Buchanan (2020), for example, describes how she eventually resolved to reach outside her department to collaborate with colleagues who could support her professionally and emotionally. She did so after repeatedly being warned against collaborating with these 
scholars by her white colleagues, who expressed skepticism that interdepartmental professional relationships with other black women would do anything but harm Buchanan's academic reputation. However, Buchanan found that these relationships provided much needed emotional and academic support, leading not only to greater confidence in asserting her needs within her department, but also to a number of wellreceived publications. The ability to tap into such resources is incredibly important in helping women navigate barriers to participating in their communities of practice, but these relationships are often difficult to secure.

As socializers themselves, women occupy a rather complex position since the mentoring of the next generation of women scholars often falls to women faculty, despite their relatively subordinate positions as producers of knowledge (Gómez Cama et al., 2016; O’Meara et al., 2017). In this role, how do women help students from similarly marginalized positions to be successful in their academic pursuits? On the one hand, it has been argued that graduate student socialization is best conceived of as a two-way street, where a student not only learns the rules of her discipline, but also learns how to subvert these rules in order to change existing research practices and promote nondominant ways of knowing (Winkle-Wagner \& McCoy, 2016). On the other hand, the freedom to explore and challenge the rules of the game may be less accessible to novice scholars once they begin to grapple with the pressures of the tenure clock and the competitiveness of the publication industry. Gray (2017) describes the challenge of teaching an idealized version of academic writing to students, only to be confronted with the conservative requirements of publication in this example, 
As a teacher, I often encourage my students to use an active voice, yet, at the same, as a researcher I have often relegated my own personal-reflexive voice to the background of my writing. Initially, this relegation was imposed externally by a managing editor of one of my early published manuscripts. Just prior to publication, the editor removed all my uses of "I" and replaced them with distancing voice terms such as "this paper examines" and "this paper offers." (p.181)

If novice scholars wish to participate in the academy, they will likely need to publish in journals that have become increasingly restrictive in their acceptance of new ways of knowing or communicating (Hyland, 2015; Nelson \& Castelló, 2012; Sefcovic \& Bifano, 2004; Tardy \& Matsuda, 2009). Some scholars may struggle to use the actual language of academic communication, resisting the impersonal tone and the impenetrable language of the abstract. They may feel that in order to clearly communicate their message, they need to write from a more relational, personal stance, using language that is still commonly dismissed in many disciplines as imprecise or biased (Gray, 2017; Mitchell, 2017; Potgieter \& Smit, 2009). Other scholars may adopt the linguistic norms, but struggle with other aspects of androcentric research practices, such as the artificial boundaries between the knower and the known, or the comparison of all non-dominant groups to Western standards (Delgado Bernal \& Villalpando, 2002; Mato, 2011; Sprague, 2016). Despite these contradictions, women mentors are still tasked with preparing their students to effectively participate in their chosen fields. In order to do so, woman faculty mentors 
may find themselves to be purveyors of the very norms which serve to marginalize the female academic voice (Esposito et al., 2017; Humble et al., 2006).

\section{Social Sciences}

The social sciences occupy a unique brand of academic thought. Grounded firmly in the study of how humans live and interact in the world, this group of disciplines (for example, sociology, psychology, and anthropology) endeavors to understand how individuals and social groups operate (Bazerman, 1988). While not a physical science, like biology or chemistry, the origins of social sciences are largely modeled on the positivist assumptions that are rooted in the physical science disciplines (Sprague, 2016). According to Bazerman (1988), the adoption of research methods based in empirical data collection and the communication of research in an objective, dispassionate tone helped early social scientists disassociate their work from epistemologies based on religion and metaphysics that had previously been used to explain human behavior. The desire of social science researchers to appear rigorous and value-neutral in their work has historically led these disciplines to prioritize positivist practices, such as research questions that preserve the distance between researcher and subject, and a style of writing that emphasizes this distance by obscuring researchers and abstracting subjects (Bazerman, 1988; Hesse-Biber et al., 2004; Sprague, 2016).

Feminist scholars within social sciences have criticized its singular focus on explaining the world through the privileged lens of the Western elite man (BoxSteffensmeier et al., 2015; Campbell \& Wasco, 2000; Collins, 1986; DiFuccia et al., 2007; Harding, 1991; Hesse-Biber \& Yaiser, 2004; Leggatt-Cook, 2011; Madill \& 
Gough, 2008; Smith, 1987; Sprague, 2016). This lens has led to the omission of a large proportion of the population from social theorizing, resulting in an unbalanced understanding of how social systems work (Bhavnani, 2004; Collins, 1990; Sprague, 2016). In addition to these historical omissions, the entrenchment of beliefs on academic voice and acceptable research methodologies limit the types of conversations that can take place in the academic arena.

In spite of such androcentric preferences in scholarship, the majority of doctorates awarded in social science disciplines are earned by women. In 2016, women earned 59\% of the doctorates awarded in social sciences, making it the second most popular discipline for PhD study for women after Education (Survey of Earned Doctorates, 2016). Unfortunately, similar to national trends, the popularity of the degree has not manifested in equal representation for women in tenured social science faculty positions. Not only are men continually hired into professorships in social science programs at disproportionately higher rates than women (Speakman et al., 2018), they are also more likely to be promoted to full professor. Ginther and Kahn (2006) found large gender gaps in promotion to full professor across a range of social science disciplines and in the field overall. In Ginther and Kahn's study, tenure-track women in social sciences were on average 8.7 percentage points less likely than men to receive tenure within 11 years of $\mathrm{PhD}$ (Ginther \& Kahn, 2006). In a study ten years later, Hur et al. (2017) found men in tenured and tenure-track social science positions continued to outpace women in number of publications and found that the number of academic publications was correlated to academic rank. The study also found that professors in social sciences were 
predominantly white and that their average age had increased between 2003-2013. These numbers are troubling, as they imply that the control of knowledge production in social sciences is still largely in the hands of professors who are likely "very male, very White, very old, and very conservative" (Margolis \& Romero, 1998, p. 19).

Such demographic entrenchment is problematic both in terms of knowledge generation and in terms of mentoring support for white women and women of color. Social sciences tend to rely heavily on individual student-supervisor (advisor) mentoring models, in contrast to physical sciences, where groups of students and professors tend to research and publish collaborative lab settings (Austin, 2002; Austin \& Wulff, 2004). This means that the process of introducing new students to the social sciences field is heavily dependent on the mentoring relationships developed between students and faculty. Considering that women hold a fraction of the tenured professorships in the social sciences and that they tend to take on the majority of mentoring responsibilities, compared with men, it is not unreasonable to assume that women in social sciences carry a heavy burden of mentorship for students in a discipline in which they are still fighting to be seen as legitimate scholars. From this position, these women need to not only advocate for their own legitimacy, but also prepare their students for similar challenges in their nascent academic journeys.

\section{Conclusion}

Although a large body of research has focused on how traditional publication practices tend to exclude the female voice by prioritizing objectivity and distance in writing style (Fleischman, 1998; Gray, 2017; Harding, 1991, 2004; hooks, 1984, 1994; 
Mitchell, 2017; Smith, 1987; Sprague, 2016; Webb, 1992), through both research topics and intentional choices in voice, women do assert their identities in their scholarship and showcase their connection to their research. Unfortunately, many of the studies that criticize the constraints imposed by androcentric modes of scholarship do not explore how women insert their voices into their scholarly work. Those that have researched women's use of voice largely focus on how the first person can be used to express a woman's authentic voice (Fleischman, 1998; Mitchell, 2017; Webb, 1992). However, it is not well known if women find other, less obvious modes of expressing themselves in their academic work, nor has it been widely researched how women scholars might explain their own strategies for subverting dominant practices in the writing that they seek to publish in scholarly publications that are designed for mainstream audiences. Within mainstream scholarly publications, are women fluent communicators in the language of the patriarchy, or do they write in an accented "father voice" (Le Guin, 1989)? Since feminist research asks us to investigate questions that highlight strengths, rather than deficiencies (Sprague, 2016), I am interested in the intentional choices that women make in asserting their voices in their written work. I am also interested in whether female scholars are actively working to change patterns of social reproduction in academia by teaching subversive practices to their mentees. In other words, as scholars and mentors how do female faculty liaise between the expectations of the establishment, their own scholarly identities, and the emerging academic identities of their mentees? 


\section{CHAPTER 3: METHODS}

The purpose of this study is to explore how women understand, describe, and produce scholarly work. More specifically, this study explores how women faculty have learned and interpreted the norms of academic communication, and how they either perpetuate or subvert these norms through their academic work and through their mentoring practices. The following chapter details the methods I used to explore this topic.

In sections below, I first describe the type of qualitative study I conducted; I then explain how this study connects to my conceptual framework. Next, I detail the process I used to conduct my study, by providing information about my study site, my participants, and my data collection process. After describing these methods, I discuss how I established the trustworthiness of my study and the limitations of my study design.

This study is a qualitative feminist in-depth interview study. Although feminist studies are not necessarily qualitative, by definition, the practice of qualitative research "runs rich with feminist contributions" (Sprague, 2016, p.146). According to Sprague (2016), qualitative studies are uniquely suited to experiencing, listening to, and learning from those whose standpoints have traditionally been obscured by dominant practices of scholarly discourse. Qualitative studies also allow for greater depth in the development understanding of a particular group's lived experience (Hesse-Biber, 2017). Since Feminist Standpoint Theory provides me with a conceptual framework to explore the lived experience of my participants, it makes sense to combine this epistemology with qualitative methods. As part of this study, I conducted in-depth interviews, also 
commonly known as intensive interviews (Charmaz, 2014), which are often used when a researcher has a specific topic or issue that she is interested in investigating (Hesse-Biber, 2017). According to Hesse-Biber (2017), in-depth interviewing differs from oral history interviewing, where the interviewer is interested in learning the life-story of her participants, rather than focusing on a particular topic. I chose in-depth interviews because the research questions I investigated were specifically related to the experiences my participants had in becoming scholarly writers.

This feminist qualitative interview study is grounded in Feminist Standpoint Theory, which seeks to center the lived experience of research participants through a gender lens (Charmaz, 2012; Sprague, 2016). By using gender to frame this study, I have chosen to highlight the experiences of women faculty as they create knowledge within the gendered university environment. Feminist research centers on gender, but through this lens, also seeks to make visible other marginalized and intersecting standpoints, such as race, class, sexuality, ability, and nation (Charmaz, 2012). In highlighting nondominant standpoints, feminist standpoint theorists work to subvert "established procedures of disciplinary practice tied to the agendas of the powerful" to counter the binary and dividing practices of androcentric methodology (DeVault, 1990, p. 96). Although the methods used in feminist research to achieve these goals can vary widely, feminist studies are alike in their strong commitment to social justice and positive social change (Charmaz, 2012; DeVault, 1990; DeVault \& Gross, 2012; Sefcovic \& Bifano, 2004; Sprague, 2016). I am therefore using this feminist framework not only to 
understand the work of women, but also to document and legitimate ways that nondominant voices have sought to enter the scholarly conversation.

\section{Study Site}

My study took place at a large regional comprehensive university (called RCU from this point forward). I chose RCU for two reasons. First, I have connections within several departments which helped me gain access to some of the faculty participants in this study. Second, RCU faces several unique challenges as a large regional comprehensive university. According to Orphan (2018), regional comprehensive universities, which are large public institutions designed to serve the needs of the local community, occupy a unique role in the context of higher education. As access institutions, these universities provide degrees and certificates to low-income and underrepresented groups, and they have historically prioritized teaching and service over research. However, regional comprehensive universities are also often chronically underfunded, leading many to pursue more lucrative agendas, where research, publication, and grant-writing become more valued than teaching and service (Orphan, 2018).

In this sense, $\mathrm{RCU}$ is a good example of a regional comprehensive university facing budgetary challenges and, as a result, instituting a number of administration-led initiatives designed to increase research and grant activity by faculty. The trend of bringing greater attention to faculty research productivity at RCU is corroborated by Gonzales and Terosky (2016), who reported that the majority of professors they interviewed at regional comprehensive universities explicitly referred not only to 
research, but also to the location of publication as essential markers of legitimacy in academia. This push toward research productivity at RCU has the potential to limit not only the type of research conducted, but also the way in which it is communicated. In order to obtain a large, competitive grant, it is likely that a researcher would need to modify her work to ensure that it met the traditional criteria of generalizability and largescale relevance. The language she would use to apply for this grant and to report on its success in mainstream publications would likely also have to conform to more conventional expectations, such as those detailed in the literature review. It is unclear whether these pressures are felt by faculty across the university, or if they are concentrated in certain fields, but it is worth noting that three of the top ten grant funding recipients at RCU mentioned in a recent university report were tenured faculty in the social sciences.

\section{Participants}

For this study, I interviewed seven women academics holding ranks of assistant and associate professor in social sciences departments at RCU. I had initially focused on recruiting associate women professors because they would have already established a coherent scholarly agenda and would have been able to draw on a variety of mentoring experiences with both graduate students and junior colleagues. After receiving IRB approval, I began recruiting participants by searching the websites of social science departments at RCU for women associate professors with the aim of recruiting at least one woman from each department. I started by emailing associate professors in each department. In my email, I shared information about my research goals and requested a 
meeting to describe the project in more detail (see Appendix A). After contacting a large number of associate professors in the social sciences at RCU, I decided to expand my criteria to include assistant professors in this pool. I made the decision to expand my pool to assistant professors, rather than seek participants from a second institution because I believed that the institutional context would be a relevant factor in how the professors in my study viewed their participation in academic scholarship.

I followed the same procedure described above to recruit assistant professors, with greater success. My final group of participants included four assistant professors, two associate professors, and one woman who was promoted to associate professor during our interviews. My participants were based in the political science, linguistics, psychology, archeology, and geography departments. By interviewing women professors with a range of academic experience, I was able to learn more about the trajectory of their professional lives, specifically with regard to pre- and post-tenure freedom. In order to protect the identity of my participants, I assigned each woman a pseudonym, which I have used in the transcripts, my notes, and in this dissertation. Although I refer to their rank and discuss their disciplines generally, I have kept reference to publications and specific areas of research intentionally vague, in order to minimize the possibility that they will be identifiable by their work. In order to protect the identities of my participants while discussing their disciplines and publication practices, I have masked the name of the institution where this study took place. In reporting this information, I have also limited identifying information in the quotes that I have chosen to illustrate the results by removing information about specific publications and research projects. 


\section{Data Collection Process}

My primary tool for data collection was in-depth semi-structured interviews (Hesse-Biber, 2017). Interviewing is a powerful tool to elucidate the lived experiences of research participants, especially in the case of feminist studies. Through these "structured encounters," researchers can elicit narratives and experiences from the standpoint of their participants (DeVault \& Gross, 2012). Women, and in particular, women from nondominant groups, are regularly interrupted, talked over, and ignored by those in more powerful positions (usually men), so giving women the space to air their voices has the potential to unleash narratives that challenge the status quo (Devault, 1990). In order create a space for women to freely describe their lived experiences, feminist interviewing emphasizes the importance of listening deeply, not just to words, but also to meanings between the words (DeVault, 1990; Devault \& Gross, 2012; Sprague, 2016). This means hearing not only what is said, but what is left unsaid and how these pauses or omissions might also contribute to the larger narrative.

For this study, I used a three-interview series based on Seidman's (2019) recommendations. Seidman suggests three interviews in order to deeply explore the meanings of the participants' experience. According to his recommendations, the first interview should focus on the participants' life history, the second should explore lived experience, and the third should provide opportunities to reflect on meaning. The three interviews I conducted with each of my participants were based on similar themes but were adapted to better align with purpose of this study. The first interviews explored themes related to how women faculty learned to write in their disciplines by asking 
questions related to general writing experience, beliefs around the use of voice, research training, and publication practices in their fields. The objective of these questions was to understand my participants' backgrounds and their approaches to writing (see Appendix B).

The second interviews were grounded in my participants' writing practice and focused on questions related to how women faculty either adhere to or subvert disciplinary norms in their writing practice. According to DeVault (1990), interviews should not just rely on talk, but should also ground this talk in the everyday experiences of the participants. For this study, everyday experiences were represented by the texts that women had produced for their scholarship. Prior to the second interview, I asked my participants to identify 2-3 texts that most typify their approach toward writing. I read these texts prior to the interview in order to build an understanding of my participants' work, writing style, and research agenda. I did not conduct a separate analysis of these texts but rather relied on them as a springboard for the interview and as a tool to discuss voice and agency in academic publication. At the beginning of the interview, I conducted member checks with my participants by asking them to reflect on a few preliminary observations I had drawn from the first interview. At this point, I also asked my participants if they had anything further that they would like to add, or if anything had come up related to topics of research and writing in the time between our first and second interview. These initial conversations proved to be invaluable in terms of giving my participants the opportunity to correct my observations and to relate unplanned stories or 
anecdotes that they had either experienced since our last interview or had not thought to relate in our first interview.

During the second interviews, I asked my participants to show me examples of where they saw their authentic voice most strongly represented in their writing. I asked follow-up questions related to how these sections represented their values in research and publication (see Appendix B). The collaborative, interactive nature of this interview created opportunities for my research participants and me to co-construct meaning around the use of voice in writing (Hesse-Biber, 2017; Sprague, 2016). These questions also created opportunities to talk specifically about how their choices in language, citation and methodology, as well as the peer review process have influenced the shape of their finished work.

The third interview I conducted was an opportunity to expand on previous themes with my participants and explored themes related to how women faculty talk about writing to their mentees. As I had done in the second interview, at the beginning of the third interview, I shared information from my preliminary analysis of previous two interviews and asked my participants whether they had any further reflections on whether their training or the publication practice in their field had influenced the ways in which they produced research. Next, I focused the interview on how these professors mentor their advisees in the disciplinary writing practices of their field and whether this advice mirrors their own scholarly practice. At the end of the interviews, I asked my participants if they had anything further to add regarding their mentoring practice or on their research practice, in general (see Appendix B). 


\section{Trustworthiness}

Throughout this study, I took several steps to ensure that the data I collected and the analysis I performed on my data was trustworthy. In qualitative studies, the researcher is the instrument of analysis, as she works to code and make sense of the data that she has collected (Hesse-Biber, 2017). Because of the centrality of the researcher in qualitative analysis, feminist research has been especially concerned with naming and centering the beliefs and experiences that inform the researcher's positionality. It is through awareness of our positionality that we are able to engage in what Harding (1993/2004) terms strong reflexivity, a process of reflecting on how our positionality affects our relationship to our research.

\section{Positionality}

I come to this research as a member of the dominant class. I am a white, middleclass, cis-gendered Anglophone American woman. I have spent the majority of my adult life in academic environments, either as a student or as an instructor. I also come from a long history of educated relatives. On my mother's side, I am the fifth generation to earn a university education and the second generation to have earned a graduate education. All this is to say that I feel comfortable with the dominant mode of communication in academia, as my upbringing and my education has prepared me well to participate in the academic community of practice. However, as a teacher of writing to international students, I have come to understand the mono-cultural expectations around writing practice, and therefore, how counter-intuitive they are for those from other cultural backgrounds. This experience, combined with my work in tutoring writing for domestic 
American students, has made it clear that I am quite lucky to have grown up in an environment that provided me with the background I needed to assimilate quickly and easily into the academic community of practice.

As both an instructor and graduate student, I occupy a lower position in the academic hierarchy than many of the women I interviewed. As a faculty member, I am, in some respects, an equal. However, as a non-tenure track instructor, I have a lower academic rank than those holding assistant and associate professor positions. While in many cases, a researcher might be regarded as someone in a higher academic position than the research participants, in my case, I was researching as a graduate student, a subordinate position in relation to that of a faculty. Especially because many of the women I interviewed had experience advising doctoral students on their dissertation research, it was clear at times that some of my participants saw me as a member of that group and treated me in accordance with this role. I often found these professors taking on somewhat of an advising role in our interviews by providing me with advice about research and publication or explaining qualitative research concepts to me.

Although I am a white woman with a strong foundation in the scholarship of dominant-culture academic writing practice, this positionality did not seem to be prominent in the power dynamics when I was interviewing women of color or multilingual women whose voices have been commonly delegitimized and suppressed in academic written communication. Rather, the two black professors I interviewed clearly assumed the position of power in our interviews, specifically in terms of their directiveness in setting up and conducting the interviews. However, my positionality as a 
white woman may have influenced the degree to which one of my black participants was willing to explore her vulnerability with writing and publication. Whereas many of the women I interviewed were willing to explore challenges they had faced in joining their academic communities, her responses in this area were less detailed and she seemed more guarded around topics dealing with potential vulnerabilities. As the interviews progressed, our conversations became deeper, more wide-ranging, but it is possible that my position as a white woman was a barrier in establishing trust early on in the interview process. In the conflicting roles that I occupied as an interviewer, I was often simultaneously negotiating many of the shifting and complicated relationships that are possible in the university environment. I was at times, an insider, a peer, or a colleague and at others, an outsider, a subordinate, or a representative of the dominant elite.

\section{Strong Reflexivity}

In feminist research, reflexivity is a tool that should be used throughout the entire research process. According to Harding (1993/2004), the practice of reflexivity can lead to stronger science by calling out how researcher bias might contribute to the questions we ask, the data we collect, and the interpretations we draw from these data. This practice “opens up the possibility for negotiating knowledge claims and introducing counterhegemonic narratives, as well as holding researchers accountable to those with whom they research" (Hesse-Biber \& Piatelli, 2012, p.559). According to Merrick (1999), reflexivity means being as explicit and honest as possible about how my own standpoint might influence my research. Hesse-Biber and Piatelli (2012) provide the following 
recommendations in developing a strong reflexive practice for feminist qualitative research:

1. Know your standpoint before entering into the research process;

2. Examine your positionality and role in the field;

3. Monitor your relationship with your participants;

4. Listen to your participants and to yourself;

5. Be attentive to difference;

6. Reflexively interrogate your data (p. 557).

I followed these recommendations of embedding reflexivity into my research practice in a variety of ways. First, by writing my positionality statement for this section, I have invested the time and intellectual effort to consider how my standpoint might (in the proposal) and could have (in the dissertation) served as a mediating factor in how I interacted with my participants and how I analyzed my interviews. These reflective practices have not been simply rote exercises for me. Considering how my standpoint contributes to the way I move through the world has become a key element in the way I conceptualize a healthy research practice. I have foregrounded my own positionality in this study because I believe that the world is "mediated by the self" (Hesse-Biber \& Piatelli, 2012, p.560), meaning that we understand the world through our unique and socially constructed standpoints. As a feminist standpoint epistemologist, it would be insincere if I did not acknowledge how my own standpoint influences the way in which I see the world. 
Second, as I conducted my research, I continually monitored my relationship with my participants by using what Hesse-Biber and Piatelli (2012) call reflexivity in the moment in order to process how I interpreted and conducted my interviews. To practice reflexivity in the moment, I wrote research memos after each interview, which helped me "uncover new angles of vision, reveal invisible barriers of power and ethical concerns, and lead to greater understandings, less hierarchical relationships, and more authentic, socially transformative research" (Hesse-Biber \& Piatelli, 2012, p.560). Through this constant reflexive practice, I worked to bring greater awareness to what my participants were really saying, in contrast with what I might have been hearing (Merrick, 1999), and to the differences between our standpoints. During the interviews, themselves, I encouraged reciprocity in our interactions, where meaning is co-constructed between the participants and the researcher through a back-and-forth exchange that resembles a structured conversation (Hesse-Biber, 2017). According to Hesse-Biber (2017), reciprocal relationships in interviews help break down hierarchies and give the participants authority over the stories that they are sharing.

Reflexivity can bring greater awareness of power and positionality, but it cannot eliminate all aspects of power differentials in the research process (Sprague, 2016). Therefore, it was important for me to be aware of the multiplicity of identities that both I and my participants embodied in order to be flexible in how I negotiated multiple simultaneous identity relationships. It was also important for me to bring reflexivity to both the collection of data and the process analysis. In the following section, I detail how I analyzed my interviews and how I used reflexivity to interrogate the data and analysis. 


\section{Data Analysis Process}

I recorded the interviews using Otter.ai, an online software that records and transcribes speech (Liang \& Fu, 2020). However, I did not rely solely on the autogenerated transcription. I also listened to each interview and proof-read the transcripts, making notes about environmental factors, such as pauses in the conversation, the speaker's tone of voice and my own experience as a listener during the interview process (Hesse-Biber, 2017). As mentioned earlier in this section, the process of listening in feminist interview studies is vital to a rich and meaningful interpretation of the participants' lived experiences (DeVault, 1990; DeVault \& Gross, 2012; Hesse-Biber, 2017; Sprague, 2016). It was important for me, as a feminist researcher to listen not only for quotable ideas which might have supported my analysis, but also for more awkward, hesitant utterances, where words fail and uncertainty looms large. It is in these moments, DeVault (1990) claims, that we might have the opportunity to hear perspectives that are more challenging to verbalize.

After listening to and checking my transcriptions, I began to analyze my data using Atlas.ti, a qualitative data analysis system (ATLAS.Ti, 2020). I began by using descriptive, or open coding for an initial analysis of the transcripts. Descriptive coding, which summarize topics in the transcripts with a word or a short phrase, is particularly useful for novice researchers who are learning to code data, as the codes are relatively simple to apply. In developing these codes, I kept an open process by focusing on the experiences of my participants, without using pre-existing codes drawn from the literature. Although my descriptive codes were not explicitly drawn from pre-existing 
themes, I recognized that the aim of this study and therefore, my interview questions, were informed by my conceptual framework and my work in reviewing previous studies. Therefore, throughout the coding process, I wrote analytic memos in order to reflect on my expectations, positionality, process, questions, and emerging codes (Charmaz, 2014; Hesse-Biber, 2017; Saldaña, 2016).

I completed an initial round of descriptive coding as I finished each interview phase. This first round of coding, while quite general in terms of descriptiveness, helped me prepare for each new round of interviews by summarizing what I had interpreted from the data thus far. These summaries were useful as an introduction to the topic for the next interview, as a way of checking my understanding of my participants' experiences, and as a basis for devising related follow-up questions from the previous interview. After coding each interview, I completed reflective memos to help me reflect on my standpoint, questions, and related ideas from the interviews. After completing all the interviews, I labeled the initial descriptive codes with one color, and began second round of descriptive coding, following the same process. In addition to memoing, I also conferenced with my advisor after completing the coding of each interview phase to reflect on emerging categories and discuss how to move my descriptive codes into larger categories (Saldaña, 2016). According to Saldaña (2016), these strategies can help codes move from description to interpretation, leading to the development of themes, which can be used in the second cycle of coding. Feminist researchers (e.g., Sprague, 2016) often emphasize the benefits of research teams and peer collaboration on research process. 
Sprague (2016) claims that different perspectives can help researchers avoid bias and overcome the limitations of approaching a subject from a single standpoint.

For my second round of analysis, I began by reviewing my existing codes. As I reviewed the codes and the associated quotes, I memoed on similarities, differences, and overlapping ideas. In doing so, I was able pair down my descriptive codes and group them into categories. I revisited my transcripts and use focused codes to group the categories I had derived from my descriptive codes. Focused codes describe actions interpreted from the data through the use of gerund (-ing) phrases (Charmaz, 2014; Saldaña, 2016). From these focused codes, I developed themes related to how women learn, use, and/or subvert the norms of academic communication in their writing.

\section{Limitations of Study Design}

There are several limitations to the design of this study. First, the sample I have drawn from is quite limited, as I only interviewed seven professors. This limited the diversity of standpoints that I was able to pull from in order to understand how these women approached their writing practices. Related to the limited number of faculty I interviewed, this study design is also limited by the broadness of the social sciences field. Social sciences covers disciplines ranging from economics to anthropology, fields which have quite different modes of understanding human behavior and different values in terms of research practices. Indeed, the women I interviewed researched in range of disciplines, using a range of methodologies, from quantitative, to qualitative, to mixed methods. Despite the differences in experiences and differences in discipline, the women I interviewed had experiences that overlapped in a number of ways. The areas of 
difference and overlap were not based solely on these women's disciplinary homes, but were influenced by a variety of factors, many of which would have existed within a single department.

In response to the lack of generalizability of such different perspectives, qualitative researchers respond with an acknowledgement that diverse and conflicting standpoints do exist. In maintaining diverse discourses, it is important to be ready to encounter contrasting narratives and experiences, and to be open to such contrasts in the research process, including in situations where these narratives conflict with each other or contrast with my own expectations and experiences (Hesse-Biber \& Piatelli, 2012). Such differences are not only expected by feminist standpoint researchers, they are celebrated. As opposed to large quantitative studies that make broad generalizations by aggregating the responses of the many, feminist qualitative researchers work to gather thick, descriptive data (Lincoln \& Guba, 1986) by diving into the experiences of a few and “chewing on the gravel” of difference and conflict (Merrick, 1999). By choosing to explore the richness of contrasts in the lived experiences of my participants, I was able to elucidate areas where dominant narratives fall short of explaining the lived experiences of my participants.

Another limitation of this study is that it takes place at one specific institution. This limits the pool of participants I was able to draw from and also could have played a role in the research practices of my participants due to RCU's particular institutional culture. This may have limited the nuance with which I was able to explore these women's participation in disciplinary practices. If I had also interviewed women from 
other regional comprehensive universities, I would have been able to connect some of my findings to the institutional culture of such a university. On the other hand, if I had interviewed women institutions that are more clearly either research or teaching-focused, the experiences narrated in the interviews may have been quite different. However, because I was unable to compare their narratives with professors at other institutions, it is unclear as to whether institutional culture, disciplinary, or departmental norms were the primary influences on these women's research practices. Despite these limitations, I strongly believe that the localized grounding of my study provided depth to this investigation of women scholars' lived experiences.

\section{Conclusion}

In summary, this qualitative in-depth interview study used Feminist Standpoint Theory as a framework to better understand how women faculty in the social sciences follow, subvert, and share the norms of academic writing in their scholarly practice. Through a series of three interviews with seven faculty at RCU, I sought to better understand the practices that these women employ in order to generate and share knowledge within parameters required by an androcentric establishment. The use of interviews as a mechanism to gather data helped me base this understanding on the lived experiences of the women I interviewed. By centering the lived experiences of my participants in this study, I have endeavored to highlight not only the challenges of academic practice, but also the ingenuity and fortitude that is present in the work of women. 


\section{CHAPTER 4: RESULTS}

The following section provides an overview of the results from this qualitative interview study. Over the course of three interviews, my participants and I explored a range of topics focused on their participation in academic scholarship. We discussed how they learned to participate in academic communication, or in other words, how they developed as academic writers and thinkers. We also talked in depth about articles they had published and how they moved from the generation of an idea to a finalized publication. We also discussed both how they were mentored and how they mentored their students in the practices of academic scholarship. I begin this chapter by providing profiles of the women I interviewed for this study, in order to showcase the uniqueness of their experiences and their voices. These profiles are followed by a description of how these women view the purpose of scholarship, which provides an indication of why and how they participate in this practice. Next, I discuss how these women became scholars through describing trends in their formative experiences and how they have evolved professionally over time. This chapter finishes with a discussion of how the women in this study have navigated their communities of practice, including how they participate in scholarly conversations and how they mold new scholars through their mentoring practices.

\section{Profiles}

I begin this results section by offering profiles of the women I interviewed. These profiles are important to illustrate the range of experiences and scholarly voices that the women in this study embodied. These profiles demonstrate that there is not one 
“women's voice" but rather a collection of expressive individuals pursuing a diverse array of topics and writing about them in a range of voices.

\section{Angela: The Manifesto Writer}

Angela is a white Anglophone assistant professor who researches language from an interdisciplinary qualitative lens. She identifies as a "good writer," which she defines through her ability to adapt her writing style for a wide range of audiences. As a writer, she was primarily influenced by early experiences and cites her active reading practice, her parents, and undergraduate writing instructors as having the largest impact on her written voice. One of Angela's strongest influences, a class on writing manifestos taken during her undergraduate degree, comes forth clearly in her writing. Her prose is forceful, funny, and exudes confidence in argumentation. She seemed to have been well-supported in her academic journey, from her parents, her undergraduate and graduate professors, her spouse, and her department. As an advisor, Angela reports being "harsh, but fair," in that she has high standards for her students' writing but is supportive in her students' quest to achieve these standards.

\section{Catherine: A Surgeon with a Scalpel}

Catherine is the newest professor in this group. She is a white Anglophone assistant professor who researches politics from a theoretical perspective. She identifies as someone who is becoming a good writer; this is a skill that she enjoys honing and is actively working on improving. She described acting as a "surgeon with a scalpel" in extracting models of excellent prose upon which she can grow her own writing practice. As a writer, she seems to have been primarily influenced through reading and did not 
describe any formative instructional experiences with learning to write as an academic. Learning to write for Catherine seems to have primarily come through feedback from professors in graduate school and feedback from reviewers as she began to participate in public knowledge generation. Catherine reported a great deal of anxiety in the process of submitting her work for peer review, but she also drew satisfaction from contributing the ideas she had generated to the scholarly conversation. Catherine's anxiety seems to primarily arise from uncertainty as to how her work will be received and whether her ideas will be valued by her community of practice. In terms of mentoring, Catherine had not yet had the opportunity to work in a sustained manner with graduate students at her new institution and therefore, was not able to talk deeply about her mentoring practice. She seemed to feel distant from her students and did not see her scholarly work and her teaching practice as interconnected.

\section{Lisa: The Historical View}

Lisa is a black Anglophone associate professor whose research is tied to both sociology and political science. She identifies as an interdisciplinary qualitative researcher who is largely self-taught in terms of writing practice. The prestigious institutions she attended had a "sink or swim" attitude towards writing, and so the writing style she learned came mostly from reading examples and following feedback from her professors. Lisa approaches writing style from a historical perspective, working to understand and connect historical trends with current events, a practice she also reported using in her teaching. The articles also appear to extend and explore issues from previous articles and from conversations she reported having with many of her literary sources, 
lending a historical track to her writing as a body of work, as well. Lisa primarily works with undergraduate students, so her mentoring practice happens mostly in the classroom, in the ways she structures assignments and engages students in political thought. She works to push her students to new understandings of themselves as gendered and racialized individuals in a complex society with kindness, humor, and an honest accounting of her own lived experience as a black woman in America.

\section{Lucy: Simultaneously, However}

Lucy is a white Anglophone assistant professor focused on quantitative methods in psychology. She identifies as a good, but inefficient writer, meaning that she tends to struggle over drafts, writing and re-writing until she feels comfortable with the product. More than other professors in this study, Lucy talked often about how "writing is thinking" and used the act of writing as a way for working through ideas, a process that often led to these struggles of writing and rewriting. In her prose, itself, Lucy described her voice as carrying a "simultaneously, however" message, indicating the complex and conflicting nature of many of the topics she researches. Lucy had strong writing influences in her graduate school experience. Her advisor was very hands-on and seems to have been quite directive in helping Lucy formulate prose. She began publishing early in her doctoral degree program and was working hard to produce a large number of articles in preparation for her tenure review. As a mentor, Lucy described being "real" with her advisees, trying to help them navigate the game of academia and discussing costs and benefits of giving in versus resisting the prevailing winds of institutional expectations. 


\section{Oksana: Not One for Packaging}

Oksana is a white multilingual associate professor whose research focuses on language. Her preference is for quantitative methodologies, but she has recently found herself gravitating towards more mixed-methods research due to challenges in finding research participants. Oksana identifies more as a researcher than a writer. She reported feeling more comfortable with the analytical (methods, results) than the creative parts of a scholarly article (literature review, discussion). This was not due to challenges with language, but rather to her identity as someone who did not care for "packaging." This means that she would have preferred to simply list key points rather than create beautiful prose. She had primarily learned writing in graduate school, through feedback from professors and advisors, and felt that she was good enough, but did not have the same drive to become a writer's writer as other participants, like Catherine. Oksana did not have much confidence in herself as a mentor of writing, but she did seem to connect deeply with her students and included them on many of her publication projects, supporting and mentoring their research interests.

\section{Rene: Lawyering}

Rene is a black multilingual assistant professor whose mostly qualitative work spans geographic, sociological, and political themes. Rene seems to think quite a bit about her writing practice and how she represents her ideas through prose. She described her writing as "not there yet" but that it was becoming closer to the type of writing that she would like to produce. Like so many of the women in this study, Rene learned to write primarily from professor feedback, but she also cited reviewer feedback from her 
early publications as key influences on the way she understands her written work. One key feature of Rene's writing style was what she called "lawyering" or arguing for a particular position. Beyond just presenting the results of her study, Rene has a clear political agenda and works to clearly articulate these in her prose. As a mentor, Rene balances socialization with creative encouragement. She does not emphasize publication as an end in itself for her advisees, but she does encourage them to submit their articles for review as a way of learning how the professional community will view their research.

\section{Sara: Meticulously Proving them Wrong}

Sara is a white Anglophone associate professor focused on quantitative archeological research. She identifies as a "good enough" writer and is proud of the fact that she has been able to use writing to secure grants and share her ideas. Her articles were detailed and meticulously constructed, with every option considered and every weakness addressed. Her writing was primarily influenced in her undergraduate years by an advisor, turned mentor who, like Lucy's advisor, would provide in-depth, constructive feedback on her written work. Sara's writing experience in graduate school and professionally was less affirming, as she struggled with acceptance in a very androcentric environment. Perhaps due to this experience, she identified as someone who seeks to challenge narratives of what she can or cannot do, saying, "anytime somebody says, I don't think that'll work and I think it's a good idea, then I really want to show, I can't help it, I just really want to show them that they're wrong." In her mentoring practice, Sara did not necessarily push this same kind of world view, but she did enforce the idea of good 
writing as an essential tool for success in her field. Because of this belief, she held her students to high standards of accuracy and clarity in their written work.

\section{The Purpose of Scholarship}

For the women I interviewed, scholarship was almost a compulsion, a drive to understand a phenomenon and to communicate this understanding with others engaged in similar conversations. Rene, for example, described her research as evolving from, "the desire for change in the world... you look around the world, you see things, and you are constantly thinking, this can't be it, you know, it can be better." These women cared deeply about the topics they researched, and for many, their interest in these topics arose out of their lived experiences. The lived experiences that women drew on for their research were at times represented in terms of a connection to physical location, as in the case of Sara or Rene, whose research has often focused on regions similar to the ones where they were raised. At other times, the personal connection to research arose from an exploration of their social positionality, as in the case of Oksana, who often draws from her experience as a multilingual scholar, and Lisa, whose experience as a black woman in the United States has served as a basis for much of her research agenda.

I think that...black life is complicated. And I want to show that's something that I continually am trying to sort out for myself, but also to sort out in a way that I can have...some argument to tell and you know, to give shed some light on that. So just the subject matter itself is something that is very me. (Lisa)

The connection these scholars had to their research influenced both what they wrote about and how they wrote. Out of all the participants in this study, only Sara and Lucy 
did not explicitly connect their lived experience with their research practice. Lucy, while acknowledging how her white identity might have facilitated her career, saw a distinct line between her work and her own positionality. As she said,

I don't necessarily focus on my stigmatized or marginalized identities. And so that I don't feel a strong like, I don't feel a strong feeling that I like I'm speaking to activism for like, for my groups that I think need activism...

Sara, on the other hand, had been actively discouraged from using her positionality as a woman to inform her research practices, due to the heavily androcentric nature of her field. Still, both of these women saw their work as important in advocating for those who did not share the benefit of their positionality.

Because beliefs about the purpose of their scholarship have been so influential in the work that these women do, it is important to explore this idea first, in order to frame the subsequent findings of this study. The scholars I interviewed conduct research in order to understand complex, meaningful phenomena. Beyond developing an understanding, they also seek to communicate, or to participate in a conversation around these phenomena. The following section explores the importance both of the subjects that these women research and the ways they communicate their findings to their intended audience.

\section{To Generate Understanding of Complex, Meaningful Phenomena}

The participants in this study believe that a primary purpose of research is to increase understanding of complex issues. Because of the complexity of the issues they research, their work is both interdisciplinary and non-binary with regard to value 
judgements. The topics that the women in this study research are interdisciplinary in that they often reach beyond the walls of a single discipline; five of the seven participants either specifically referred to their research as interdisciplinary or described collaborating with researchers from a variety of other disciplines in order to draw from a variety of intersecting disciplinary traditions. As Rene said, “...my research is truly multidimensional...it's very interdisciplinary research on a range of issues." Sara also related a similar sentiment when describing her work,

...I guess I'll just say my work is really interdisciplinary. And I think that's what draws a lot of us to archaeology is like a fascination with people. But you know, a lot of us have backgrounds in geology or biology or chemistry, um, because of a way that we are studying the material past.

In addition to (or perhaps because of) the interdisciplinary nature of their work, these women saw the topics of their research as multidimensional, non-binary phenomena. This means that they viewed their research not in terms of absolutes, but along a continuum of benefits and drawbacks, positive and negative outcomes. As social scientists, my participants often described the challenge of trying to understand messiness of human life and the possibility of outcomes being simultaneously both harmful and beneficial. Angela acknowledged the complexity of social science research by saying, "we deal with people who are messy and meaning is messy." This acknowledgement addresses a key component of women's work in the social sciences. Instead of trying to simplify the messiness of the human experience, the women I interviewed dove into what Rene called "hydra-headed wicked problem[s]," and in their writing, worked to elucidate the 
intricacies of people's lives, needs, and experiences. Catherine, for example, saw such complexity as key to helping her readers understand their attachment to the world and, "all its messiness...everything that helps to make us who we are, but that we like to push outside the frame." This sentiment was reflected both in the topics that women chose to research, and in the prose itself.

\section{Choosing Complex Research Topics}

The women in this study emphasized that good research topics do not have easy answers, and they did not seem satisfied with what Lisa described as "little teeny incremental advances" in understanding of a topic. Although Lisa was referring to quantitative methodologies, it was not just the qualitative or historical researchers who sought out complex, multidimensional topics. For example, Lucy (a quantitative researcher) and Rene (who uses mixed methods) both study the impact of policy on different populations. Both structure their research to resist the binary of good versus bad outcomes, preferring to explain how a variety of outcomes, both good and bad, would be present for each policy decision. In Lucy and Rene's work, much of their analyses focus on competing costs, of weighing choices. For example, Lucy described the challenge of making policy changes within organizations still governed by structural racism and sexism,

...so much good stuff, like trying to increase the diversity of your organization, trying to lift up marginalized students, so many, like really important efforts have hidden costs because of the structure, because we can't just like cancel out racism or cancel out sexism in a specific context. (Lucy) 
In a similar vein, Rene described how she wanted to focus her research on "what people were feeling and the injustice of relocation, but also the positive part of it if it was done well." Like Lucy and Rene, other women in this study dug into contradictions that they saw in their work and in existing research as an important piece of understanding the complexity of the human experience.

Frequently, these scholars contrasted their work to earlier research that they felt was incomplete or reductive in its conclusions. For some, like Sara, the drive to understand her research area in more nuance led her to directly challenge the status quo in her field,

I have never been satisfied with sort of the existing analysis in my area. It just never is that rigorous, which is probably why I make people mad because I'm always like, well, it's only based on like three dates. I'm really careful about how I talk about things because I don't want to be insulting, and I really respect what they've done. But there's so much more to know. (Sara)

The idea that there is "so much more to know" was reflected in interviews with several other participants, as well. For some scholars like Angela and Rene, this meant intentionally reframing their research from non-Western, or non-dominant perspectives. Angela pursued this practice in her literature reviews by intentionally seeking out and citing non-Western researchers; Rene chose to reframe narratives that uphold the West as the default, or standard against which all other cultures should be compared. In order to reframe narratives of the Global South, Rene chose non-Western countries as her 
research sites, comparing them with each other, rather than holding them up against a Western standard,

...a lot of people compare the Western world and the Global South...But when we compare two countries... who have both been colonized, and then look at the growth trajectory, look at the governance, it's easier for me to make that kind of meaningful comparison.

In comparing the post-colonial experiences of countries in the Global South, Rene intentionally positioned these countries in dialogue with each other, rather than in service to the "Western eye" (Mohanty, 2003). Such positioning interrogates the simplicity of a binary world, where the West is positioned as the ideal and all other regions are poor proximities, at best.

For other scholars, like Catherine, pushing at the boundaries of knowledge involves challenging the ways in which relationships with nature are theorized in the political sphere. She described good writing as, “...the kind that makes you stop and question the stuff that you already think is true, right, not just add on something else within the existing schema, but to shake it up a little bit." Despite the excitement that might come with "shaking up" one's field, a researcher who intends to challenge the status quo needs to move with caution. This caution was expressed in the meticulousness and depth of their research, as well as in the prose used to articulate their processes.

\section{Writing Complex Research Topics}

The desire to understand the complexity of the human experience was evident, not only in research topics, but also in the prose that women use to describe their research. It 
is one thing to present straightforward ideas in a linear fashion. It is quite another thing to present more complex, nuanced ideas in a way that will be convincing for an audience that may be more accustomed to dominant viewpoints. Especially if ideas run counter to the status quo, arguments need to be laid out in a way that is recognizable for a disciplinary audience. The women in this study did not report difficulty in constructing their prose to meet such expectations; some, like Sara, even found expectations of structure in research articles to be helpful, in that these expectations reduced her need for decision-making in the organization of her arguments. Still, several participants reported making intentional choices within this structure regarding how they framed their ideas. Rene called this practice "lawyering," saying,

... the whole goal of academia is about, you know, it's like we are lawyers, but a different a different type of lawyer. So lawyers will stand in front of the judges, and they'll plead their case, and they will cite precedents inside the constitution or whatnot, you know, and the judges decide. We have the judges to write, our judges are reviewers, and the juries are the editors. But what we're doing is that we don't have the opportunity to stand before the reviewers and say, this is what I'm doing. But what we can do is to write those papers in a way that even when the reviewers come with question, the question would already be answered in those texts. So even if they can't see you, your text is already telling them what they need to know. So when I'm writing, I'm thinking as a lawyer, I'm thinking, I'm writing to a judge. How do I convince this judge that this idea is important and should be published? 
Many of the women in this study described lawyering or, as Oksana put it "packaging" their ideas in one way or another. Although there was very little overlap in the ways in which women in this study described their particular styles of argumentation, a few themes did emerge in relation to vocabulary and rhetorical moves.

In terms of vocabulary, Angela and Lucy frequently pointed out phrases and words they used in order to indicate areas of tension or contrast in their research. Angela, for example, described frequently using words like "while" and "although" in order to show that "Ah, it looks like it should be one thing but wait. If you look closer, it's totally not that thing at all." Lucy refers to this as "yes, and" or "simultaneously, however" in her writing.

... "simultaneously, however", it's kind of like the..."Yes, And" that I think of in my research so like, yes, this is good, and there's some bad. There is this positive thing... but you know...there's not just good. There's also bad in it...that feels very me. (Lucy)

It was important for both Lucy and Angela to highlight the fact that two, apparently conflicting ideas can exist at the same time. In doing so, they specifically sought to highlight this complexity of the human experience, rather than to aggregate or simplify for the sake of an easy explanation. This belief was evident in Lucy's assertion that good writing is "honest," meaning that it does not shy away from articulating successes and failures in policy, as well as in research.

In communicating complex knowledge, writers need to present their arguments with clarity and precision. Five of the seven participants described their writing as 
careful, detailed, or meticulous. Angela described how the sometimes "excruciating detail" that she includes in her prose is "more than detail for the sake of detail. I think it's trying to convey thoroughness, trying to convey a in depth knowledge of the context." Oksana also described her writing as clear and concrete. She contrasted this style with that of her male co-authors who she felt wrote with more finesse saying that their writing, “...just feels a little fudged to me and not too clear. And that seems to work great for audiences, but I can never write something like that."

In addition to clarity in language or phrasing, the women in this study also expressed clarity visually, through tables and bullet-pointed arguments. As she was describing one of her favorite articles, Sara repeatedly referred to a table she had created, Table 1, of course, it doesn't look very exciting, but it's actually very interesting to me. And it was a lot of work to put that together and so, I still feel happy when I look at this table. I don't know it's so weird thinking about what gives you like, happiness.

The table represented a clear representation of a large amount of work, analysis, and synthesis of information that hadn't previously been compiled. She later used the information that she had communicated through this article and through the table, as a basis for other research projects. The values that women placed on clarity in their prose and in their visual elements reflects a desire to present their complex ideas in ways that are palatable for their audiences. Even though their ideas are complicated, their prose does not need to be similarly hard to grasp. However, the clear expression of nuanced 
ideas cannot easily be produced by a busy, occluded mind. This is one reason many women in this study reported that their research takes time to produce.

\section{Complexity Takes Time}

Investigating complex topics and presenting them in a clear way for one's audience takes time and intellectual energy. Nearly all the women in this study emphasized that the time it takes to complete their research often runs contrary to expectations of publication productivity. Rene, in particular, railed against the capitalist machine that pushes greater quantities of publication rather than encouraging the generation of knowledge that contributes to a deeper understanding. She described her process of writing, saying,

Like I'm writing a paper right now, which I mean, I'm thinking through it very carefully. But if I, if it was just about, you know, getting it out, I should have been done. Like, just when I'm thinking, Okay, how does this idea connect to this one, you know, then I double check my sources, then I go on the internet and double check. Who else is writing about this?...And making sure the ideas are not what you know, it's not like you wouldn't say what other people have said, but the point is, what is the new knowledge we're adding to the world? And, you know, and that takes a while, you know, producing something new and radical in some ways.

For Rene, the process of thinking through a new idea takes time. She wants to make sure her research is innovative, rather than simply a reiteration of ideas that have already been explored. This involves both understanding what is already known about her subject and thinking through her own ideas so she can "lawyer" in a convincing manner. As Rene 
described, part of the time-consuming process is learning deeply about new areas of thought that she wanted to investigate. Oksana also frequently found herself in this position, as she commonly sought to research topics that had not been widely pursued before. She contrasted this style of working with advice she had gotten from a recent writing workshop she had attended, And [the workshop leader] always talks about...I can easily write a paper from what I already have, maybe look for a couple more references and there I have it. And I thought to myself, that never works for me, because...the way I write is usually I want to know the answer to this question... I don't care if I have the background in it or not. I'm just really curious. I'm just going to go for it, and I know it's going to take me ages, but I don't know. Maybe it's going to slow me down in my work, and I won't be able to write as many publications, but I just can't think any differently.

For the participants in this study, reading, thinking, and organizing thoughts was a timeconsuming, but necessary step in producing research that was both rigorous and innovative. Although some who were pre-tenure described feeling pressured to produce more research, there were no women in this study who reported wanting to simplify their research topics or pursue other ideas that were "easier." Rather, the general consensus among the women I interviewed was that they were committed to producing research on complex, innovative topics, regardless of the time it took to generate this knowledge. 


\section{To Communicate, to Participate in a Conversation}

Participating in a scholarly conversation was another important reason why the women in this study conducted and published research. In light of this goal, women were intentional about the venues in which they sought to place their articles, specifically choosing journals that would reach one particular audience or another. The desire to communicate knowledge or understanding of a concept to a variety of audiences led the participants in this study target audiences beyond their own discipline through nondisciplinary or discipline-adjacent publications. For example, in writing about the attitudes of black leaders on immigration, Lisa chose to publish in an ethnic studies journal, rather than a more mainstream political science publication, in order to speak directly to black intelligentsia and to inform their scholarly discussions on immigration. Angela, whose work focuses on the linguistic analysis of different disciplines, writes for professional newsletters in the disciplines she researches, as well as in academic publications in her own discipline. The following section describes how the women in this study participate in scholarly communication through their research. I explain how both scholarly audience and tenure requirements interface in order to influence the communicative choices these women make in their publication practices.

\section{The Influence of Audience on Communicative Choices}

The choice of one journal or another often resulted in a negotiation of vocabulary or rhetorical frame in order to adapt to the disciplinary expectations of the targeted audience. Just as one might change her style of speaking when interacting with different colleagues, scholars also need to adjust their styles when writing for different audiences. 
Despite the occasional frustration of adapting to different audience expectations, the women I interviewed did not see this negotiation as significantly impacting the authenticity of their written voice. For many, this was a natural part of communicating meaning to a variety of audiences. In fact, one of the reasons why Angela identified as a good writer was her ability to recognize and apply forms or structures required by different types of publication to her prose. This type of flexibility helps writers like Angela reach a wider audience beyond the ones traditionally defined by their disciplinary boundaries.

As they seek to communicate with a variety of audiences, scholars often need to negotiate different values and ways of expressing ideas. This negotiation can be as simple as changing terminology or as complex as rewriting an article from a different rhetorical perspective. For instance, Lucy described a negotiation with a reviewer about the term, allostatic load; although she had intentionally used this word to reference an existing body of research, the reviewers argued that she had not applied the standard definition of this term. In the end, Lucy decided to change allostatic load to physical health risk rather than submit her article to a different publication that may have been more tolerant of nonstandard uses of the term. She did so because she specifically wanted to place her argument in front of the audience of this journal in order to add more nuance to their scholarly knowledge base.

Several other professors described needing to change the rhetorical frame of their papers in order to please the reviewers. Rene, for example, explained how she changed the structure of an article in order to have it published by a particular journal. She did so 
because she wanted to reach an audience that she felt was using two distinct terms interchangeably,

I wrote the paper, send it to this journal, and then they came back to me... and said, Oh, we like the paper, but it's long, but it's also based on literary view, rather than like an empirical work. And so because of that, can you rewrite... as a perspective? So I said Okay, yes. And I didn't have to say yes. I could go have gone I'm going to take to another journal. But I said yes, because that journal is one of the top journals that people read on that topic. And so I felt if I really need to get to people, who were using this word interchangeably, that is a good outlet. (Rene)

Although this type of negotiation was common for everyone I interviewed, some had an easier time than others. For Oksana, in particular, the process of negotiating her prose with reviewers was often torturous. In reference to a paper she had recently submitted for review, she said, ...the editor kind of went through our paper, asked us to revise it once and then after that asked us to revise it one more time. And I just felt, I mean, like, I don't know... if I could only just let her edit it the way she wants it to be and I'd be just fine with that...This is impossible but, but I really felt our original version of the paper was okay. I mean, we had five people working on it, two of them...full professors...who've had a lot of experience writing... and she just wanted something a little different. So I just feel like you just never know, what do other 
people want to see in your paper. And so, while it's a little bit frustrating for me, I also realize well, that's just how it is. (Oksana)

Throughout our interviews Oksana repeatedly referred to her frustration with the subjective nature of the review process. She understood that editors often have a clearer understanding of what the audience might be looking for in an article. However, she saw many of the requested changes as arbitrary, ones that were based more on the preferences of the editor than on some objective measure of quality.

Regardless of the types of changes that they were asked to make, the women in this study did not think that the peer review process had a large impact on their written voice. They saw the changes requested by reviewers and editors as stylistic edits to appease a particular reader, but in most cases, found their voice securely rooted in the message they intended to convey. This suggests that a woman's scholarly voice is deeply rooted in her body of work, her message, and her research agenda, as opposed to residing solely in the construction of a particular sentence or turn of phrase. However, the flexibility with which a scholar can exercise her voice through her research agenda is heavily influenced by her department and, to a lesser extent, her institution, through the requirements of the tenure track.

\section{The Influence of Tenure Requirements on Communicative Choices}

For the women in this study, tenure requirements within a department had a good deal of influence on the frequency and location of their published work. The women who worked in departments that had greater flexibility for what would count towards a tenure portfolio seemed to have greater freedom to pursue communication with different types 
of audiences. However, with flexibility also came uncertainty in what would ultimately be accepted by tenure committees. The tenure requirements in Angela's department were open enough to allow her to publish in trade magazines, journals outside of the discipline, and textbooks. She wrote several papers in trade publications for other disciplines and participated in co-authoring a textbook for undergraduates, neither of which would typically be encouraged for a new professor in a similar department at a more competitive institution. Despite the support of her department, she reported getting conflicting messages about how these different publications would count toward her tenure portfolio, leaving her confused and nervous about a process that would ultimately have a large impact on her scholarly career.

All of the assistant professors in this study expressed a similar degree of nervousness at the prospect of tenure review, being uncertain about whether their work would count toward tenure. Catherine, for example, was worried about needing to publish in political science journals, which might not be as accepting of her theoretical style of writing as the more humanities-focused journals that she has tended to publish in, saying, ...tenure requirements are different stories...I'm still trying to figure out...how much I can finesse them. Because if I am indeed required to publish in very sort of straight and narrow political science journals, then yes, my writing will absolutely and my thinking will have to change drastically. I've got two things I'm going to send out to like political science adjacent journals and just publish enough that no one can say to me. Well, you're not right, you're not producing. 
The stress of not knowing whether or not hard-earned publications would count toward a tenure portfolio is palpable in Catherine's statement. Even when publication opportunities presented themselves, it was a challenge for some of the professors to know whether it was a good choice to take these projects on. Lucy, for instance, struggled with whether or not to take on a publication project that she was excited about, knowing that it would take time away from other research that she would need for promotion. In the end, she settled on accepting this project because it offered an opportunity to contribute original theoretical material to her field, which was one of the requirements for her tenure portfolio. Although she was personally interested in writing the article, it was ultimately the need to check off a box for promotion that convinced her to take on the project at that time.

Once tenured, however, the women in this study seemed to feel greater freedom in the type and scope of work they were able to pursue. This freedom opened up the possibility to pursue avenues of communication outside of the insular network of academics. Now that Lisa has tenure, she reported being more comfortable targeting journals outside of political science, for example, sociological and ethnic studies journals. Sara, whose written work primarily falls into either archeological reports for public agencies or traditional scientific journal articles, described wanting to try new forms of writing now that she has tenure. She said,

But I think that writing in a more humanistic, humanistic style and taking that approach in like structuring something is much more easy for non-specialists to like, relate to what we're doing...I mean, I think that all of my writing from my 
work is pretty much in the same style. And I'm trying to write in a different, I'm trying to expand my skill set. And I think I'm at the stage where I'm reading different kinds of things and getting different ideas, and there are just more different kinds of forums where we write things now.

Sara's goal was to reach a broader audience, one that might not necessarily read a long report or a journal article, but one that might benefit from her findings. This goal speaks to similar goals espoused by other women in this study, who want their work to reach audiences beyond the limited academic sphere in which specialists typically participate.

In summary, the women in this study conduct research in order to better understand a complex and dynamic world, a world in which they actively participate as citizens and investigators. They publish research in order to communicate their understanding of this complexity to a wide variety of audiences, both within their disciplines and beyond the academic sphere. To do so, they construct arguments carefully, working to convince their readership to lay down their long-held beliefs and consider a more nuanced way of understanding. As these women participate in the publication process, they engage in a number of negotiations around how their work is presented, from the language to the rhetorical style of their work. Still, the work that the women I interviewed produce is uniquely their own and remains so in spite of the multiple mediating factors that arise during the generation of a published research article. In their development as scholars, these women have learned how to balance these factors with their own academic agendas, with varying levels of success. The ways they approach this balancing act has contributed to their perceptions of themselves as scholars, 
an identity which is neither fixed nor finished, but rather an evolving professional identity.

\section{The Process of Becoming a Scholar}

The women in this study did not instantaneously become scholars upon the completion of their PhDs. Rather, the development of their scholarly identity seems to have extended over their academic careers, often beginning with a particular class or advisor as undergraduates, continuing through their graduate degrees, and then beginning to solidify in their early years as professors. Still, even as professional academics, the women I interviewed saw their scholarly selves not as fixed, but as constantly evolving, driven by new ideas and often inspired by their students, peers, and mentors. In the section that follows, I describe how these scholars were socialized into their discipline by mentors, the culture of their graduate schools, and early experiences with publication. I then discuss how the development of professional or scholarly identity appeared to be an iterative process for many of the women in this study.

\section{Socialization}

Throughout their development as scholars, the women in this study have become socialized into their academic disciplines. This means they have learned to understand and apply the rules of the disciplinary game they have chosen to join, including how to participate in communicative practices, like academic publication. No one in this study "became" a scholar in graduate school. When I asked about how they learned to write, for example, very few of these women described being explicitly taught the norms and expectations of academic prose while earning their doctorates. In describing how they 
learned to write, many cited early training in academic practices (writing and thinking) during their undergraduate degrees, and a few described guided practice led by professors or advisors in their graduate programs. The graduate programs, themselves, including the ways that students and professors worked together, also played a role in how the scholars in this study were socialized into writing and research practices. Finally, several participants described formative experiences with publication, either in the later years of their doctorates or early years following their degrees as teaching them how to participate in the scholarly practices of their fields.

\section{Mentors and Advisors}

Most women in this study cited a particular person who had acted as their guide in learning disciplinary practices. Although this is the role most commonly assigned to graduate advisors, women found mentorship in a variety of other locations, as well. Interestingly, most women cited their strongest mentors or influences to be other women. Two participants, Sara and Angela reported learning the foundational practices of academic writing from women undergraduate advisors or professors, practices that they would later apply in graduate school, but in different ways: Sara's undergraduate experience was quite field-specific, helping her learn about disciplinary form and content, whereas Angela's experience helped her develop confidence and assertiveness in her written voice, which would later serve as the foundation from which she would build her identity as a disciplinary scholar. Angela, Lucy, and Oksana also received supportive mentoring in their graduate degrees from women advisors and professors. In these cases, 
the women spoke of in-depth, specific feedback on language, structure, and argument on drafts and on co-authored work.

Sara developed much of her understanding of writing in the time between her undergraduate and graduate degrees, when she worked with her undergraduate advisor, doing work for a local indigenous tribe. In this work, Sara, "ended up doing a lot of stuff that people don't do at that point in their career usually, like...writing really long reports." During this time, Sara was writing descriptive field reports and submitting them to her former advisor, who would give her "real feedback" on them. Sara described this feedback as indecipherable handwritten comments that her advisor would have to explain; as she did so, the two would have the opportunity to discuss the form and structure of archeological writing.

Although Angela did not get discipline-specific writing instruction before entering graduate school, she did begin to develop her written voice during her undergraduate degree. Angela described developing argumentative strength in her writing, based on the instruction provided by one of her undergraduate professors who taught writing through the lens of manifestos. This professor not only developed her students' writing ability through regular, structured practice, but also taught them how to "go out on a limb" to argue for strong positions in their work. Angela used this strategy in her later professional writing "as a way of making an argument about something that [I] cared about." This experience was reinforced by her graduate school mentor who encouraged Angela to minimize her use of hedging language (words such as seem, may, or might), as a way of addressing, 
...some of the research out there on powerful and powerless language... and how you get perceived when you're when you're hedging in particular ways and tying that to being a woman in academia... Women were more likely to put more of that kind of stuff in their writing and therefore, keep an eye out for it and see, do you really need that seems or is it something that just is?

Angela was one of the few participants in this study who had close, supportive relationships with their graduate school advisors. Her advisor not only gave her advice on writing style, but also opened doors for her in getting work published. When Angela was seeking to publish her dissertation as a book, she had an informal conversation with a publisher at a conference she was attending,

And then I mentioned it to [my advisor], she happened to be at the same conference as and she was like, here's the publisher you should talk to and she like, directed me towards kind of one of the bigger publishers in the field, and apparently then she did some behind the scenes, to kind of go like, "Oh, yeah, she's the next whoever."

Angela did get a book contract because of her advisor's advocacy, and as a result, was able to enter the job market as a newly minted $\mathrm{PhD}$ with a book publication already on her CV.

Lucy also had a close graduate advisor with whom she still collaborates on publications. She described the advice she got from her advisor in much the same way as Angela, as feedback and rewritten sentences to make her arguments "more forceful or clearer." In addition to this advice, Lucy's advisor also helped her writing become more 
disciplinary by bringing attention to field-specific vocabulary or seminal authors who should be included in a review of literature. The collaborative relationships that Sara and Lucy had with their advisors seemed especially influential on their work and their careers, and both women referred to these ongoing relationships as a source of emotional and professional support. It is notable that for the participants in this study who specifically described close relationships with advisors, all the advisors were women. Although other participants also had positive mentoring relationships with their male advisors, the connections did not seem to be as lasting nor as influential on their professional trajectories.

Although the differences in relationships between advisors of different genders and the women in this study could have been driven by differences in personalities, it is notable that advising style also seemed to differ between genders. The type of socialization practiced by Lucy and Angela's women advisors could be described as quite "hands on." This means that these advisors marked up papers and provided sentencelevel editing advice for their mentees. By providing their mentees with direct, specific advice on not just what to write, but also how to write it, these advisors helped shape their written voice. In some respects, this type of support seemed to alleviate much of the stress of learning how to participate in a new community of practice, and the women I interviewed seemed to have appreciated this support. Although Oksana did not describe her advisor as providing such hands-on support, she fondly remembered one graduate school professor who would provide her with word-level feedback on each of her drafts, but never take off points. She said, 
I remember I would always, I would always get all these drafts, you know, with Track Changes everywhere. And yet, I would never lose points, like she would completely, I feel, not rewrite the paper for me, but really edit a lot and I did learn from that I was so appreciative that somebody took the time to do that.

In each of these cases, women reported learning the most from advisors and professors who were quite hands on, either during their undergraduate or graduate experiences. They seemed greatly appreciative of the time that these expert academics would spend on helping them learn the conventions of academic writing. These experiences contrasted greatly with those who reported being primarily mentored by men.

In contrast to the hands-on approach taken by many woman mentors, the relationships that my participants had with male advisors in graduate school had a different character. Both Lisa and Rene worked with men of some scholarly renown in their graduate programs. Neither woman described a hands-on mentoring relationship with their advisors, like Lucy or Angela, but rather, described a more cultural socialization; their advisors would facilitate peer writing groups or retreats, where novices would gather, exchange ideas, and provide feedback on each other's writing. For example, Lisa told the story of how her advisor had invited her to a retreat at Stanford with his illustrious friends and their favorite advisees. At this retreat, she "got to hang out with them and eat and talk," and eventually publish an edited book based on these discussions. In a similar vein, Rene described working with a group of students put together by her advisor, a Nobel Laureate, 
Those of us that were working with him was that he made us read each other's work...so we're all part of this project that he had set up...And so we're supposed to publish a book and a journal and whatnot.

These examples show the cultural component of socialization, where the exchange of writing and ideas reproduces a particular school of thought. Both Rene and Lisa reported positive relationships with their advisors, and in general, depicted them as encouraging. However, neither Rene nor Lisa mentioned that their advisors had given them specific, detailed feedback on their actual prose, as was the case for Lucy and Angela. Rather, the focus seemed to be on developing a culture of thought from which the practicality of writing would naturally arise. In learning the mechanics of writing, both Rene and Lisa described reading and learning by example, rather than from direct feedback. It is interesting that both black women in this study had similar experiences in their graduate degrees, especially considering that according to both women, their fields are still largely dominated by the scholarship of white men.

In contrast to the positive socialization experiences of Rene and Lisa, Sara had a notably challenging experience with advising in graduate school. From Sara's description, it appears that her $\mathrm{PhD}$ advisor remained somewhat aloof throughout her time working with him. She seemed to have a hard time approaching him and described him as quite busy with his own academic work. When she did receive feedback from her advisor, she said that the paper would just be "bleeding" with red ink, giving her the feeling that "you don't even know where to start because nothing seems good enough." This relationship provides an interesting contrast to Sara's experience with her 
undergraduate advisor, who also provided substantive feedback on Sara's drafts, but with whom she had a more emotionally supportive relationship. In our conversations, Sara was always careful to balance her disappointment with her $\mathrm{PhD}$ advisor by saying that he was open to talking through problems with her and that he was actually quite helpful when she asked for advice on publication. For example, she often qualified her experience of working with her advisor by attributing her negative experience more to the culture of the program than the advisor, himself,

...it was definitely more of a traditional $\mathrm{PhD}$ program without a without a ton of like, mentoring or being taught how to be a scholar. And I say that when I like I have a good relationship with my $\mathrm{PhD}$ advisor, and I think I had like the best one and I think he's a really good person. It was just the culture of that program. Still, it is interesting to note that Sara resisted attributing the development of her scholarly identity to her graduate school experience. Her relationship with her undergraduate advisor remained the formative disciplinary experience that she drew from in her writing and research practices, despite the advanced training in research and publication she received during her $\mathrm{PhD}$.

Oksana also reported a similar contrast in her graduate school socialization experience. The professor whom she reported learning the most from was the woman mentioned above, who would provide detailed feedback on word choice and grammar yet would never take points off of Oksana's classwork. In contrast, Oksana described a class she had taken the subsequent term, in which she repeatedly clashed with a male professor. 
And so the second instructor I really felt was kind of picking on me. Maybe he wasn't, I don't know, but I just felt that he was maybe because the feedback wasn't as clear and as detailed as the previous instructor's. It was more vague and maybe I just didn't know what to do with it. And one particular comment I remember was, you need to give like a roadmap paragraph or something like that, and I was thinking it was either a roadmap paragraph or summary.

In her writing for this class, Oksana resisted revising her work to include a "roadmap" or overview paragraph, despite multiple exchanges of drafts. It was only once she started teaching that she realized the value of her professor's advice and began advising her own students to include roadmap paragraphs at the beginnings of their essays. When I asked Oksana about the differences in how she responded to feedback from her two professors, she said,

... the first instructor really had...not a personal connection but just felt, I don't know she she's a woman. She had two little babies, and I just thought, wow, how hard it is for her to do that, like I just somehow could relate to her to her in some way, not that we were friends in any way but I guess with the other instructor I didn't feel like I could relate. So I wonder if, if that already influenced how I was taking in their feedback.

This connection went a long way in how Oksana responded to feedback; although the woman professor had been rather heavy handed in her feedback on Oksana's writing, Oksana described quite positive reactions to the comments. Not feeling a personal connection to the male advisor could have led Oksana to resist his feedback, seeing it as 
more arbitrary or not as valid. Oksana's experience may be similar to Sara's, who reacted negatively to the markups from her male graduate school professor, but positively recalled the feedback from her female undergraduate advisor. It is possible that Sara's negative experience in graduate school was also a response to the contrast between her undergraduate advisor, to whom she felt a deep connection and her graduate advisor, from whom she felt quite distant.

The process of becoming a scholar is shaped in many ways by the personal relationships a novice forms with other academics throughout her academic trajectory. Although graduate school advisors typically have the most contact time with their advisees, relationships with undergraduate advisors and classroom professors can also be quite influential. For many of the participants in this study, same gender mentoring relationships had a lasting positive impact on their identities as scholars and their writing practices. Though the participants with male advisors also generally reported positive experiences, it appears that socialization practices were more culturally socializing, in contrast with the practices of women, who engaged in more direct, hands on mentoring practices.

\section{The Culture of Graduate School}

In addition to the individualized instruction scholars receive from mentors in their graduate work, simply being in an environment of scholarship with other students can be invigorating and instructive. Many of the women in this study reported that the way they had been socialized was due to the culture of their departments and institutions. In some cases, the women in this study sought out socialization of a particular type by enrolling in 
an institution because of its cultural reputation, a reputation that was guided by a professor or group of scholars. In other cases, at institutions where graduate students were admitted as a cohort, the collaborative nature of being part of a group brought about certain type of cultural socialization. Several women described collaborating with others in their cohorts by reading and commenting on each other's work, taking advantage of an intensive collaborative environment that was hard to recreate outside of graduate school. For some who had pursued quantitative research methodologies, such collaboration involved working as part of lab, where they would collect, process, and share data with other graduate students and a lead professor.

Several women in this study (Lisa, Catherine, and Rene) specifically mentioned choosing a graduate school either because of the culture this school projected, or because of a scholar they wanted to work with. One might say that these women chose to be socialized in a way that matched their values of scholarship. For example, Lisa had been accepted to two graduate programs, one with a heavy focus on statistics, and the other with more of an interdisciplinary historical focus. Having chosen the second university for graduate study, Lisa reflected on how it had been a much better fit for her; since her advisor held doctorates both in sociology and political science, Lisa realized that it was possible to reach across disciplines in her research and was likely supported in this endeavor by her department. Her research is still quite interdisciplinary, likely due in part to her positive graduate school experience.

Catherine had also chosen a graduate school with a distinct culture that fit with her emerging scholarly identity, where writing was more about telling a story rather than 
presenting what she described as a more formulaic narrative. She had gone to this school in order to work with two political theorists, both of whom she described as having beautiful writing,

And their writing is, it's excellent writing. It's imaginative, and it's beautiful, and...it makes conscious use of metaphor and simile and the kinds of technique you would find writers' writers using. And there's not just to be pretty but for a reason, right? Because... ideas and writing are so bound up with one another that that tone that you set...with your prose is important, particularly when you're talking about ideas that affect, you know, all, all of us as people.

In working with two senior scholars whose prose she admired, Catherine was socialized to develop creatively as a writer, giving her the tools that she was looking for to develop in non-traditional areas of thinking. The support Catherine received in developing a more non-traditional scholarly agenda was also supported by her university, through a yearly colloquium which was "a safe space for grad students to present their work and receive feedback." The cultural mentorship in this space likely came from both students and faculty, creating a web of social support from which participants could collectively align their scholarly values.

In contrast to the experiences of Lisa and Catherine, whose graduate school environments encouraged creative and non-traditional scholarly agendas, Sara struggled to fit in with the more androcentric culture of her graduate department. She described a culture that was based on traditional masculine values of individuality and competition, rather than one that was supportive and inclusive. Because of this, much of her 
description of her graduate school experience reflects a sort of isolation or detachment from members of her cohort and from the department itself. In addition to the working environment, there was also a strong cultural overtone of what topics were and were not appropriate. In her dissertation, for example, Sara was reticent to write about gender for fear of being labeled as a "women's scholar." She described her dissertation and early publication experience by saying,

I felt like I couldn't even write about gender early on because even though I studied something that's highly gendered at least ethnographically like pottery, modern people, it's women. Like $95 \%$ of potters are women. I wrote a whole dissertation about pottery and I had like one section about like, one paragraph about that because I felt like coming from the program that I came from that people would just give me a hard time and I would get put in a box.

This experience had a lasting impact on Sara's scholarly agenda. In our interview, more than ten years later, Sara described just recently beginning to write about gender and pottery in her published work.

Although the culture of graduate school is mainly determined by the professors who set the scholarly agenda, lead research teams, and mentor novice academics, the peers in one's cohort are also an important source of socialization. Catherine, Lisa and Rene all described meeting in cohorts where they were encouraged to read and provide feedback on each other's work. This exchange of writing and ideas seemed to help bring the students closer to a group norm of academic communication. Rene, in particular, 
reflected on how formative this group was in the development of her disciplinary writing skills,

And in my case, I think my writing at the time was just ok, you know, was just average. But when I read some of the other work from [my] colleagues, I was like, Oh, this is actually very interesting. This makes sense, you know, and so I wanted to improve.

Working in a close cohort of like-minded peers under the guidance of a prestigious professor helped Rene learn the norms of academic communication while being supported by others with complementary skills. Although advisors can foster this type of environment through the strength of their personality and willingness to bring students together, socialization can also arise between peers in research labs. Two of the quantitative researchers in this study, Oksana and Lucy described working in labs in their early grad school years, which supported them in the publication process early in their graduate school careers. In Lucy's case, her participation in a research lab gave her early access to data that another student had collected.

I think one of the first papers I wrote in graduate school was...was someone else's study that they had run and I had actually been a research assistant...for that study. So it was a graduate student who left right as I was arriving... and basically, when I arrived, this graduate student who had collected the data, got a job in the private sector, [she had] no desire or need to, you know, write anything up for publication. So she basically worked with me to understand the data set and sort of gave me that data set to write a paper on...so I didn't design the study, but 
I...ran the analyses and figured out how to think about it. And I think...that was a formative moment in my relationship with my advisor because I was able to think about it in a slightly different way than they were thinking about it. And that really helped kind of open up the possibilities of, of the data set.

In being part of the lab, Lucy gained first-hand, guided experience in analyzing data from a peer and was able to use this opportunity to make a positive impression on her advisor. Oksana had a similar experience as a research assistant in a lab where she was fully involved in conducting the analysis for a project, but where the construction of the paper, as well as the responses to reviewer comments were mediated by more experienced peers and the lead professor on the team. Both women reported these experiences as formative in their understanding of research and publication; their positive experiences with copublication demonstrate how a community of scholars at different stages of their socialization can provide norming and support for a novice scholar's research agenda.

\section{Early Experiences with Publication}

Early experiences with publication were also formative in the socialization process for many of the women I interviewed. Although many had their most formative publication experiences in graduate school, under the supervision of their advisors, the women in this study continued to be socialized through the process of revise and resubmit, even after they had left their graduate programs. Throughout their academic trajectories, many reported that the "learning through doing" aspect of participating in publication has been important for them in seeing how their ideas stand up to the 
criticism of peers. Themes in our interviews focused on how these women were socialized through reviewer feedback and guidance from senior scholars.

Reviewer Feedback. Reviewer feedback was, at times, quite influential in the ways that the women in this study developed as scholars. Although the revise and resubmit process can be fraught with experiences of power or tension in the reviewers' versus the researcher's vision for the article, the process of submitting work and receiving feedback was seen by nearly all the participants in this study as having a positive influence on their final published product. Much of the developmental feedback from reviewers came while these women were still in graduate school, but many reported continuing to learn even from more recent publications. One way in which reviewers had provided socializing feedback on the academic work of the scholars I interviewed was through the suggestion of theoretical frames. Rene and Catherine both described having reviewers suggest a theoretical framework that not only helped improve their paper, but also set the groundwork for future work. For example, a reviewer suggestion pushed Rene to pursue a social justice track in her work, which has since led to a book deal and increasing attention to her research from news outlets. For Catherine, a suggestion to incorporate conceptual and theoretical frameworks helped her pull together the ideas in one of her publications and made her writing feel more cohesive. She described how the use of such frameworks have become integral to the way she constructs a text by saying, ...a piece of advice I received from one of the reviewers for that article is something I still think about, it still helps me with my writing. The reviewer suggested that the piece needed either ... a conceptual focus or a thematic one... 
to basically tie it all together from start to finish, because I tend to...draw from different kinds of disciplines in the same piece, and it was a bit disjointed, so the recommendation was to streamline it either with a conceptual or thematic focus. It was a great piece of advice. And actually...I still...refer to it all the time, and I ended up adopting both.

This reviewer suggestion helped Catherine pull together the disparate sources and ideas she works with into a more cohesive argument. Since receiving that feedback, she has begun to use theoretical and conceptual frameworks to shape the through lines of her articles.

Reviewers can also be instrumental in helping novice scholars understand the types of topics or the depth of scholarly inquiry commonly accepted by one's peers. Encouraged by a professor's compliments on her writing while in graduate school, Rene had submitted an article that was based on one of her term papers for publication. However, the feedback she received from the reviewer was surprising. She recounted this experience by saying,

I think the reviewer said, this is such a bad paper. Not bad, but...like we know all these things already. There's nothing new in this paper. Please don't work on it anymore. So that was a good feedback, because I didn't realize at the time that writing a paper was about making an important contribution to the literature, not repeating what other people have said...I don't know whoever that person is, but I'm so thankful for that feedback. Because...oh, it was like a eureka moment. 
In this case, Rene saw the feedback she had received from the reviewer as formative in helping her understand the purpose of scholarly communication. She repeatedly referred to this experience in our interviews, describing how happy she was that this paper hadn't been published, for fear of future embarrassment. Rene also encourages her students to follow a similar path, telling them to "send it to a journal and see what happens... because I like people to test out things." This experience of testing out how one's arguments hold up in a community of scholars can be a useful exercise, especially during graduate school, if a novice scholar is not under pressure to publish. However, once a scholar is looking to establish a scholarly agenda for the job market or is facing down a tenure clock, this type of experimentation may be less of an option.

Publication Support from Senior Scholars. Senior scholars were often instrumental in helping the women in this study learn about the norms and expectations of scholarly publication. Four of the seven participants referred specifically to early publications that they had completed under the leadership of a more senior scholar, who helped ease the process of publication. These senior scholars were often faculty in graduate school, with whom the women in this study had connected via a research lab, a class, or a common research interest. In working with these scholars, women learned how articles are structured, how to write about different types of results, or how to craft an argument for the study in the literature review. Sara reported that her experience of working with a senior scholar on her first published article in graduate school was "probably the easiest paper I ever published" because she had been able to draw from the scholar's expertise in researching, writing, and seeing the paper through to publication. 
Not only did these senior scholars help novices write the articles, they also helped them interpret conventions around the act of publication. For example, in order to get an article published, it is important to know how to introduce ideas through cover letters or how to respond to reviewer comments. Although these acts are not visible in the final product of a published research article, knowing how to navigate what Swales (1996) calls "occluded genres" is an important piece of scholarly communication, and therefore an importance piece of academic socialization. In providing this kind of support for academic socialization, senior scholars helped the women in this study understand processes of publication that are not necessarily explicated when novice academics learn how to write up empirical research.

One area in particular that many women referred to is how senior scholars helped them navigate reviewer comments on the articles they had submitted. Oksana recalled that one professor told her that she should respond to every comment from a reviewer, even if she disagreed with it,

...because she has been a reviewer for some papers where, you know, they asked her to review the paper again, she doesn't really see any revisions or too few. And she, of course, gets really upset that she put in that time and her comments didn't get addressed.

The expectation that a writer will respond to every comment in a revise and resubmit process is not something commonly practiced in genres outside of academic publication. In the writing that these women produced for their classes or for their culminating projects with their academic advisors, they were not expected to respond to comments on 
a draft, but rather, take them as instructive feedback on how well their writing had met the professors' expectations. Especially for the women who worked with more hands-on advisors (those who would make multiple word-level changes on drafts), corrections were generally seen as being given in service to the development of the students' disciplinary development. As such, the idea of responding to or negotiating with such comments is not one that most students would entertain, but it is very much a part of the publication process, and therefore needs to be clearly explicated to new academics seeking to engage in this medium.

Another area where responding to reviewer feedback needs explicit guidance is in dealing with conflicting or critical comments. Such comments took an emotional toll on participants like Sara, Lucy, and Oksana, who reported often feeling hamstrung by feedback that they did not know how to manage. Oksana described a situation where she sought advice from a faculty member on a set of reviewer comments during graduate school,

...I think I said, I don't really know, like how to proceed. These comments are so difficult. They're kind of conflicting. How do I address something where, you know, it's conflicting? And I think she said sort of things like this happen all the time. Sometimes you feel like you just want to file that paper for two years and then come back to it. I guess in your case, you really can't because you have to do it as part of the program. You don't have that time. So just kind of, you know, plow through it. But I do remember kind of that effective, those effective 
comments and feedback that we all go through it and kind of learn to deal with it emotionally.

Lucy also reported frequently deferring to her advisor or more senior co-authors, even post-graduate school, who would help her distinguish which comments were valid and which were overly critical. This helped Lucy understand not only how to process these comments, but also how to feel about the revisions on her articles.

Learning to become a scholar involves not just writing in topics that are disciplinarily appropriate, but also learning how to navigate gatekeepers like reviewers and editors. Some of this academic socialization can come from the reviewers themselves, in the form of constructive feedback. Even outright rejection, as in the case of Rene's first attempt at publication, can be instructive, as it teaches novices where the boundaries of academic expectations lie. It can also be helpful to have an expert scholar at hand who can help a novice navigate the more occluded or complex aspects of academic publication. Learning how to respond to reviewer comments can be challenging, for this is not a skill that is commonly taught in areas outside of academic publication. However, because the negotiation that comes with peer review is an essential part of participating in a scholarly conversation, it was important for many of the women in this study to have explicit instruction in navigating such turbid waters.

Although the bulk of the socialization that the women in this study received happened during graduate school, through the mentorship of their advisors, professors, peers, and publishers, I do not believe that any of the women in this study would consider themselves fully formed as scholars. Rather, they seemed to be constantly in the process 
of professional evolution, working to hone their research interests, their writing practice, and their mentorship work. This professional evolution embodied different forms, depending on where these women were in their careers, but regardless of whether they were tenured and widely published or just entering the academic ring, the dynamism of their professional trajectories was a common theme in our interviews.

\section{Professional Evolution}

The women in this study all described being socialized as scholars throughout their student and professional experiences. However, viewing the development of scholarly identity through the lens of socialization assumes that the end point of socialization is basically assimilation to the norms and expectations of a discipline. Certainly, socialization and some degree of assimilation is important. Even if a scholar disagrees with the norms and expectations of her discipline, she needs to be able to work within these norms in order to establish a platform for her own scholarship (for example, a tenured position at a university). A scholar's professional trajectory can include socialization, but it does not have to stop there. The professors I interviewed continued to evolve as professionals even after they had become comfortable as scholars within their disciplines. In becoming scholarly writers, these professors' experiences aligned with three themes of writerly development: performative, generative, and expansive views of themselves as writers. Because of the iterative nature of these stages, most women I interviewed were not fully in one stage of writing or another, but were moving from one stage to the next, based on their goals for a writing project and the type of audience they were trying to reach. 


\section{Performative}

For the women in this study, the performative stage of writing development represented a time when they (or their students) attempted to mimic the conventions of academic scholarship, without understanding the intention behind these conventions. Casanave (2019) defines such performances as novices seeking to "display more expertise than they currently embody," rather than participating in "intentional fakery" (p. 58). This means that novices are not necessarily faking their way through academic norms, but they are using certain communicative mechanisms without fully understanding the relationship between these mechanisms and audience expectations. In this stage, novices attempt to embody their scholarly agendas, but regularly run up against the rules and norms that implicitly govern academic communication. Although the women I interviewed had generally moved beyond this stage of writing, for some, the experience of performing writing in graduate school was still very salient for them. For example, as mentioned above, Rene described learning not only the form, but also the purpose of academic writing, when she submitted her coursework for publication and received feedback on the types of topics that are acceptable for academic publication. Angela, whose undergraduate writing experience was quiet formative, recalled that her early attempts at writing centered around misconceptions about what academic writing was supposed to look like, "It was like, how do I perform what a good piece of writing is? ...what's a topic that will seem like the kind of topic that is important for a person to write about?" 
Although the theme of performing writing was quite common in the interviews, the majority of women in this study did not often refer to their own writing as performative. Instead, professors often used language referencing this stage to describe the experiences of their students and their efforts to help their advisees move from performing writing to generating knowledge. Lucy repeatedly referred to this as learning that academic writing is thinking, not performing,

I've really tried to instill in my students of like, you're not writing to have a finished product... this isn't a performance. It's not like you're going to get a grade, you're writing to participate in the discipline, you're writing to help you learn how to think and to... make yourself do hard thinking work, when it's really easy to not hard thinking work? Right, like, the purpose isn't to finish, it's to do.

In this quote, Lucy extends the concept of performative writing as writing to prove knowledge for the purpose of a grade, and contrasts it to academic publication, where the purpose of writing is more to generate and exchange ideas.

Even in the classroom, professors endeavored to help their students use writing as a means of idea generation, rather than simply using it as a means to earn a grade.

However, Sara and Lisa described how challenging it is for students to move past the idea of writing as a performance. Lisa talked about how her students (mostly undergraduates) tend towards more stilted, academic prose in order to mimic what they think academic writing should sound like, rather than developing their own authentic voice. She helps her students through this stage by encouraging to express their ideas through personal storytelling, a technique that she feels opens up their creativity and their emotional 
connection to their written work. One challenge in getting students to tap into their authentic voice, as explained by Oksana, is that students often think they should be pursuing "hot" or popular topics, rather than investigating ideas that are of more personal importance to them.

[Students] often asked me questions like, what would be a good topic now? ...what they're really asking me is what topic is in fashion, but they would, of course, put it as what kind of topic would...help me to get a job? And I come back to them and say, you know, it really doesn't matter what topic you choose, as long as you like it, because you're going to have to work with it.

Finding one's own path as a researcher can be challenging, especially as a novice transitions from the sheltered environment of an undergraduate to the world of scholarship, where research should be innovative, yet disciplinarily appropriate. According to Sara, students are used to being given assignments by professors as part of their class. However, when they need to write a proposal for their own research project, they have to come up with a unique idea, which can be quite challenging for them. This is where a writer moves from student to scholar, from reproducing knowledge on a written assessment for a class to creating or generating knowledge for an insider scholarly audience.

\section{Generative}

I am defining the stage of generative writing as the ability to fluently produce writing and research that is disciplinarily appropriate. The women I interviewed whose scholarly identities fit within this stage had developed a particular style of writing, 
typically based on their innate abilities and preferences and governed by the conventions of their disciplines. For example, the quantitative researchers felt comfortable constructing prose containing tables and bullet points, whereas the qualitative and theoretical researchers felt more comfortable with the descriptive aspect of writing. As Oksana said, "just for me personally...how I approach the world and my own sort of learning preferences, all of that influences how I approach writing." Oksana's way of expressing herself and her preferences for research matched up well with the expectations of quantitative writing; she described how she enjoyed the analysis aspect of doing research, and how she struggled with what she called the more "creative" skills that are often needed when constructing arguments in introduction and conclusion sections.

The three women (Oksana, Lucy, and Sara) who were primarily quantitative researchers fell in naturally with what Sara called the "scientific" style of writing, meaning writing that is typically written in third person, with a heavy focus on the research subject or methodology, where the researcher is portrayed as distant, rather than involved. In contrast to feminist research, which criticizes the androcentric bent of this type of writing, none of the women I interviewed felt as though they were unable to produce the type of research they were interested in because of the confines of the scientific style. In fact, Lucy and Sara both described feeling more comfortable with the Introduction-Methods-Results-Discussion (IMRD) format of empirical research articles because of the predictability of the form. Not only were these women more comfortable with this detached, androcentric style, they specifically described being uncomfortable when asked to write in a more relational tone. For example, Lucy described a situation 
where she had struggled to write a positionality statement in a qualitative research article she had written with a student, and Sara reflected on the difficulty of writing a blog post for a non-academic audience.

Most of the women I interviewed seemed to reside primarily in the generative stage of their writerly identities, although some were farther along in their understanding of themselves as disciplinary writers. Catherine, as the newest faculty member in the group, seemed to still be finding herself as a writer of political theory. She frequently described working to engage more directly with the literature commonly cited in her field and producing arguments more in line with political discourse, as well as developing her own, "more lyrical" voice as a writer. Catherine described her development as a writer by saying,

... I came to writing with no idea what on earth I was doing. But I have worked on it and do seek out good examples...I work on my writing, and I can see it getting better as I as I go. And it's one of my favorite things is to become a better writer. It's something I really enjoy.

As Catherine refines and solidifies her written voice, she is also developing a body of work that reflects her research agenda and her impact on her field. Other women in this study who had more definitively established themselves as scholars projected a confidence in their work that said, "I have a clear scholarly agenda, and I know how to distribute my work to the appropriate channels." This confidence and the consistency in voice allowed women to dive into their research agendas, to produce the type of work that is needed in order to meet the requirements of a tenure portfolio. This is perhaps the 
reason why several of the professors who had achieved tenure reflected their desire to, as Sara said, "expand their skillset," or move beyond their most comfortable writing tendencies and topics.

\section{Expansive}

For personal or professional reasons, none of the women in this study were fully committed to being locked into producing work that only fell within their comfort zone. Rather, the women I interviewed all saw the need for and the benefit of expanding their research work beyond the areas that they naturally gravitated towards. In this way, these women's scholarly identities evolve and grow over time, often building on their interactions with colleagues and graduate students who open up new possibilities and contribute complementary research skills. Some of the women in this study intentionally sought out change, whereas others were pushed into it as the result of the work of their graduate students or the changing nature their fields.

A few of the women in this study who approached writing from an expansive perspective did so as part of their scholarly identities. Angela, who personally identified as a "good writer," draws this identity from her ability to mold her writing to the needs of different audiences. She provided examples of her work, which crosses a wide variety of disciplines, from social sciences to hard sciences, and is published in a number of different mediums, such as textbooks for undergraduates, academic books and journal articles, and trade publications. For Angela, being a good writer means, 
...being able to think through audience in a really clear way and think about, what do they need and when do they need it?... What background knowledge do they already have? What can I link this to that's going to be familiar for them?

Angela's confidence in her ability to shape-shift from a writer of traditional academic prose to someone who would publish an unapologetic rant against current research practices in a trade publication was unusual for the more novice scholars in this study. It was more frequent for women who had achieved tenure to express a desire to expand the scope of their writing practice and publish outside of the mainstream publications for their field.

Both Sara and Lisa, the two established associate professors interviewed for this study reflected on how achieving tenure had opened up possibilities for them to pursue a wider range of venues for publication. In referring to the possibilities opened up after achieving tenure, Sara reflected that,

I knew I had to produce things that kind of fit a certain mold to have any chance of getting a job. And I needed to tick the major journal boxes, or that was the easiest way to get tenure. And it came easiest to me because that's how I was trained to do certain things...I wasn't thinking about it before I got tenure. And then I got it. And after about a year, like, Whoa, okay, that's when I realized that it was so freeing and...I hadn't even realized that I had been like policing myself somehow. Because I was just trying to make sure that I got like the essential things done, and I felt more worried about what people thought of me. I think whereas I don't care as much now. 
Now that Sara has achieved tenure, she expressed the desire to expand her writing skill set by pursuing topics and avenues of publication that might necessitate a different communicative approach. In a later interview, Sara qualified her reflection on the freedom of tenure by also discussing how her interests had shifted over time.

I guess I would just clarify that I think that part of how I write is influenced by the topics that I'm writing about. And, and it is true that...there are things that I'm more interested in pursuing now, and part of it is tenure. Probably part of it is just your research evolves. And doing more and more community engaged writing, which is a different thing, like writing for communities.

These evolving research interests and the freedom granted by tenure had the combined effect of removing barriers and providing Sara with new opportunities for a more expansive writerly identity. Lisa reflected on her research agenda in much the same way. Although she had entered academia as someone whose research naturally bridged the scholarly traditions of political science and sociology, Lisa now felt as though she was freer to expand the distribution of her work outside of the realm of mainstream political science journals:

... I didn't realize until later that I didn't have to always publish in political science journals. So it's much easier now to publish. I can publish more qualitative work in sociology or ethnic studies journals that I took, I don't have to worry about getting tenure anymore. So that's somewhat freer.

In our first interview, Lisa described herself more as a "book person" than someone who publishes journal articles. Indeed, the majority of her earlier publications were either full- 
length books or chapters within edited books. Lisa did not specifically mention the influence of post-tenure publication opportunities on her choice of venue for her research; however, it is possible that the freedom to publish her research outside of political science journals has allowed Lisa to focus her work instead on ethnic studies or sociological publications, which has made publication an easier objective, as these journals are a more natural fit for the research agenda she has chosen to pursue.

While Angela, Lisa and Sara intentionally pursued expansion in their writing and research practice, other researchers have been pushed to expand some aspects of their practice, despite their research preferences. Two quantitative researchers in this study, Oksana and Lucy, have expanded their research practices in a more qualitative direction: Lucy from the influence of her advisees, and Oksana because of lack of participants for her studies. Although Lucy is trained in quantitative methodologies, the students she advises have at times chosen to pursue more qualitative research questions. She described the challenges of developing familiarity with the qualitative research practices by saying, ...Because of the research interests of my graduate students, I've become more familiar with qualitative data and qualitative writing and the like. So in a recent paper that I that my graduate student wrote...we included a reflective statement. Where...both of the authors are women and their positionality is like, we sort of explained our position relative to the material under study. And that felt really weird to me.

This expansion of Lucy's skill set to include more qualitative writing comes despite her clear preference for quantitative methodologies and her desire to stick with a clear path 
towards tenure by working within her established scholarly agenda. Like Lucy, Oksana has also found herself needing to become more familiar with the more descriptive qualitative writing despite her preferences for the clear-cut quantitative style.

I used to do more quantitative research, and I think that's because, like, I am thinking more concretely and...I somehow find the writing and the quantitative papers more straightforward. Um, now that I really don't have access to enough participants, it's hard to do quantitative research, I'm switching more to some mixed research, where here it's a little bit quantitative, a little bit qualitative. And so collaborating with others...who have done more qualitative research. I feel necessarily because of that my writing is changing.

Rather than being driven by her students, Oksana has needed to forge new alliances with qualitative researchers, due to the lack of participants for her studies. This change in methodologies, combined with new collaborations have expanded her writing skill set, as well as her research practices.

Whether the women in this study were still finding themselves as scholars or whether they were seeking to expand their research agendas and writing styles, none of their trajectories could be described as "stagnant." For those who were seeking to establish themselves within their disciplines, the focus seemed to be on honing their practice of writing in order to express themselves with clarity, grace, and efficiency. For those more established in their fields, the goal of reaching new audiences brought new challenges in their communicative practice. Working with students or pursuing new 
research questions also brought opportunities for further development in their scholarly agendas.

\section{Navigating a Community of Practice}

Joining an academic community of practice is not a spectator sport. Rather, it is an exercise in navigating the politics and expectations of a highly specialized group of thinkers. In constructing and sharing academic work, the women in this study reported engaging in a variety of negotiations from a project's inception to the publication of an article. Throughout the process of drafting, review, and revision, a text is molded by a number of forces besides the author, herself. In order to maintain the integrity of her vision, a scholar needs to navigate these forces, negotiating with, pushing back on, or strategically accepting the mediation of her work by others. Women also must navigate barriers that may prevent them from becoming full participants in their communities of practice. These barriers may be intentionally constructed, by gatekeepers seeking to maintain a more insular group of like-minded individuals, or they may be the product of androcentric and/or raced defaults, where women are dismissed or ignored because they do not match gatekeeper expectations based on how they look, sound, or research.

\section{Navigating the Conversation of Scholarship}

A finished article is rarely the product of a single mind. Instead, texts are often heavily mediated by co-authors and reviewers before they appear in publication. Even single-authored articles are shaped by a number of participants, whether they shape a text in an official capacity, through peer review, or unofficial, through conversation or presubmission feedback. In spite of these influences, the texts my participants shared with 
me in this study were all very clear representations of their voices, regardless of whether they were co-authored or single-authored. The women I interviewed sought out and negotiated this mediation throughout the process of constructing a text, frequently expressing deep appreciation for the collaborative nature of academic thought, particularly when this collaboration was the result of co-authorship.

Before an article is submitted for review, it has often been touched or molded in some way by a number of people besides the first author. Nearly all the women I interviewed for this study reported writing in collaboration with other scholars, illustrating the frequency of co-authoring as a means of knowledge production in academia. Writing with others benefited these women, as their co-authors added complementary strengths to their projects, both in terms of research expertise and writing prowess. One of the most common reasons why my participants co-authored with other academics was to bring another research methodology into the study. Lisa, Sara, and Oksana each provided clear examples of such collaboration in our interviews. Lisa described an article she was working on with another scholar whose research focused on social media analysis; Sara frequently collaborated with other scholars whose archeological work included new methods of dating samples; and Oksana participated in a research project with two other scholars from different methodological backgrounds to analyze the same dataset from different perspectives. These collaborative relationships with scholars from other disciplinary or methodological backgrounds added depth and nuance to their research projects, providing new ways of looking at or describing the data. These collaborations appeared to be more than each author working in isolation on 
different sections, but were instead a dialectical exchange of ideas, where the authors met and discussed their respective contributions, each learning something from the other. It was also common for the women in this study to collaborate on drafting the articles, themselves. In such cases, the lead author would draft sections or the article as a whole and the collaborators would fill in sections, as needed. Oksana described this process by saying,

...whoever's the first author writes the majority of the paper, other people maybe contribute sections, here and there...for this paper, we talked about the order of the different sections. And we went back and forth on that order a few times and then we changed that order, again, after the reviewers looked at the paper. This process of drafting and revising was a common relationship between advisors and students, especially in cases when advisors were providing guided support on the publication process for their advisees. In relation to her evolving role in generating research, Lucy reflected on how, at the beginning of her academic career, she was the primary generator of a text that her advisor or senior co-authors would then augment or edit. Now as an advisor of graduate students, Lucy finds herself more often responding to work that has been generated by her students, and rarely creating something from scratch.

This back-and-forth exchange of drafts is often a process of negotiation for the women in this study. At times, having access to this process can be a relief. When asked who they turn to for help in the writing process, several of the women I interviewed referred to their co-authors as their primary source of support in their drafting process. Having a colleague to process ideas with helped these women hone their written 
arguments, allowing them to better express the key message of what they want to convey. Lucy described a paper where she was struggling with what to highlight in the discussion, saying,

... I was so focused on like, the nitty gritty of, of explaining things that I was having a hard time saying what is the important part of this?...that's also where talking it through with my co-author was helpful in sort of just like taking a step back and being like, ... what is the contribution here because I'm having a hard time hard time isolating it.

The negotiation with co-authors seemed, for most of the women I talked with, to be a positive experience. Even when the co-authors disagreed, there was an opportunity for mutual growth as the collaborators debated ideas and eventually came to a consensus.

One collaboration that was particularly notable was described by Oksana, whose interactions with her co-authors seemed to frequently surprise and delight her. As mentioned above, Oksana had begun to pursue more mixed methods studies, as opposed to the quantitative methods that she was more comfortable with. To do so, she had begun to collaborate with two male full professors with whom she published several articles. Her co-authors' styles of research and writing differed fundamentally from hers. Coming from a qualitative tradition, both men wrote in a more fluid style, using words and phrases that Oksana consistently described as "vague." In comparing her writing style with one of her male co-authors' style, Oksana said, He's great at stating things kind of vaguely, and it still works and I just can't state things vaguely. So I think he was a big help on that. How do you how do you kind 
of present that idea that we didn't really separate these two variables but not in a negative light more in a positive light? So I feel like that's really the creativity and the, you know, the art of words that he has and I don't.

To illustrate further, Oksana pulled out the phrase "to address this lacuna" from one of her articles, saying, "I've never heard the word lacuna, before...I finally get what they're saying, but it's still not an expression I would ever...use for now.” Although her coauthors were more privileged in terms of gender, academic hierarchy, and first language, these men appeared to value Oksana's contributions and listened to her arguments about the content or structure of the articles. In working with these co-authors, Oksana's texts were mediated to include both methodological approaches and language or phrasing that she would not have naturally tended towards. She later reflected on the lasting impact her co-authors had on her own writing, pointing out several areas of an article where she felt her language was more vague or had a greater level of finesse than she would have tended toward before collaborating with her two male co-authors.

In each of these instances, the women I interviewed felt strongly that their articles were representative of their voice, despite the mediation from co-authors. As Oksana said, “That's the voice I think, it is just kind of interspersed with other people's wording, how to make it more cohesive and sound a little better and more...but otherwise, I think it's still my voice." Other women too did not see their voice as only the words on the page, but rather as the ways in which they had laid out their arguments. This indicates that the exchange of ideas, the mediation of their texts by others, did not diminish, but rather served to strengthen these women's arguments and focus their work. 


\section{Navigating Barriers}

The women in this study faced a variety of barriers in joining their academic communities of practice, some intentionally crafted by gatekeepers, some natural or existing formations based on the androcentric origins of their fields, and others selfimposed. These women were resilient in spite of these barriers and spoke of the support they received to bolster their resilience from others in their professional communities, from loved ones and spouses, and from the students who were seeking mentoring, themselves.

\section{Hostility}

It was rare for the women I interviewed to describe hostile or aggressive gatekeepers in their academic practice. This points to a culture where it is becoming less acceptable to approach academia as if research publication were a combat sport; still, both Oksana and Sara experienced hostility from reviewers on articles they had submitted, and although the articles were both eventually published, the emotional toll and additional labor that accompanied these hostile reviews took an obvious toll on both women. For Oksana, the hostility came in the form of an excessive focus on language use. As an international scholar, Oksana had heard that reviewers can be dismissive of non-native sounding English writing, but perhaps because she so frequently published with Anglophone colleagues, she had yet to have such an experience.

So the last paper, I wrote that with two other colleagues ...And we got this comment from this reviewer on two or three occasions like we had to rewrite and rewrite it...No specific comments, pointing out what is exactly wrong in terms of 
the grammar or non-native formulation, but just saying, this paper doesn't read like a native speaker writing or like it's not grammatically correct and you need to fix it. And that's it...I think maybe there was one example given and we all thought our formulation was just fine. This is just an alternative...so one of the co-authors works at Educational Testing Service... we ended up having someone who works at ETS who was kind of like the main editor for the company to take a look at the paper again and see if she could find anything and she found maybe two little things, which she said again, they're not really problems but if maybe if we reformulate these two things, they'll see that we tried...I don't know if the reviewer was just mad about something. It seemed that way.

From Oksana's description, the comments that authors received from the reviewer were not the type that would improve the content or structure of the paper, but instead, they were intended to harass or dismiss authors who were perceived as writing non-native English prose. She navigated this barrier by drawing on her support network, including her co-authors and their connections, in order to get the paper published.

The experience Sara had with a reviewer on one of her recent publications also seemed to originate from a desire to keep her out of the scholarly conversation, rather than to contribute to the improvement of scholarship. She told the story of submitting a paper to a top-tier journal where one of the reviewers who recognized Sara's work wrote what she called "a really gnarly review," which attacked her, personally, and dismissed her work in ways that were not substantiated. In this case, the editor was key in helping her navigate this intentional obstruction, telling her, "ignore reviewer three because 
there's, they have a problem with you...I don't trust this person because they're not they don't sound impartial or, you know, they're not being fair.” Although this editor was supportive, by the time Sara had finished the revisions and resubmitted the article, the editorship had changed hands and the new person in charge was less helpful.

[The new editor said] you're going to have to address that one reviewer, that, that reviewer one or whatever, the jerk. And I just was so frustrated and...I probably read too much into her response, but it was it didn't seem very supportive to me and like she cared or had like, availed herself of information that was clearly there. I sent her the correspondence in a long email. And she seemed like she hadn't looked at it at all. I just thought, forget it. And so then we... submitted it to this other journal. And it went out for review again and it went again, I think to the nasty person, and then two other people. And one of those people was like, I already reviewed this, why hasn't this been published? This is such a good paper and then there was a nasty person. And then the third person, you know, had some additional methodological things they wanted to see. And so we did one more kind of additional analysis that's in the supplemental data. And then it got accepted.

Both Oksana and Sara's cases clearly show how editor support can be essential in helping scholars navigate a hostile terrain. In the process of peer review, one person was able to block knowledge from being disseminated through a particular channel, for what seem to be largely personal reasons. This experience seems to have left Sara with a complex mix of emotions, spanning hurt, frustration and pride. She said, "It's weird. It's like, oh, I've 
arrived. I have someone that likes to write personal comments [about my work]." Due to the unique nature of her research, Sara's work is clearly identifiable, even in blind review, so she felt a certain pride in being attacked personally, associating it with having reached a certain level of notoriety in her field. Still, it is clear that these comments stung and that the need to rely the editor for support was frustrating for Sara. Oksana, on the other hand, did not have editorial support, and was forced to find ways of addressing comments that directly targeted her status as a multilingual scholar.

\section{Epistemic Exclusion}

Epistemic exclusion has been defined by Settles et al. (2020) as the devaluation of the scholarship of Faculty of Color, an act that systematically delegitimizes their contributions to academic thought. This experience was not widely reported by the women interviewed for this dissertation; however, out of the two Faculty of Color I did interview, one reported an instance of epistemic exclusion that was notable for both the perpetrators' callous disregard of her academic worth and the way the experience catalyzed her professional growth. In our second interview, Rene told the story of how she had joined a research team to contribute her expertise from one area of the world in conjunction with theirs. After the article had been submitted for review, the editors asked the team to incorporate a social justice framework as part of their analysis. Rene, having experience writing from a social justice frame, offered to take on this work. She described what happened next, saying,

And the other three people, the two of them were students, master's students, and he was a professor. They're all white. And they didn't understand why the...angle 
mattered. And why it also mattered to me, and they were like no, no, we were not going to change it because a reviewer said...And so, so they were very they, they just kept on pushing back every time I and sometimes in a way that felt racist, because I was the only black. So I, I was very worried about it. And I sent an email to them. I said, I'm going to pull my part of this work, and I'm going to publish on my own. You guys publish whatever you want to publish.

After pulling her section of the article, Rene recrafted a new manuscript focusing on the social justice framework and published this new manuscript as a solo-authored work. This act of defiance appears to have catalyzed her career as a social justice researcher in her field. Based on this publication, Rene was interviewed on her work by the New York Times and offered a book deal from a prestigious publisher. Although this particular instance turned out well for Rene, it represented only one case of epistemic exclusion out of a pattern of such behavior she encountered from other researchers and even her own students. The strength needed to push through such barriers can be draining when barrier after barrier are erected by those who do not value the work of scholars who are not white cis-gendered men.

\section{Gendered Defaults}

Although the experiences of a hostile interaction or epistemic exclusion can be quite traumatic, they were not commonly reported experiences in my interviews for this study. Instead, the women I interviewed seemed to most often come up against what Cheryan and Markus (2020) refer to as masculine defaults, or ways of doing things that fit the male model of socialization rather than the female model. For example, Western 
men are conditioned to value independence and self-reliance, a set of values that still form the bedrock of many doctoral programs. Several of the women in this study reflected on their experience of needing to fit this model by describing their experience of learning to write academic prose. Five out of seven participants described learning to write on their own through reading examples, and several referred directly to the idea that they had been expected to enter their graduate school experience as fully formed academic writers. As Lisa said, "In graduate school... If you couldn't do that, then they were sort of feeling like, are you we're not sure you should be here. There's no remedial anything." Sara's program had a similar perspective, assuming that "you just either performed or you didn't perform." For both of these women, as for many of the others I interviewed, writing and learning how to write was taught as a solitary act, one that happens out of the public eye, where norms of communication are implicitly understood.

This expectation of independent scholarship was something that many women struggled to overcome once they entered the professional realm of writing and research. Rene, for example, said that she had been assigned mentors through the NSF Enabling Fellowship, but that she was reticent to call upon their support.

So I have two mentors on that fellowship and...they're supposed to help with...like if I write a grant, give me feedback or not. And then I think I asked them one just recently, can I send a paper to them to review?...They said, Yeah, absolutely. But I just couldn't because I know how hard most academics work like, especially those who are professors. So to ask them to like review grants, and then ask them to review papers, I just, I mean, they're being paid for it, I think. 
But I'm so reluctant to ask them. No, I don't want to take the time. They have kids like I do. They have students like I do. They have their own papers, they have their own grants, even though they are supposed to be my mentors. It just doesn't feel right asking them to review a paper. You know, so I've never done that.

Rene's reluctance to ask for the support of people who are assigned to her and paid to help is indicative of how many of the women in this study have been trained to avoid asking for help, even from those designated to help them, like graduate school advisors or fellowship mentors.

Indeed, the cultural expectation of working alone was particularly noticeable when I asked the participants whom they turned to for help. In response to this question, three out of the seven women responded with some version of "I don't seek out help" or “I don't seek out help enough.” As Lucy said, I say that I probably don't turn to people enough. Until I have a draft that I feel okay with, I'm really hesitant to give it to anyone to look at. And I don't think like that's not what I would advise anyone to do. But that's just sort of like I still have fear about what other people think of my work. So eventually, if I get frustrated enough, I will turn to my co-authors, so, you know, I've asked my grad students to take a look at some stuff and give me feedback. You know, they're kind of I think they don't want to be too harsh, but you know, so I turned my former mentor and my other co-authors to look at stuff but mostly I just kind of suffer alone until I feel ready to ask for help. 
Like Lucy, many of the women in this study seemed to want or miss support for their writing and research practice but were often reluctant to appear vulnerable or unprepared in front of their academic communities.

I think that gender dynamic, it's harder to be like, vulnerable is a funny word, but like, professionally vulnerable, like, "I don't know what to do. This thing is a piece of crap. And I can't figure out how to write my way out of it. Help me.” It just, it doesn't help you if you're a woman. (Sara)

...if I were to give women some specific advice, it would be about just, you know, confidence holding your own, being okay with being vulnerable, but do that with your friends. (Lisa)

This reluctance to reach out for help or admit to struggling with a project seems to arise from a fear of being seen as incompetent. As Catherine notes, it is common to "frame struggle as incompetence" when speaking of women in academia, a stereotype that most women in this study seemed to not only recognize, but also actively work to avoid.

Perhaps because of the gendered defaults against appearing vulnerable, the women in this study were more likely to seek support from people with whom they had a personal relationship, such as former mentors, co-authors, students, or even romantic partners. These relationships seemed to shift or develop over time. As these women became farther removed from their doctoral work, they had less frequent collaboration with their dissertation advisors and doctoral cohort, and more frequent collaboration with a wider range of colleagues and students with different or complementary professional interests. For example, Lisa, a self-described extrovert whose career has brought her into 
contact with people in politics, academia, and ethnic studies, described her support group as a network of "very smart people" who would read each other's writing, and offer commentary and feedback prior to publication.

I have a lot of people around the country that I've known from different aspects parts of my life. And, I think I'm an extrovert... so I mean, I know a lot of people...I've done favors for people and, and so it's just, it's easy for me now to kind of, if I needed to go to anybody, really most of these people, I could just say, Hey, could you just read these couple pages for me? And then they would say yes, but it's kind of like, lifelong relationships.

Lisa's long-time relationships have been cultivated through personal connections and academic exchange, to where she feels comfortable reaching out to them for support on projects. Catherine, on the other hand, who had more recently finished her $\mathrm{PhD}$, was still quite closely connected to her graduate department. In seeking feedback on her drafts, she tended to default to her dissertation advisor, as well as a writing partner with whom she had attended graduate school. It was clear that Catherine was seeking to further develop her network, by joining online writing workshops and social media groups for academic writers, but that connections beyond her graduate school had not yet been fully formed.

\section{Perfectionism}

One of the most common barriers that the women in this study struggled with was self-imposed. Six out of seven participants reported at some point our interviews a frustration with their tendency towards perfectionism. The determination to produce near- 
perfect writing seemed driven by a variety of factors, but often arose from the desire to preempt any criticism of the work that they show to an outside audience. This was the reason that participants like Sara and Lucy gave for feeling uncomfortable about sharing their work before it was either close to done or they were so frustrated that they gave in and asked for help. For example, Lucy described her fear of writing collaboratively on a platform where other co-authors might view her work in progress,

I think one type of writing that I haven't really done and scares me is...multiple people on the same Google Doc. Right? Where we actually see someone write live... I feel like it's a nightmare, because it's like, no I need to think very carefully and then delete stuff that I was like, why would I say that? And then, the writing process is too transparent at that point...I'll just be like, find citation and...I'm probably not supposed to do that.

Lucy often seemed frustrated by this need to have her work be fully formed before it is viewed by others, as she saw herself being slowed down by this tendency. She compared herself to one of her graduate students, who, when responding to reviewer feedback, would simply perform minor revisions and send the article back. In contrast, Lucy tended to completely rewrite her articles in attempt to fully address the reviewers' concerns. Apart from the discomfort with having others view their unfinished work, the women I interviewed also often described writing with what Angela called "excruciating detail" on previous literature, methodological choices, data collection, or the explanation of results. This included not only laying out an argument step by step, but also 
anticipating and explaining any possible holes in one's research that might open oneself up to criticism. Sara compared her work to that of others by saying,

But I've also seen there are other papers, some of which I cite in here on similar topics..., or things that were kind of published around the same time, and they write in a much more sweeping way about some of these things. And, you know, I just don't I, I want to know I want it to be grounded in like large sample sizes and like clarity about what I know and don't know. Before I say the large sweeping statements, you know, that's what I want to get to, but I'm really interested in establishing it really clearly. On sort of here's the information that I have. When I look at this, I can see that.

Such sweeping or, as Oksana refers to them, vague statements were not mentioned by any of the women in this study as indicative of their writing styles. Rather, a few of these women (Oksana, Sara, and Catherine) specifically associated this type of writing with male researchers. Considering the relative authority associated with white men, it is not surprising that the women in this study have this perspective. Whereas a sweeping statement may be considered a valid argument when a writer is pontificating from a privileged position, those in more marginalized locations may not have such freedom. Instead, many of my participants felt compelled to meticulously construct water-tight assertions, despite the amount of time it took to pull their arguments together. This does not mean that the women I interviewed were cautious in their argumentation. They argued positions vigorously, confidently, and allowed themselves moments of "rage," as Angela described doing in more than one of her articles. Nonetheless, the women in this 
study made sure their evidence was clearly documented and that their arguments were carefully constructed, resulting in a final product that they were proud of. Sara described a publication that she had put a lot of work into in order to create a baseline study for other work she was interested in pursuing,

...it feels good to get papers published...And then I'm I was basically excited, because now I can refer to this paper. Every time I have this wonderful point that I want to make, I just refer this paper...And I'm proud of like, I think it's a good example of how much works goes into saying something pretty simple.

Although many of the women in this study lamented their tendency towards

perfectionism, this character trait also resulted in published work that was both rigorous and innovative. However, it is also true that the drive towards perfectionism did slow down the research agendas of some women I interviewed, as they spent time revising and re-revising, instead of sending their papers out for a quicker review. If these scholars had spent less time on perfecting their arguments, instead letting their papers be more heavily mediated during the review process, would they be as proud of their work? It is also possible that Sara's perfectionism was the tool that allowed her to challenge much of the work that had come before her. Although this tendency can be draining, Sara and many others of my participants won grants and had their articles published in top-tier disciplinary journals, despite the fact that many were actively challenging the status quo.

\section{Finding Resilience}

Despite the external and internal barriers that many women face as they seek to participate in their academic communities, all of the women I spoke with had published 
multiple times and were employed in competitive, tenured or tenure-track jobs. In achieving this success, they had each found ways of tapping into a resilience that helped them push through barriers and overcome obstacles. This resilience came not only from within, but also from the strength and breadth of their support networks. As Catherine said,

I think it's important for every woman and like gender non-binary person to understand and have a support system in place to help them cope with the quiet sexism of the academy that still exists. Again, depending upon the institution, right, it's better some places than others. But there are still boys' clubs and you still get certain kinds of mentorship and opportunity if you are a boy. And you have you know, there are gender differences in the way that people understand their own abilities and their own importance. And those things play out in the kinds of work that people put out there, where they put it out there, how they put it out there, and who pays attention to it.

As discussed above, the barriers that these women experienced in their academic work were usually not overt or hostile. More often, they encountered certain expectations based on androcentric norms regarding how a scholar should work (independently) and whose opinions are most valid (white cis-gendered men's). Because of these more subtle challenges, it is important to have a network of people who can serve as both role models and sounding boards.

The women in this study drew emotional and professional support from a wide array of professionals in their fields. As mentioned above, several of the women I 
interviewed connected with women mentors and professors who served as academic supports, role models, and at times, emotional support. Some of these women mentors had young children, which, for novice academics like Oksana, demonstrated that it was possible to have a career and a family at the same time. It was also essential for the professors I interviewed to have support from professionals who believe in them. Some of the encouragement that my participants received came early in their careers. Lisa repeatedly referred to people who supported her early on saying, I had these people that were pushing me and telling me, giving me advice and getting in my face and saying, you've got to work this out...here's how. Let's talk about it. So yeah, just a lot of people took me under their wing.

The support that Lisa drew from early in her career was not necessarily academic in nature. Instead, it seemed to have been more the emotional encouragement from people who believed in her that helped give Lisa the confidence to pursue her studies at a number of prestigious institutions.

Other women in this study have also received emotional support from their professional networks. Lucy described outsourcing her defensiveness on reviewer comments to her former advisor, who would tell her when this feedback was valid and when she should be offended by biased comments. Oksana also described how her two co-authors insisted that she stay first author when she felt defeated by her inability to address reviewer comments. Such support was essential for finding one's way through the complex terrain of academic communication. Despite a growing number of women participating in academia, many participants still felt as though they regularly had to 
contend with the "boy's club" of scholarly communication as Catherine called it. This club may be more or less exclusive, depending on the discipline or depending on the intersections of a participant's identities. In order to keep new members out, some gatekeepers impose artificial barriers, criticizing or blocking publications to prevent full participation by people they consider to be interlopers. To overcome the emotional toll of navigating such comments or feeling like a perpetual outsider in one's own field, it was essential for the women in this study to build networks of support with peers and loved ones.

\section{Navigating Scholarly Reproduction}

In addition to producing their own work, women academics are also often in charge of socializing the next generation of scholars or professionals. However, not all the women I interviewed were mentoring future scholars. In fact, only two (Lucy and Rene) worked directly with doctoral advisees in their fields. Three of my participants (Angela, Oksana, and Sara) worked with graduate students in professional master's programs, and two (Lisa and Catherine) worked primarily with undergraduates. Regardless of the relationships that the professors had with their students, writing was a salient theme in the ways that they taught and conceptualized disciplinary thinking. In working with students, the women I spoke with drew from their personal experiences in learning to be scholars and thinkers, including their relationships with their advisors and mentors. The messages that they communicated to students about participating in academic thought varied based on their students' goals in relation to their education. In 
our interviews, these professors reflected on how they use writing as a tool to craft disciplinary thinkers and on their roles as mentors.

\section{Writing is Thinking}

For the women in this study, writing is more than just words on paper, put there to explain a research project; it also has a role beyond the communicative function of a published article. In addition to these more outwardly facing functionalities, writing was also seen as a place where both experts and novices could work through ideas, clarifying and refining them in a way that one can only do through writing. This idea of writing as thinking was a reoccurring theme in my interviews with Lucy. Her argument was that no writing is ever wasted because it is through the composition process that deep, hard thinking about a topic takes place. She passes this belief on to her advisees, saying, I tell this to my graduate students, most of what you write, no one will ever see. And that's okay. Because writing is thinking, right? So, you know, trying to think of those drafts not as trash but as an opportunity to think and figure out what, what needs to be said. And like, even if it doesn't ever go anywhere, or even if those words don't get used, the thoughts still were happening, and the thoughts were still important to the draft you end up with.

Lucy's approach to writing gave permission to her students to understand writing as a process of figuring out ideas, seeing how they work on a page, and how they connect to form a cohesive argument. Lucy's perspective on the connection between writing and thinking was also expressed in multiple other ways in the interviews for this study. Although not all the participants described the drafting and re-drafting process with the 
same level of detail as Lucy, several explained how they use writing to assess and cultivate clarity in argumentation and encourage disciplinary thinking in their students. Clarity in writing was a theme that arose for each participant at some point during the interview process. Clarity was a quality that these women valued and applied to their writing, but not necessarily one that they described striving for. Instead, they saw clarity as a foundational principle from which more nuanced arguments could grow. Perhaps because of this belief, the idea of clarity primarily arose when the interviews turned to these professors' mentoring practices. In describing what she looks for in student writing, Catherine said,

I think for students who have not yet reached a certain threshold of sophistication in their thinking and writing, the number one thing that I work with them on is clarity. So learning to clarify their thinking and then how they express those thoughts to readers. And until you have clarity, you don't have, it's hard to do much else.

As part of their advising and teaching practice, the women in this study sought clarity in student writing as a barometer for judging student understanding of key concepts and readiness to move forward on a project. As such, Angela, Sara, and Lisa all require the students they work with to submit some form of writing (an outline, a draft, a literature review) as an initial step in their advising. As Angela said, "I often work from what they give me rather than kind of foregrounding kind of direct instruction. So I kind of see...a first attempt at some section." Through an evaluation of the clarity of their students' arguments, these professors can then move forward in helping their students develop 
move deeply as thinkers. Lisa, especially, was adamant about students coming to her with a piece of writing where thinking had already begun to take place.

I want something on paper, even just two page, one pager or something, so they just begin to clarify what it is we're talking about and what the argument is and narrowing things down... Because otherwise you can flail around for a lot of time.

As evidenced in Lisa's quote, the development of clarity was seen by many of my interviewees as a process, something that emerges over several rounds of thinking, writing, and refining. They also acknowledged that this process happens both on the micro level (essays, short papers) and on the macro level, as students develop their disciplinary understanding. To help students develop clarity in their writing, professors often endeavored to bridge the gap between student experience and academic knowledge. For the undergraduates that Lisa works with, clear writing often organically emerges when students are able to connect the theories they are studying to their lived experiences. In describing how she works with her students to move them away from performing what they expect academic thought to look like, Lisa said, when you're in college, you're reading a lot of academic writing, but it seems to me, sometimes it seems like they feel intimidated by that, and that they have to avoid talking about themselves, they can't use the first person. And I think we can move away from that and, and kind of get into more of a narrative. You know, it's about stories ultimately. And they seem more able to, to they seem to like that better. 
According to Lisa, some of the narratives that her students produced were close to publishable quality because they had been able to tap into their authentic selves to analyze real world political events.

Being able to understand, relate to, and clearly articulate theoretical concepts was a common goal for the women working either with undergraduates or new graduate students. As these students begin to internalize the concepts associated with their disciplines, their sense of self needs to shift to make room for new ways of seeing the world. This process is messy and disorienting for many. Through writing, however, novice academics have the opportunity to refine their new disciplinary selves, clarifying their relationship with their discipline and their world. According to the professors I interviewed, the intended result of a writing practice is for students to be able to both understand themselves in relation to their discipline and articulate this understanding in a way that is appropriately framed within disciplinary expectations; in other words, to begin thinking like an academic in their fields. At the graduate level, students needed to take this disciplinarity a step further by articulating their original research interests within the context of their fields.

Unlike undergraduates, who according to Lisa and Angela, often feel intimidated by academic prose, graduate students seem to be fully ready for academic socialization. It is therefore up to the advisors to guide their students in finding the intellectual tools they need to participate in disciplinary conversations. In order to train their graduate students as disciplinary thinkers, Lucy, Rene, and Sara begin socializing their students through writing. These three professors all have their student advisees begin writing early in their 
relationships, starting with literature reviews or summaries of articles. Rene, for example, requires her graduate students to take a seminar with her where they write weekly summaries and reflections of articles they have read in class. She described how this weekly exercise helps them process complex theoretical concepts and think about how these concepts might relate to their research interests. In a similar vein, Sara guides her students through the research process by asking them to begin with a literature review, which they later build into a proposal for a project. Over the course of multiple drafts, she begins to socialize her students in how to base their research on disciplinary foundations and grow it into an original project.

This process of writing through socialization indicates a back-and-forth relationship between writing and thinking. In order to think disciplinarily, it is necessary to engage with ideas through writing. This act provides a mode of communication between the professor and her students, where ideas can be proposed, critiqued, and refined. Whereas many of the women in this study asked their students to learn a thinking practice through writing, both Lisa and Rene expressed their own writing practice in opposite terms, describing how good writing comes from clear thinking. Rene detailed how, as a graduate student, she spent much of her time writing and revising. As she said, “...you write, and you cancel, you write and you cancel, you write. And people say, that's what you need to do." Now, as someone who has learned the disciplinary modes of communication, Rene explained that she thinks more before writing.

I believe good writing comes from good thinking. Most people want to write...But now I think more before I write more, a lot of my time is spent 
thinking through things in my head. And then when I start the writing process, it's easier compared to when I'm writing but the idea is not clear and it's just messy.

The ability to see a concept clearly in one's head requires a good amount of disciplinary knowledge as well as confidence in one's communicative capabilities. This level of proficiency may not be attainable for novice academics or, indeed, for many professionals. However, the practice of mediating thought through writing is one way of strengthening this capability in novice academics

\section{The Practice of Mentoring}

Most of the women I interviewed seemed to derive a deep satisfaction from their mentoring practice. This was especially true for the women who worked with graduate students, as these relationships were typically longer and more involved than those with undergraduates. Despite a consistent theme of negatively gendered interactions with male students, the women in this study all related experiences of being nurtured, inspired and pushed by their students, in many unexpected ways. At the same time, these professors bore the burden of preparing their students for a challenging professional landscape; as a result, they constantly negotiated the line between "being real" and being compassionate.

\section{Reciprocal Mentoring}

For most of the women I spoke with, mentoring graduate students, both in the classroom and in advising sessions has been a positive and nurturing experience. They described being inspired by their students to pursue new areas of research and to think about their own research agendas in new ways. As mentioned earlier in this chapter, Lucy often found herself pushed by her graduate students to participate in qualitative 
methodologies, although she had not been trained in this tradition. For Oksana, having to explain the structure of a research article in her classes helped her learn to better structure her own articles. In another example, Angela talked about how her students' sometimes visceral reactions to dense academic articles had influenced the way that she has approached writing and the publication venues she has chosen to pursue. In one piece of writing we discussed, she said, "I pictured myself talking to my students. And like, ...what would I tell them that would be exciting?" For each of these women, the experience of working with an advisee or talking through an idea with a class full of engaged, novice academics had in some way helped her hone her own academic style. Rene, in particular, seemed to have close, reciprocal relationships with many of her advisees. For example, although she would rarely reach out to other professionals for feedback on her articles in progress, Rene regularly asked her students to read her drafts and give her feedback. She described how she uses student feedback to assess the clarity of her ideas in a paper she plans to submit for publication,

When I send a paper to them to review, then they may question some things and say, Oh, why did you say this? or Why did you say that? And then I have to clarify, I'm like, oh, maybe this is how, someone else might read this, even though it's me, to me. It's clear what I'm saying... It may get me to think okay, I need to rewrite this section for clarity.

Rene saw this exchange as mutually beneficial, where students can learn about the writing and publication process and she can get feedback on her writing. This reciprocal relationship was, for her, more comfortable than a relationship of dependency, as she may 
have seen the mentoring fellowship in which she was participating. Rene also described reaching out to her students to connect with them on a personal level, even when they were away doing fieldwork, saying,

...one of my students was in California then and I was like, also monitoring him like so, Okay, what's going on today, how many interviews did you do? Do you make sure and eat, because I literally take them like my younger sister or brother...

The way in which Rene spoke about her relationships with her students was unique in that it seemed more symbiotic, more connected than the relationships between most other professors and their students. The only other person who specifically described a similar level of connection to her students was Oksana, the other international scholar I interviewed. She regularly described bringing in her personal experience as an English language learner to inform her classes and add concrete examples to the theories her students were discussing. Other professors were not neglectful or uncaring towards their students, but from our interviews, it seemed as though they preferred to keep their personal life separated from their work, in that they generally refrained from talking about themselves or their personal struggles with their students in advising sessions or in classes.

\section{Intersections of Race and Gender in Mentoring}

Despite generally reporting positive experiences with their students and advisees, three out of the seven women in this study had experienced at least one negative interaction with a male student. It was interesting that, when asked how the gender of an 
advisee would influence their mentoring style, most participants demurred, saying that they would work with any student the same, regardless of gender. Nevertheless, the only negative stories that emerged from these interviews about mentoring experiences were related to white male students challenging the authority of their professor or advisor. Although these experiences were few and far between, they seemed to have disproportionately impacted these women's experience as mentors. Sara described one such instance,

I had one student who...just pushed all the gender buttons for my whole career and then the frustration of like, I'm the professor and you are still doing this, you're doing this stuff? ...He acts with a lot of male privilege and then also just has some personal communication issues. But how much it bothered me was because of all the experiences I'd had before. And I spent a lot of bandwidth on it because it was irritating, and I also wanted to be sure that I was being fair to him even though he was bugging me a lot.

Because Sara works in a field that is still heavily androcentric, this experience had a triggering effect on her, despite her hierarchical role as this student's advisor. For Rene, who also works in a field heavily dominated by white men, the intersection of race, gender, and language regularly manifested in how her white male students valued her opinion and listened to her advice. She described how several of her white male advisees sought and privileged advice from other professors in the department when they were dissatisfied with the feedback that she had provided for them. According to Rene, these 
students would come back to her with feedback from her white colleagues, in order to push back against her comments on their drafts.

...So where you are a black woman telling the white Caucasian who is an English speaker, the what they've written is bad, then you're a black woman whose English is not your first language and you say that sort of thing. And then the others who read it, they are white, Caucasian. They are my colleagues who said it's okay...You're not sure why this student is asking you that question. [Is it] because they're genuinely serious or because they're thinking, why would this black person be telling me [one thing] and all these white people say it is correct? Rene's experience shows the challenge of being an advisor operating under multiple intersecting layers of marginalized identities. Her own advisees sought to override her feedback by pursuing opinions from other faculty upon whom they placed greater

authority. Fortunately, Rene says this tendency has begun to dissipate as more applicants to the graduate program intentionally seek her out as a potential mentor and advisor to their graduate studies based on her professional reputation.

\section{Balancing Empathy and Reality}

In their mentoring practice, six out of the seven women I spoke with also specifically described the tension between "being real" and being empathetic. This tension indicates the importance for these women, as mentors, to prepare their students for professional success. For some, this meant being "harsh, but fair," as a student once described Angela's mentoring practices to her. Being harsh, but fair means that these professors often hold their students to the same high standards to which they hold 
themselves. In order for students to be prepared for their careers, either as professionals or as academics, they need to be able to think, and in order to think, they need to be able to write. Both Angela and Sara described being rather exacting with their students' writing, despite the fact that their students were generally going into professional fields. As Sara said,

I want them to be able to write a really good report for their company that they work for. Because there's a lot of mediocre work out there that's accepted and is supposedly fine, and I don't think it is. And I don't want them to be in that position. I want them to be the best that they can be like, very employable. For Sara, good writing was an important part of employability; therefore, teaching her students to write well would make them marketable to the industry and able to produce good work once hired. For other professors, like Angela, good writing was an indication of students being able to understand and participate in their fields. The ability to not only write, but also produce accurate, disciplinarily appropriate writing was a primary goal for the professors in this study who worked with masters' and PhD students. This was especially true for those who worked with PhD students, as they mentored their advisees in the world of academic publication.

The two participants who worked primarily with $\mathrm{PhD}$ students, Lucy and Rene, had quite different approaches in advising their students' publication agendas. Lucy felt a high degree of pressure to have her students publish multiple articles while still in their graduate programs. She said that if her students intend to seek work at an R1 institution, they needed to have at least a dozen publications under their belts by the time they 
graduate, including one first-authored paper each year. This need to "distinguish yourself" was echoed by Lisa and Catherine, who, when reflecting on their own academic work, both discussed how important it is to publish often and early if one intends to seek an academic job. Because of the importance Lucy ascribed to publication, she was very clear on how one should weigh choices in the pursuit of publication. She said she often tells her students,

...what good writing is in our discipline is writing that gets published...sometimes it does feel like selling it a little and yucky to most academics. So I think sometimes like I try to one, acknowledge that it is kind of transactional, like your papers' not just an expression of yourself, right, like it's a something you're trying to sell. It's something you want people to read. It's something that has to have compromises in it, so, it is never going to be exactly how you envisioned it and wanted it.

Lucy has tried to balance this type of feedback with more generous explorations of what different choices of methodologies or publication venues might mean for her students' publication timelines. Still, their publication record has a very real impact on not only their career prospects, but also hers. She described the impact her students' work has on her career by saying,

I think that at this point in my career, I may be a little more hands on than I will eventually be just because like, mistakes are really costly for my career at this point. I want, you know, I want to have my students working on projects that I think will work. And that feel consistent with my work. So it really affects me in 
my career if a student doesn't write at all, or, you know, like, falls off the face of the earth...

Lucy's vulnerability as a new assistant professor certainly has had an impact on the ways she advises her students. In contrast, Rene seemed to have a much different relationship both with publication and with her students' work.

Rene had a very strong reaction to the capitalist forces driving ever greater pressure to publish frequently in academic journals. She stressed that good scholarship was innovative, deeply conceptualized, and therefore, time consuming. Rene had also enjoyed measurable success in her efforts to push back against these forces and pursue a more critical scholarly agenda. As a result, she did not report feeling pressure for her students to publish, although she described it as "not compulsory, but...it's important in the sense that it helps them become marketable when it comes to jobs." Her mentoring strategies also seemed much more open than Lucy's in terms of allowing her students to pursue their own interests, even when these interests ran counter to a dominant narrative.

They're doing their own thing...my student who is trying to understand the relationship between water insecurity and...transgender relations with water, something like that, which isn't people haven't really talked about that...And I remember somebody was telling him... nobody's writing about that, that's very uninteresting. And I'm thinking if that's what you want to do, please, by all means, because that means you're creating a new area of research that nobody has done. So the good news is he has one paper accepted on a particular issue related to something close to that and now he's looking at that kind of work, which I think is 
exciting, to even create a narrow research area that people are not really focusing on.

In this quote, Rene describes how she encourages her students to pursue topics of research that might be unconventional or counter to the dominant narrative. The fact that her student has an article accepted on this topic validates this encouragement and, in some ways, relates to her own narrative of finding success after following a less welltraveled path.

Lucy and Rene's styles of mentoring are quite different, despite the fact that they both put effort and care into socializing their students into their disciplines. Both held high standards for their advisees and worked with them to scaffold effective participation in their scholarly communities. However, Lucy was much more focused on how the success of her advisees reflected on her scholarly potential than Rene. Both women were also assistant professors and would have needed to demonstrate their effectiveness at mentoring and publication in their tenure portfolios in due time. The difference may have been related to disciplinary or departmental conventions about how graduate students are expected to contribute to departmental scholarship; Lucy's field was much more labbased, where teams depend on each other for scholarly success. In contrast, Rene's field seemed to encourage more individual or paired scholarship, perhaps creating more freedom for graduate students to pursue their own research interests. The differences in advising styles could also be due to Lucy and Rene's scholarly experiences. Whereas Lucy's success had come through her participation in research teams, Rene's greatest successes had been self-driven. 
In working with students, the women in this study drew on a range of beliefs about the purpose of writing and scholarship. They used writing as a means of bringing their students closer to disciplinary ways of thinking in order to mold them as future academics and professionals. For the most part, students were willing participants in this socialization, especially those pursuing graduate degrees. However, hierarchical power relationships in terms of race and gender still played out for many of these participants, where their legitimacy as knowers and as gatekeepers themselves was challenged by those holding more privileged social identities.

\section{Conclusion}

In describing the ways in which they understand, describe and produce scholarly writing, the women I interviewed demonstrated a range of voices and relationships to their academic work. They produce scholarship that is unique and complex, in that it engages with social issues in interdisciplinary and multifaceted ways. These women do not seek easy answers to the questions they ask, nor do they remain stagnant in their scholarly practice. Instead, they explore, challenge, and expand their capabilities in writing and in scholarship. For many, the path to becoming an academic has not been easy. Several women in this study have encountered roadblocks thrown up by those who do not see them as legitimate participants in the generation of knowledge. Still, these women persist. They find support from peers and students, and still actively work to reproduce disciplinary expectations of scholarship through their mentoring practices. However, despite their active participation in the perpetuation of academic norms, the women in this study are also quite subversive. In the section that follows, I provide a 
discussion of these results, and show how, when seen through the lens of Feminist Standpoint Theory, these women scholars are participating on their own terms to expand and complicate notions of academic scholarship. 


\section{CHAPTER 5: DISCUSSION AND CONCLUSION}

“...every woman resists. Often it is private. Most of our resistance is so every day that women don't think twice about it. It is life." - Jennifer Nansubuga Makumbi

The purpose of this study was to explore how women understand, describe, and produce scholarly work. More specifically, this study explored how women faculty have learned and interpreted the norms of academic communication, and how they either perpetuate or subvert these norms through their academic work and through their mentoring practices. The quote from Jennifer Nansubuga Makumbi that begins this chapter is an eloquent expression of how many of the women in this study approach their scholarly practice. Few of the women I interviewed would call their practices subversive. And yet, they engaged in many practices that challenged existing narratives and that pushed at the boundaries of academic norms. These practices ranged from challenging dominant disciplinary narratives to simply saying "no" to those who sought to delegitimize and exclude their voices. At the same time, the women in this study actively participated in perpetuating academic norms in their own work and in the ways that they mentored their students. In most cases, these norms did not prevent their academic success, but rather made it predictable, learnable, familiar.

The discussion that follows addresses how the women I interviewed danced within the framework of academia to produce work that was both original and disciplinarily aligned. I begin this chapter with a discussion of women's acts of participation and resistance. I then describe the mechanisms that women commonly use 
in order to participate in subversive practices. Next, I explain how the women in this study participate in mentoring practices and how they build relational networks that support their work, emotionally and professionally. In discussing the implications of these results, I draw on the recommendations of my conceptual framework, Feminist Standpoint Theory and consider how the perspectives of these women might counter certain myths of women's academic participation that have originated from Euro- and androcentric biases. I finish this chapter by discussing the implications of this study and suggest opportunities for future research.

\section{Subversion and Reproduction: Both, And}

The women in this study both subvert and reproduce academic norms in different areas, in different ways, with different purposes. In their academic work, many of these women employed research practices that would be considered subversive by traditional androcentric standards. In some cases, the topics that several of my participants chose to pursue were subversive by default in terms of interdisciplinarity, connection to practice, or focus on in-group, rather than between-group comparisons. In other cases, some participants pursued topics or methods that were subversive by design, in that they intentionally challenged existing ways of thinking, researching, or citation. However, the subversive practices that my participants employed in their research and writing practices did not replace practices that reproduced academic norms. In fact, many of the women in this study simultaneously subverted and perpetuated androcentric expectations, ways of writing, or ways of researching in their own research and mentoring practices. 
Despite the varying levels of push and pull that the women in this study encountered as they participated in their disciplinary practices, they all pushed to some extent at the boundaries of traditionally defined androcentric expectations. As opposed to masculine narratives that hold groups and concepts in binary, value-laden categories, the women I interviewed chose to pursue narratives that violated the sanctity of these lines. They did this by researching topics that were both interdisciplinary and connected to their lived experiences. The women in this study also subverted boundaries by challenging existing bodies of knowledge that had formed the canon of their fields (typically research that had been conducted by white men). Although not all the women in this study participated in all forms of subversion to the same extent, at least one of these forms of subversion was present in the narratives of each woman I interviewed.

\section{Subversion of Disciplinary Boundaries}

Androcentric beliefs around research practices hold that scholarship should deeply investigate a singular topic, to the exclusion of all others (Gonzales, 2018; Mato, 2011; Sprague, 2016). This narrowed focus asks researchers to limit their investigations to a single line of inquiry, within a single discipline. In this respect, Gonzales (2018) has argued that women's tendency to work interdisciplinarily is a form of subversion. Like the women in Gonzales's study, most of the women interviewed for this dissertation spoke of their research as extending beyond the confines of one discipline. In fact, being an interdisciplinary scholar was a point of pride for many of the women I spoke with, who typically mentioned this aspect of their work early in our first interview. Scholars focused on politics and policy, like Rene, Lisa, and Catherine, saw the interdisciplinary 
nature of their work as an indication of the global relevance and urgency of their research. Scholars like Angela and Sara, whose research topics naturally intersected with those in other disciplines did not necessarily see their interdisciplinarity as a subversive practice, but rather as one that added new dimensions to the type of research they were able to do. In reflecting on their cross-disciplinary collaborations with scholars in other fields, both Angela and Sara detailed how these collaborations extended or deepened their own research.

Although the multidimensional nature of their work may have prevented some of these women from publishing in the mainstream disciplinary journals of their fields, the idea of being pigeon-holed into communicating a message for a limited, disciplinespecific audience was uninteresting for many women in this study. Instead, they sought out journals with audiences for whom knowledge they wished to impart was most relevant, thus broadening the reach of their ideas. Aside from not being able to access mainstream publications, the interdisciplinarity of their work also may have slowed down the pace at which these women were able to publish.

\section{Subversion of Boundaries between Personal and Professional}

In addition to subverting the boundaries of disciplines, women also often subverted the boundaries between the personal and the professional. Traditional androcentric research practices separate the individual from her work, refusing to validate the connection between one's lived experience and her research practices (Sprague, 2016). However, the experiences of women in this study aligned with those reported in other studies (Gonzales, 2018; Gonzales \& Terosky, 2020), which argue that women, and 
especially women from marginalized backgrounds often draw inspiration for research from their own lived experiences. This practice was evident from white Anglophone women like Angela, who drew research questions from her teaching practice, to Lisa, who sought to elucidate the complexities of black life, to Rene, who was drawn to researching "hydra-headed wicked problems" endemic to the region where she had grown up. In basing their research on topics that were close to their lives, these women are also able to draw on the social and cultural capital of their membership in various communities. This social and cultural capital has the potential to not only emotionally sustain these women in their work, but also add a unique dimension to the knowledge they are able to generate. For example, Lisa's work engages with many scholars whom she knows personally, thereby adding nuance to her critiques of their work and their ideas. Similarly, when Rene researches her home city or Angela brings examples from her classroom, they are able to leverage that experience in their access to participants and their ability to bring a deeper understanding to the context in which their research takes place.

Out of all the participants in this study, only two white women, Sara and Lucy, did not see their research as arising from their lived experiences. Lucy specifically stated that her research does not advocate for the marginalized identities that she holds, and Sara had avoided bringing in her identity as a woman to inform her archeological research. However, as Sara advanced in her career, she was beginning to draw more intentionally or more visibly on her lived experiences as a woman to challenge commonly held assumptions that were largely, in her perspective derived from 
"men...mostly talking to men." Lucy and Sara's cases are interesting because they both publish research that can be used to advocate for marginalized communities; however, they did not identify personally with these communities and did not see their personal experiences as having influenced their choices to pursue their research interests, despite being clear-eyed about their positionality as white women in relation to the groups they researched.

Perhaps this distance between self and research was related to the fact that both Sara and Lucy were quantitative researchers, and thus, had been encouraged through training to see their research as external to themselves as investigators. Sara, in particular, cited ways that she would have been sanctioned by the academic establishment in her field if she had sought to highlight women's perspectives more visibly in her research. For Sara, and perhaps for Lucy, who was still early on the tenure track, subverting the norms of the personal-professional divide may be too much of a risk for their professional careers. On the other hand, it is also possible that the cultural and social capital that Sara and Lucy brought with them to their academic careers provided them with a stable platform from which they could expand into researching topics beyond their own personal experiences. This capital could have come from their positionality as white women, or it could also have come from the fact that both had very strong women mentors early in their academic careers, who supported their aspirations.

\section{Canonical Subversion}

Although Lucy and Sara minded the boundaries of androcentric norms in terms of their separation of self and research, they joined many of the women in this study in other 
subversive practices. One of the primary ways that the women in this study participated in subversive practices was through their consistent efforts to reassess the validity of the established canon of knowledge within their fields. Scholars like Lucy, Sara and Rene published articles that challenged the simplicity of canonical thought in their disciplines by asking questions designed to explore the nuance of problems, rather than to present simplified, aggregated results. For example, Lucy's use of her scholarly platform to explore "simultaneously, however" questions defies the androcentric expectation of providing clear cut answers that can be easily generalized. Her willingness to sit with the discomfort of this experience and encourage her readers to do the same is subversive despite her more conventional academic frame.

Several of my participants also challenged canonical thought by changing the frame of analysis from one constructed largely by white Western men to one that included a wider range of frames from participants and non-Western researchers. According to Sprague (2016), Western androcentric research practices commonly default to between-group comparisons, especially between privileged and marginalized groups. When disadvantaged groups are compared with more privileged ones, the resulting analysis creates "ranked dichotomies" (Weber, 2004), which enforce the notion that some groups are more superior than others. When Rene intentionally positioned countries in the Global South in comparison with each other, instead of in comparison to the West, she not only practiced subversion, but she also provided a more authentic frame of analysis for countries that are more comparable with each other than with the West. 
Rene's work pushes back on the notion that the West should the standard to which all other regions of the world are compared. Such dominant beliefs negate the relevance of non-Western (white androcentric) thought, and as a result, research conducted by scholars from underrepresented groups has traditionally been ignored, marginalized, or discredited by the dominant class (Buchanan, 2020; Delgado Bernal \& Villalpando, 2002; Huber, 2009; Settles et al., 2020). This is practice is yet another example of epistemic exclusion, defined by Settles et al. (2020) as "the combined impact of formal institutional systems, or established systems for the evaluation of scholarship, and individual biases in determining what knowledge is valuable and who is deemed a credible contributor to knowledge production" (p.10). The practice of epistemic exclusion results in a higher valuation for intellectual work produced by white Anglophone men and dismissal or exclusion of intellectual work of those from marginalized groups.

Many women in this study intentionally addressed issues of epistemic exclusion by highlighting non-Western writers and thinkers in their academic work. Angela did this in her writing by carefully considering whom she cited in prominent locations in her texts, focusing on non-Western or non-Anglophone authors; Sara sought to incorporate indigenous voices in her research by using ethnographic interviews as background literature, saying, "You can't tell from this that like, oh, that wasn't just, it wasn't just a book I got from the library. That's an interview tape that was transcribed and translated by somebody else.” By neglecting to distinguish the ideas in these ethnographic interviews from those of published researchers, Sara elevated voices that have been commonly dismissed or overlooked in archeological research. The highlighting of 
underrepresented voices in literature is a form of collective uplift that many of the women in this study practiced. Not only do women tend to cite other women at higher rates than men cite women (McElhinny et al., 2003), the women in this study also highlight nonWestern thinkers in their citation practices. By acknowledging the validity of this intellectual work through citation, these women use their sphere of influence in order to create space for other marginalized voices.

Through challenging the singularity of narratives, frames, and voices, the many of the women in this study practice canonical subversion, both covertly and overtly. They recognize that systemic inequities apply not just to them, but to other marginalized communities as well, and therefore, are committed to using their success to advocate for narratives that decenter the white androcentric voice.

\section{Subversion of Time}

Women in this study practice subversion in their research practices, but also understand subversion can be time-consuming. This idea runs counter to expectations of academic capitalism, which now seems to start a publication count from the minute a novice scholar enters a doctoral program (Paré, 2010). Several of the women in this study talked about the time-consuming challenges of connecting ideas from sometimes disparate fields of thought and the amount of time needed to clearly think through how to present the complexity of their ideas in a reader-friendly format. For many women in this study, this hard intellectual activity is tied to the reasons why they conduct scholarship and understand that thinking deeply requires time and effort. From assembling literature from a wide variety of sources (as Oksana and Sara did) to mentally wrestling with a 
concept until it is ready to be "birthed" (as Rene described it), the intellectual pursuits of the women in this study required time.

In addition to the intellectual labor that is required for creating work, the toll of fighting against racist and androcentric ideals can be emotionally and physically draining. The need to spend time recuperating from such challenges can also take productive time away from writing and research, forcing women who regular encounter such roadblocks in the construction and dissemination of knowledge to choose between either slowing down their production or facing burnout (Settles et al., 2020). In considering the balance between research quality, personal care, and academic expectations, the women in this study chose, when they were able, a more careful, considered pace of knowledge production.

Academic capitalism pushes for perpetual growth in research activity, asking scholars to produce an ever-increasing quota of publications in order to raise the research profile of an institution of a field (Mountz, 2015). This tendency has resulted in something akin to a monoculture of academic thought in some disciplines, where similar studies based on incremental advances flood the pages of academic journals. Rene, Lisa, and Catherine all directly criticized this trend in the mainstream tracks of their fields and clearly distinguished their research agendas as a more of a "slow food" option: research to be savored rather than merely consumed. The call for slowing down one's research practice echoes calls from Mountz et al. (2015), who advocate for a feminist-informed "slow scholarship" in order to counter the ever-increasing pace of academic capitalism. 
These scholars argue, as did many of my participants, that quality research requires time: time for ideas to percolate, time for careful research, writing, and refining.

For women to resist the neoliberal pull of fast knowledge, they place themselves in a vulnerable academic position. They may not produce as many publications, and these articles may seem more disparate in focus for a tenure review committee, as these women seek to weave narratives from across disciplinary spectrums in their research. Still, the women I interviewed did not seem interested in changing their approach in order to produce more, nor did they regret their choices in research pursuits. As Oksana said, "I'm just really curious. I'm just going to go for it and I know it's going to take me ages... and I won't be able to write as many publications but I just can't think any differently.” The women in this study did not see the value of changing their research interests in order to participate in a system that was unappreciative of their innovative work. However, this does not mean that they were unresponsive to the systems in which they were operating. They used a variety of mechanisms in order to ensure that the research they were interested in was published, even if it ran counter to disciplinary expectations.

\section{Mechanisms of Subversion}

Resisting an entrenched, hierarchical system is not easy, and the women in this study were not exempt from these challenges. In order to make it past institutional gatekeepers with their research agendas intact, these women employed mechanisms that have at times been maligned in both mainstream and feminist literature. Either intentionally or by default, they protected their arguments by meticulously constructing indestructible fortresses of evidence. They also used what are commonly thought of as 
masculine tactics in order to aggressively argue for their positions and to preempt attempts to discredit their work.

\section{Perfectionism as a Mechanism of Subversion}

Perfectionism is a topic that is often maligned in literature, especially when concerned with women's performance. Indeed, tendencies toward perfectionism are commonly associated with stories of women overcompensating for their imposter syndromes and are blamed for lower levels of academic production, burnout, and other factors that weigh on a woman's academic career. I do not dispute the challenges of being a perfectionist. Several of my participants visibly struggled with deadlines due to wanting the final product to be perfect. They wrote and rewrote drafts, often starting from scratch when asked for revision, were fearful of appearing vulnerable when they truly needed help or support, and in many cases, were reticent to have any writing that wasn't fully formed be viewed by collaborators or reviewers. Many admitted to me that they were slower to produce research and respond to revisions because they would get caught up in trying to perfect their argument. The challenges that my participants faced in getting their work out the door are reflected in research showing that women tend to submit fewer publications to higher-tier journals than men and resubmit less often when revisions are requested (Fulkerson \& Tushingham, 2019; Rautman, 2012). This could mean that women take longer to produce work because they are bound up in self-imposed expectations of perfectionism, to the detriment of their research productivity and ultimately, their career. 
Taking into consideration the very real challenges of perfectionism and women's work, I would like to extend an alternative to the origins of such perfectionism. I propose that the origins of perfectionism are not only due to feelings of inadequacy or fear of failure but could also be related to the ways in which women are attempting to change narratives within their fields. Changing narratives is tricky, especially when they are entrenched in a system that is still firmly in control of the means of knowledge generation. For the women in this study, efforts to change narratives can also be tricky because pushback from the establishment may come in a variety of forms not directly associated with the argument a narrative changer is trying to put forth. For Lucy, pushback against her arguments often came in the form of methodological criticism; for Rene, it took the form of dismissal from her co-authors; in Sara's experience, pushback was through harmful personal attacks. In each of these cases, it was necessary for the women to construct air-tight research so their arguments could not be dismissed based on straw-man criticisms.

In addition to perfectionism serving as a defense against unwarranted attacks from elites who feel that their way of being is under threat, research has found that perfectionism can have positive effects on academic achievement, especially for women. For example, Rice et al. (2013) found that undergraduate women who self-identified as perfectionists earned higher grades in their STEM classes, but lower grades when this measure was low. Furthermore, perfectionist tendencies appeared to mitigate poor performance due to stereotype threat conditions for women (the stereotype threat is borne out in poorer performance on assessments when subjects are reminded of negative 
stereotypes of the groups to which they belong). The researchers suggested that the attitude of, "I'll show you that women can do science," was likely driving better performance for women under these conditions (Rice, 2013, p.291). In contrast, the undergraduate men in this study earned lower grades when they reported higher levels of perfectionism and higher grades when the opposite was true. It is important to note that this is one study amongst a wide array of studies indicating that perfectionism can have debilitating effects on women, professionally. However, the roots and the purpose of perfectionism may be more complicated than previously considered.

Although many expressed frustration at the amount of time it would take them to produce high-quality research, the professors I spoke with for this study also seemed to value their perfectionist tendencies. This was evident when they described the detail with which they construct evidence and arguments. In doing so, intentionally or unintentionally, many contrasted their work to that of their male colleagues. While Oksana described her writing as detailed, she considered the writing of her male colleague was "vague." Similarly, Catherine described how "braggadocious" many of the men in her graduate program were, saying, "most of the time they were full of hot air...Take a pin and you go pop and the whole thing falls apart." The language that the men in Catherine's world spoke with was imbued with an authority of power and privilege. In contrast, she said, "when you're a woman, you just do, and if you're gender non-conforming or gender non-binary, like you also don't sound the same. Like you don't carry the authority in your voice." The difference in perceived authority was not directly addressed in any of the other interviews. However, the ways that the women in this study 
used detail and careful argumentation to construct their arguments may speak to their need to establish authority, not through privilege, but rather through hard work and meticulous research.

In considering the less apparent dimensions of perfectionism, it is worthwhile to question the pathologization of perfectionism as a disorder brought on by one's own feelings of inadequacy. Seeing perfectionism as a pathology not only dismisses the challenges faced by women as they negotiate with the heavily critical eye commonly leveled at their work; it also feeds into the perception that quality of women's work is due to hard work, rather than brilliance (see Leslie et al., 2015). If women's work is the product of the slow grind of perseverance, whereas the work of men is the product of innate talent or brilliance, then knowledge produced by women may be seen as less theoretical and thereby less widely applicable (McElhinny et al., 2003). Or, even worse, is when "we frame struggle as incompetence" as Catherine said. The perception that any type of struggle is an indication of incompetence gaslights the fact that women must also defend themselves from being judged incompetent based on the quality of their work. Such perceptions connecting women's work to effort and men's to talent could have an impact on how widely an article is cited, as well as the relative value that peers attribute to the work of women, especially those from multiple marginalized identities (McElhinny et al., 2003; Settles et al., 2020). Instead of pathologizing perfectionism as a woman's problem, it may be more useful to see this tendency as both a tool and a barrier, but one that is born from the necessity of operating in a community still rife with systemic inequities. In this light, it is possible to understand perfectionism as a mechanism through 
which women scholars demand recognition for their work as valuable contributions to the academic conversation.

\section{Using the Master's Tools for Subversion}

Many feminist authors attribute the lower rates of women's publication to the androcentric writing and research practices enforced by the establishment (Fleischman, 1998; Mitchell, 2017; Webb, 1992). These include a prohibition on the personal perspective in academic writing, including first person narratives, reflective statements, and the explicit connection of research to one's own lived experience. The argument put forth by these scholars is that language defines what ideas can be communicated. If, for example, a scholarly publication does not permit the use of first person, the individual writing the article is therefore summarily erased from the article (Mitchell, 2017; Webb, 1992).

This perspective was not confirmed by this study. In fact, none of my participants cited the actual prose or structure of an academic written argument as a barrier in their research agenda. Rather, many had embraced not only the language, but also the conventional form of an empirical research article, finding it the most efficient and predictable way of conveying their research. In terms of language, none of my participants were concerned about the use of avoidance of the first person. Rene, for example, described feeling comfortable removing personal language depending on the requirements of a journal, without it compromising her vision for an article. Even writers like Angela, who often used the first person in her prose, saw this language as a reference to herself as a character in the research, rather than a representation of herself as a 
researcher. Aside from this relative ambivalence regarding the use of personal language, a few women in this study whose research was more quantitatively focused described feeling simply uncomfortable using personal language in their writing.

Aside from the language used in publication, the structure of argumentation is also one that is commonly criticized as being constraining or unnatural to women writers. Such structures include clearly stating one's argument at the beginning of a text (in a thesis statement or topic sentence), as opposed to using a more relational style of argumentation that might begin with background information or a narrative intended to build a relationship with a reader. The former style of argumentation is commonly used to establish authority and preempt attacks has been described as "masculine" by feminist critics like Fleischman (1998). Mitchell (2017) expands on Fleischman's arguments, criticizing composition courses for teaching practices that endeavor to dominate the reader by "attacking, defending, forcing the thrust of a powerful argument - all characteristics regarded as masculine." She compares this instruction to the linguistic preferences of women, which are "more reflexive, co-operative, and relational" (p.4).

However, Fleishman and Mitchell's criticisms of the aggressive masculine tone were largely written from the standpoint of white upper-middle class women. In their exploration of gendered defaults, Cheryan and Markus (2020) described how white and Asian women are expected to be passive or relational in order to project socially constructed notions of femininity. Two of the white women in this study (Angela and Lucy) specifically addressed this tension in our interviews, describing how their advisors had intentionally worked with them to increase the assertiveness and directness of their 
prose. Based on this experience as well as the experience of learning to write manifestos as an undergraduate, Angela identified aggressive argumentation as a key component of her voice, rather than a barrier to the authentic expression of her written self.

Although white and Asian women often contend with stereotypes of passive femininity, black women are often stereotyped as aggressive (Buchanan, 2020; Cheryan $\&$ Markus, 2020). There are a variety of reasons why black women and other women of multiple intersecting marginalized identities need to be assertive in their argumentation. For example, Settles et al. (2020) found that black professors developed a more assertive stance in their departments in response to experiences of epistemic exclusion. This coping mechanism seemed to be effective and "helped them to feel empowered and agentic in otherwise difficult circumstances" (p.9). Although Setttles et al. were primarily addressing assertiveness in interpersonal settings, this assertiveness may also carry over into a scholar's prose. The black feminist scholar and cultural critic, Tressie McMillan Cottom (2020) described how she often deliberately "pre-argues" in her writing through the use of distance and authorial voice against the ways in which her readership would collapse or diminish her work.

Rene also described pre-arguing in her writing, calling her process of argumentation "lawyering." She explained how, when she is writing, "I'm thinking as a lawyer, I'm thinking, I'm writing to a judge. How do I convince this judge that this idea is important and should be published?" For Rene, a black multilingual woman, it is essential to emphatically argue for the validity of her scholarly contributions, especially since no one else is likely to do so. Although some feminist writers may argue that such 
moves impede a woman scholar from expressing her true self, it is possible that this style is the very thing that allows women to assert themselves. Audre Lorde (1984/2007) cautioned her readers that "the master's tools will never dismantle the master's house," but in some cases, aggressively establishing authority in one's prose may, like perfectionism, be a necessary tool for women writers to firmly assert their legitimacy and begin to reconstruct a house that does not fit their needs.

\section{Teaching Participatory Practices through Mentoring}

In their mentoring practices, the women in this study also communicated both subversive and participatory messages. In doing so, many referenced a need to equip their students for effective participation in their chosen fields, while at the same time preparing them for a world that may not always respond kindly to their personhood or their work.

\section{Scholarly Reproduction in Mentoring}

Mentoring students into academic norms was important for the women in this study because they saw the ability of their students to write in a discipline-appropriate fashion as a key factor in their employability. In training these students to participate in and effectively communicate established disciplinary research practices, these professors were providing them with the necessary tools to obtain a professional or academic job. This was especially true for Lucy and Rene, who advised doctoral students, and for Sara, who regularly published with students in her professional master's program. In socializing their students to produce academic work, these three women described bringing their students into their projects through what Lave and Wenger (1991) have called legitimate peripheral participation (LPP). This practice brings novices towards the 
center of a community of practice through increasing levels of responsibility, under the guidance of a senior practitioner. In this way, LPP works to pass down an awareness of embedded norms or behaviors in the communities that a novice is seeking to join.

Sara, Lucy and Rene wrote regularly with their students, involving them in a range of levels of LPP. For example, Rene would often have her students outline or write literature reviews for articles that she was working on, whereas Lucy and Sara, whose work was more quantitative, often had advisees run data analyses or write up results sections for papers that they were leading. These tasks were outsourced to new advisees in order to give them a feel for participating in the process of writing an article under expert supervision. These were similar tasks to those that had been assigned to these women when they were in graduate school. Not only Lucy, Sara, and Rene, but also Oksana referred to formative experiences in research labs or in collaborative projects with mentors that scaffolded their integration into research and publication practices in their fields. For Lucy and Rene, who were training novice academics, this supervised collaboration later morphed into supported student research, where the advisee would take the lead on a research project and the advisor would provide expert support and guidance. Although Lucy and Rene seemed to practice similar methods of LPP with their doctoral students, once students began to generate their own empirical research, the paths of these two women diverged. Lucy practiced a type of supervision that encouraged frequent, focused publication in her advisees, whereas Rene's supervision style did not emphasize publication as much as the exploration of novel research topics. Comparing 
these two styles of advising could help elucidate how women professors are motivated to either perpetuate or subvert academic norms in their advising practices.

As mentioned earlier, Lucy's publication practice was not overtly subversive in many of the ways commonly associated with women's work (Gonzales, 2018; Sprague, 2016). Related to her own work, Lucy's mentoring practices also perpetuated academic expectations, specifically around the need for frequent publication. For example, Lucy expected her students to produce at least one solo-authored paper per year and encouraged them to stick with the quantitative methodologies she was familiar with, for fear that pursuing a qualitative path would lead to delays in publication. Lucy's expectations of such frequent publication are supported by research showing that psychology $\mathrm{PhD}$ students tend to produce nearly double the number of publications compared with others disciplines in the social sciences, averaging 8.4 publications by the time they graduate, with 4.1 of these publications first or solo-authored (Hatch \& Skipper, 2016). Such high expectations leave little room for improvisation or negotiation of norms. For scholars like Lucy, an assistant professor whose research is focused on topics related to social justice, having an equally radical writing and mentoring practice may harm not only her students' chances of securing an academic job post-doctorate, but also her chances of passing her tenure review. Lucy was well aware of this challenge and spoke about it frequently in our interviews. She described much of her mentoring practice as helping her students through this constant negotiation of costs and benefits, balancing her students' visions for their work and the necessity of establishing a basis from which to grow their careers. For Lucy, her advisees, and others in similar fields, the higher a bar 
is set, the higher one needs to jump in order to distinguish herself. Thus, the pressure to publish and the level of conformity within Lucy's field seem to have a positive correlation.

In contrast to Lucy's approach, Rene's mentoring style was less focused on publication and more on helping her students pursue research topics of their interest. Although she did co-author with students, such collaboration was not as frequent as in Lucy's case. Perhaps one reason for this was that most of Rene's advisees researched topics that were merely tangentially related to her specific area of study, so while students occasionally helped her write sections of her articles, she seemed to serve more of an advising than a co-authoring role on their first-authored publications. Rene's philosophy towards publication also differed fundamentally from Lucy's. Whereas Lucy saw frequent academic publication as a burdensome, yet necessary aspect of demonstrating one's worth to the academic community, Rene repeatedly disparaged the expectations of "academic capitalism" in the valuation of quantity over quality. As a woman coming from multiple marginalized identities, Rene may have just decided to pursue her own path in academic publication, knowing that trying to play the game would not serve her interests. Meyerson and Tomkins (2007) write that marginalized individuals "are more likely to become conscious of gaps and shortfalls in existing arrangements and more motivated to challenge them" (p. 309). In Rene's case, she may not have had much to lose from pursuing her own path, especially considering the ways that more traditional options were often blocked for her. 
The apprenticeship model of academic mentorship (described using theories such as legitimate peripheral participation) is often criticized for not taking into account the challenges faced by many novices as they shed their old identities and adopt new ones as academics in their new communities of practice (Fujioka, 2008; Ivanič, 1998; Kim, 2015; Kubota, 2003). In contrast with these criticisms, the professors I spoke with rarely described such conflicts either in their own experiences or with the graduate students they worked with. Rather than seeing their identities in conflict with the modes of communication in their communities of practice, they saw conventional academic discourse as a language they needed to learn in order to communicate effectively in their fields. It was a similar case with their own students. When asked whether their students ever push back against the rules and norms they are trying to impart, the women in this study also reported that their graduate students intentionally practiced adopting the language and means of communication valued by their disciplines in their written work. Based on this information, it appears that many graduate students want to be socialized and recognize that a certain style of communication is essential for full participation in their fields.

The only exception to the apparent willingness to legitimately peripherally participate in learning the academic practices of one's field appeared to have been mediated by gender. As a graduate student, Oksana's negative experience with her male professor led her to resist his advice of adding a "roadmap" paragraph to her essays until she became a professor and began recommending this structural component to her own students. As professors, several of the women in this study reported working with male 
students who did not see them as legitimate experts and therefore did not want to follow their advice regarding revising or structuring their prose. Rene, Sara, and Angela all reported similar experiences in this respect, but for Rene, the multiple marginalizations of being a black multilingual woman exacerbated the pushback she received from her students. As opposed to reporting a single example of a frustrating experience with a male student, she referred to patterns of behavior, explaining how many of her male students viewed her feedback through the lens of, "a black woman telling the white Caucasian who is an English speaker that what they've written is bad." Such student resistance to their advisor's attempts at LPP may look subversive due to the relative power dynamic between the two parties. However, it is important to note that these acts of rebellion are not necessarily directed at the establishment, but rather the person who is not seen by the novice as a legitimate representative of the community of practice they wish to join. Such behavior could be an act of resistance for someone, like Oksana, who occupies a lower position of power in terms of gender and first language, but it may be an exertion of power by a white male student over his black, white, and/or multilingual woman advisor.

\section{Explicit vs. Implicit Communication of Norms}

Gender also played a role in the socialization experiences of the women in this study. Those who had male advisors in graduate school (Lisa, Rene, and Sara) described their LPP experiences with their advisors as more of a cultural socialization than one based on learning the mechanics of academia. Lisa and Rene described working under the somewhat distant eye of their renowned graduate advisor, who would bring students on 
retreats or place them in working groups, where they would discuss ideas, share work, and develop an academic community around their scholarly pursuits. From such meetings academic work arose organically, based on the shared experiences of the group and an implicit understanding of academic norms. While this strategy of building LPP through a social experience worked for Rene and Lisa, it did not work for Sara. In contrast to Rene and Lisa, Sara's description of her graduate school experience with her male advisor sounded isolating and frustrating. This could be because she did not connect as well with her cohort and was therefore unable to find the peer support necessary to navigate the expectations of her supportive, yet somewhat distant advisor. It could also have been personality driven. While Rene and Lisa are both rather extroverted, Sara identified as an introvert, and may have benefited more from a close one-on-one advising relationship. Because Sara had previously had such a relationship with her undergraduate advisor, she may have been disappointed to not have found similar levels of support in her graduate school experience.

The experience that Sara had with her undergraduate advisor was similar to those who reported working with women graduate advisors. Both Angela and Lucy painted a picture of more "hands on" socialization from their advisors, consisting of direct, focused feedback on prose and active advocacy in networking and publication. Although Oksana did not talk specifically about her advisor in our interviews, she described appreciating similar in-depth feedback from a woman professor during her graduate program. Regardless of their experiences with mentors, the women in this study who worked with graduate students (Rene, Lucy, Angela, Oksana, and Sara) all reported being similarly 
engaged in such mechanical aspects of student socialization. These women had a variety of reasons for doing so, ranging from feeling an obligation to prepare their students for professional work, to a keen awareness of how the quality and consistency of their students' work would reflect on their own research portfolios. However, all seemed to believe that intentional, in-depth feedback on writing and research practices was essential to their students' progress through their degrees.

The difference between reported socialization styles of the men and women advisors in this study has been touched on in the literature, although most scholarship tends to typify male advisors as distant, intellectual, and demanding, whereas female advisors are typified as either warm, informal, and nurturing, or as strict "iron maidens" (Dua, 2007, p.604). While some of these characteristics were born out in the experiences of my participants, there were other dimensions that warrant further exploration. For example, Angela related how a student told her "you were harsh, but fair" in reference to her advising; Lucy described herself as compassionate, but "real" in her advising practice. This balance of care with high expectations and explicit instruction does not fit neatly in the dichotomy of warm/informal versus "iron maiden." Rather, it speaks to the need of highlighting "the paradoxical nature of preparing students to labor and succeed in academia, a space that often rewards the status quo" (Esposito et al., 2017, p. 161). This type of care emphasizes the need for strong academic performance for not just learning, but excelling at the genre, in order to establish the unquestionable right to participate in academic discourse. 
In earlier research, the socialization of graduate students has been primarily conceptualized through an androcentric lens, approximating more a process of osmosis than an active learning experience (Austin, 2002; Jones, 2016). In this type of socialization, students work under the tutelage of an advisor, reading and adopting his mode of academic communication through a mix of intuition, feedback, and revision. This works for students who are either already equipped with the cultural capital necessary to intuit the expectations of academic communication or those, like Lisa and Rene, who are able to build networks of peer support and independently build an understanding of communicative expectations through reading and self-study.

However, women like Sara, who may benefit from collaboration or one-on-one social support, the distance of an advisor and the need to essentially self-discover the means of academic communication can exacerbate the feelings of isolation and vulnerability rather than help them socialize into their disciplines (Roberts \& Plakhotnik, 2009; Wolgemuth \& Harbour, 2008). Although these differences between men and women advisors may seem like a simple case of socialized personality differences, the lack of explicit instruction from an advisor can be more insidious. According to Bourdieu and Passaron (1977/1990), the failure to explicitly communicate such norms is one way that hierarchical forces in academia maintain power. If expectations remain implicit, then it is more challenging for marginalized groups to access them. This is one of the reasons why some scholars have advocated for direct and explicit discussion of norms, even those that may seem repressive (Delpit, 2006). In such cases, the act of explicitly "decod[ing] 
the hidden curriculum" (Bertrand Jones et al., 2013, p. 331) gives students the tools they need in order to bring greater agency to their academic practice.

With this in mind, could a direct explication of norms actually be a form of subversion? On the surface, most of the women I interviewed would not be considered subversive in their mentoring practices. Even women like Rene, who encouraged their students to pursue topics that diverged from the status quo, still enforced rules around the means of scholarly communication, expecting their students to produce work in a form that was acceptable to the academic establishment. In this manner, the women in this study mentor their advisees to communicate their research in forms that are easily recognizable to the established elite, mostly as empirical journal articles or class assignments that approximate such forms. However, by clearly explicating the rules behind producing such work, these women are teaching their students how to play the academic game. As Cassanave (2002) suggests, once novices understand these rules, it is possible to begin to improvise, to make the game of academia less one of chance, and more one of creative improvisation.

In summary, the women in this study play a delicate game of negotiation and balance, perhaps at times, without even realizing they are doing so. In contrast with Gonzales' findings, which present subversion as a more overt act of resistance, the majority of my participants have largely approached subversion as "tempered radicals" (Buchanan, 2020; Meyerson \& Tompkins, 2007). According to Meyerson and Tompkins (2007), tempered radicals push at the status quo-shaped boundaries by working within the norms of their institution. They work gradually, subversively; they nudge, adjust, suggest, 
and challenge, finding holes and grabbing opportunities to break through. As tempered radicals, the women I interviewed are committed to their disciplinary communities and to all the contradictions that participating in such communities hold. From the margins, they are able to both work within and see beyond the boundaries of their discipline in order to make incremental changes in their spheres of influence.

In order to make these changes, these tempered radicals develop and maintain legitimacy in their disciplinary communities by participating and excelling in institutionalized practices. From this position, they are able to put forward new or subversive ideas in ways that are recognizable or acceptable to the establishment. It is important to emphasize that women reproduce or subvert with eyes wide open. They are constantly evaluating their relational power and their ability to push at certain weak points in the wall of epistemic patriarchy. Regardless of whether they eventually decide to submit to or subvert some expectations, these women know what they are doing, and they are proud of their work.

\section{The Importance of Relational Networks}

Although the notion of a radical brings to mind a picture of solitary individual, perhaps with fist or pen raised in protest, what remains unacknowledged in this picture is the network of colleagues, allies, and admirers who support and inspire the radical to do her job. The women I interviewed for this study drew from a range of support systems for emotional and professional support. In this section, I refer frequently to mentoring in the context of support, and in doing so, I hope to broaden the conceptualization of a mentoring practice. Based on the experiences of my participants, I see mentoring not as a 
single relationship between an expert and novice, but rather as a multi-dimensional, reciprocal network, where lines of expertise and support are traversed in both directions, and where knowledge is exchanged, challenged, and expanded.

\section{Layered Mentoring}

In navigating the complex landscape of academic publication, the women I interviewed turn to a wide network of professional allies. The practice of building a network of people who can provide professional and emotional care relates to what Buchanan (2020) termed "layered mentoring" where different mentors can provide different types of advice (p. 101). This method of distributed support allows women to expose some of their insecurities to some people but not all their insecurities to all, a strategy which can help preserve an overall veneer of success and confidence, even when they feel vulnerable. It was important for many of the women in my study to project confidence and self-sufficiency. As Lisa said, when asked about advice that she would give to women seeking a $\mathrm{PhD}$ in her field, "be ok with being vulnerable, but do that with your friends." The supports that the women in this study turned to filled both professional and emotional needs. Some professional allies served as academic brokers, by giving publication, editing, and research advice (Kamler, 2010; Lillis \& Curry, 2006), and others served as emotional supports, by helping women process their emotions around mentoring, reviewer feedback, and professional goals. The women in this study seemed to need both types of support in order to feel connected to and accepted by their professional communities, a finding that echoes that of Gonzales and Terosky (2020). Those with rich ally networks seemed happier and more confident in their research 
practice, whereas those who did not report close connections often used language indicating insecurity and isolation.

Most women in this study found collaborative, supportive relationships through their research. These relationships came from a variety of sources and offered a wide range of support. Joint publication, especially, provided opportunities for women to build a community of allies who support their work both from professional and emotional standpoints. For example, Oksana described drawing on the skills of her male co-authors to help her "package" her ideas with more finesse and dividing up tasks so she could avoid writing the dreaded literature review, allowing her to focus instead on methodology or results sections. For Lucy, the only people she would turn to besides her spouse for writing advice were her co-authors, whom she asked for help in framing her arguments and cutting back articles that were too long. Aside from providing professional support, these co-authors were also emotional collaborators. Both Lucy and Oksana described how their co-authors would help them process reviewer feedback. Oksana depended on the encouragement of her co-authors to resubmit an article when she felt that the requested revisions were beyond her skillset as a researcher, and Lucy related how she depended on her co-authors to provide perspective on the validity of reviewer requests.

These collaborations shaped how the women I interviewed participated in research and publication and may have had some influence on how confident they felt in their connections to their communities of practice. This finding is supported by research into faculty mentorship, which has found that women faculty need benefit professionally from mentoring relationships that provide both academic and emotional support (Kelly \& 
McCann, 2014). In addition to projecting confidence in their research practice, the women in this study who reported close, collaborative relationships with other researchers or co-authors tended to express less anxiety about the outside valuation of their research. Oksana, Lucy, Angela, and Lisa all described supportive relationships with co-authors or other professionals in their fields and expressed confidence in their ability to not only publish, but also have their work valued by their professional communities. Although Oksana and Lucy drew this support from frequent collaborations with certain co-authors, this was not the only source of support for the women in this study. Angela described feeling strongly supported by her department in pursuing new avenues of publication, and Lisa described relying on a broad network of professionals who supported each other academically and emotionally. These connections with professionals both within their fields and across academic disciplines helped my participants feel connected and valued as producers of academic knowledge.

\section{Reciprocal Mentoring}

Not all the women in this study felt supported or valued by their professional communities. For a variety of reasons, Sara, Rene, and Catherine did not seem to have the same degree or depth of positive connections to other professionals in their fields as the other women in this study. For Sara and Rene, this lack of connection seemed to stem from multiple instances of epistemic exclusion from their fields, which both women described as still heavily dominated by white male perspectives. Sara related how hard it is to be professionally vulnerable in such an environment, saying she has no one to tell, "I don't know what to do. This thing is a piece of crap. And I can't figure out how to write 
my way out of it. Help me." Although Rene did not relate this sentiment in similar words, her hesitancy in turning to her assigned professional mentors for help (even when they were being paid) implies a parallel reluctance to appearing professionally vulnerable. Despite (or perhaps because of) the challenges in connecting with their peers, both Sara and Rene seem to have found emotional and professional support in their mentoring relationships with their students and advisees. Sara had published frequently with her advisees, and Rene often asked her doctoral students to "tear [her] papers apart" before she sent them off for peer review. Rene described turning to her students for feedback on her writing because these interactions felt more reciprocal than receiving feedback from academic peers; she felt that her students would benefit as much from reading her papers as she would from their feedback.

Most women in this study reported collaborating with students on some level. However, these connections were not necessarily central to the well-being of women with supportive professional networks. In contrast, for women like Sara and Rene, whose interactions with their professional communities were fraught with instances of exclusion and dismissal, choosing to build connections with students may have been a safer option. In the absence of professional affirmation, the experience of being centered by students seeking support and guidance may have also been affirming in itself. By connecting with novice scholars, women can build their own professional communities from the ground, up, imparting their values and research practices on a new generation.

The practice of reciprocal mentoring counters androcentric narratives of mentorship, which typically frame mentoring as a burdensome, unidirectional 
relationship that distracts from "real academic work" like research and publication (O'Meara et al., 2017). Especially for the women in this study who work with graduate students, this is not an adequate descriptor for their mentoring work. Not only did students often provide emotional and academic support for their mentors, but they also challenged their advisors to adopt new ways of thinking or new research practices. Lucy's experience writing a reflective statement for a qualitative research article, Sara's experience writing an article focused on women in archeological analysis (after neglecting to include women in her dissertation for fear of being sidelined as a "women's scholar"), and Rene's introduction to issues of water rights for trans people were all brought about by collaborations with graduate students. In fact, many articles that the women in my study referenced had been initially spearheaded by one of their graduate students. This raises questions about the seemingly inverse relationship between mentoring loads and publication productivity. Is it possible that mentoring students could lead to a more diverse and productive research agenda? Indeed, the relationships between the faculty in my study and their students seemed sustaining in a way that is not often discussed in scholarly literature. Although research has clearly indicated the benefits of mentoring for faculty and graduate student recipients (Dua, 2007; Esposito et al., 2017; Terosky, 2019), the ways in which mentoring relationships can benefit faculty mentors themselves has been relatively underexplored.

The dependence of these women on their mentoring relationships for professional kinship and valuation brings to light an interesting conundrum. Many women facing epistemic exclusion are also often overburdened with mentoring loads. Research has 
shown that women, and particularly black and brown women are often tasked with disproportionally large number of formal advisees and informal mentees, compared to white men (Griffin, 2020; Griffin \& Reddick, 2011; Guarino \& Borden, 2017; O’Meara et al., 2017). In fields that still recalcitrantly cling to their white androcentric identities, many white and BIPOC women faculty may need to draw affirmation from a robust mentoring practice; simultaneously, however, they may be disproportionately tasked with mentoring all students who do not check the White Man box. Despite the benefits of growing a community through mentoring work, at a certain point, there are sure to be diminishing returns.

The need for the women in this study to build ally networks for emotional and professional support runs counter to androcentric narratives centered around individualism (Gonzales \& Terosky, 2020; Mountz, 2015), but is well supported in the literature (Bertrand Jones et al., 2013; Buchanan, 2020; Dua, 2007; Griffin, 2020; Terosky, 2019; Thein \& Beach, 2010). The image of the sole academic working on his seminal work of genius is not one that the women in this study naturally gravitated towards. Rather, these women sought out and developed professional relational networks with peers and, in some cases, with their students. Although some of the women I interviewed were "going it alone," for the most part, these women expressed feelings of isolation and seemed to wish for a broader community from which they could draw support. For example, as the newest faculty member in this study, Catherine occupied a liminal space between the protective support of her graduate program and the wider academic community. The main professional relationships she described were with 
former classmates from her doctoral program, and though she seemed to be searching for community through joining online writing group, she did not yet seem to have found a place in a professional network outside of her graduate program. Her published writing was primarily solo-authored, so she also did not have the opportunity to work in collaboration with other professionals through co-authorship. In addition, she was new to teaching and had not yet found much of a connection with her students. With neither the feeling of kinship within her larger professional community nor the connection with novice scholars to draw on for support, Catherine seemed to be struggling to find her place in her field and expressed a high degree of anxiety around her writing and research practices.

\section{Summary}

Joining a professional community can be stressful. It taxes our intellectual and emotional capabilities because we are often required to intuit established norms of interaction, as opposed to being explicitly told them. Having a guide can ease this transition, both because she can explain the rules, but also because she has likely been through this process before and can empathize with the challenges inherent in traversing the unfamiliar terrain. The professional advice and emotional empathy provided by our guides help normalize feelings of confusion or inadequacy that come from the initial forays into a strange land. Having a network of people to turn to allows us to distribute our emotional needs, so we neither overburden our allies nor overexpose ourselves. However, these guides are not always easily accessible. For BIPOC women professors, who are often the only non-white person in a department, it may be challenging to find an 
in-house disciplinary peer to build co-authoring relationships with. In such cases, it may be necessary to build connections outside one's department or from the ground up with one's advises. Both of these options come with additional challenges, including the dismissal of interdisciplinary work by one's departmental peers or over-extension in one's mentoring relationships.

\section{Implications}

In discussing the implications of this study, I have framed my recommendations in terms of myths of women's publication practice. In doing so, I interrogate the androcentric assumptions that have been made about academic work and describe how the women in this study subvert these assumptions. I will also discuss how these myths might be addressed in order to help academia be more welcoming of women's publication practice.

\section{Myth \#1: Women's Research Practices Should Emulate those of Men}

A large body of research has focused on the quantity of women's publication in comparison to men (Aiston \& Jung, 2015; Benevento et al., 2017; Gómez Cama et al., 2016; Lundine et al., 2019; Mayer \& Rathmann, 2018; McElhinny et al., 2003). These articles tie the relative dearth of women's publication to a variety of causes, from androcentric publishing expectations to the disproportionate amount of time that women spend on non-research-related tasks in comparison to men. The problem here is two-fold: 1) articles focusing on women's deficits in publication perpetuate a capitalist agenda that values quantity over quality, and 2) work outside of research is not seen as a potential contributor to a scholarly agenda. 
The first problem is the assumption that a scholar's goal should be to publish more and that white male publication practices are the standard to which all researchers should be held. This assumption feeds into narratives perpetuated by academic capitalism, which assert that quantitative growth is the only path indicating forward momentum (Mountz, 2015). The perspectives of the women in my study indicate that very few wish to publish more frequently, and those who do are primarily driven by outside pressures in service of their tenure portfolio requirements. Rather than seeking to produce a lot of articles, the women I interviewed sought to produce in-depth, complex, high-quality research; in other words, they strive to produce research that takes time and works to deepen or disrupt, rather than perpetuate existing narratives.

The second problem inherent in the myth that women should produce more scholarly publications relates to the assumption that it is necessary to bifurcate oneself from one's research to achieve this goal (Gonzales \& Terosky, 2020). The idea here is that everything outside of research, including teaching, mentoring, as well as one's life and personal identity, distracts from, rather than adds to a scholarly agenda. While it is true that time is limited, and that research does take a special kind of focused attention, it is important to acknowledge the value of relational work. The women in my study were supported professionally and emotionally by their communities, peers, and students. Many also drew inspiration for their research from their teaching practice and from their conversations with students and advisees, indicating that much of their work with students added to, rather than detracted from their research practice. Several of the women I interviewed also drew from their lived experience to build their research 
practice. Investigating topics related to the complexity of their own lives gave them a depth of understanding that would not necessarily be accessible to an "objective" outside observer.

If women's scholarship is to be valued, it is important to celebrate what makes our work unique, as opposed to lamenting the fact that it does not emulate the scholarship practices of white men. Departments can start this process by re-evaluating how the quality of a scholarly agenda is defined. By androcentric standards, a narrowly focused research agenda with a large number of publications in a small number of high-tier academic journals is an indication of scholarly success. However, valuing a scholarly agenda that follows a single thread or narrative could disadvantage women who work interdisciplinarily, as well as those who support students and draw inspiration from their mentoring relationships. This type of research may take time, it may be disciplinarily broad (as opposed to narrowly focused), and it may not be publishable in more "popular" journals. Unfortunately, if women tend to publish in journals that target specific audiences outside of their discipline because of the interdisciplinary nature of their work, their research often does not get the same validation by other scholars on hiring and tenure committees. According to Buchanan (2020), the high-tier publications commonly valued in traditional academic circles have attained their status based on indices that primarily rely on readership numbers. If more specialized publications have a narrower readership, their indices are naturally smaller, but it is this narrow readership that allows women to target an audience that is "willing and capable of hearing us" (Dotson, 2011, p.238). 
Women need to be able to share their knowledge with appropriate audiences and have those audiences value their work. Departments can insist that professors on the tenure track publish to certain high tier journals, but what if these publications are not the appropriate audience for the knowledge generated by women scholars? In order to better support women in communicating with audiences who are receptive to and able to understand their work, Settles et al. (2020) recommend, ...assigning equal value to publications in "specialty" journals and generalist journals, or considering indicators of societal impact (e.g., use of findings in the creation of public policy; general readership or class adoption of a book; advancement of technology; improvements in community outcomes) that may be more difficult to measure than traditional impact factors. (p.13)

These measures may be more challenging to assess, but they offer a more nuanced perspective on the ways that women's work is valued.

Most of the women in my study were fortunate in that they worked at a regional comprehensive university, where tenure requirements were more open to a wider range of publication types, from interdisciplinary journals to textbooks. While many did feel some pressure to clearly establish their legitimacy as scholars in their tenure portfolios, only one assistant professor, Lucy, seemed to be actively concerned about reaching a specific publication quota. This might have been a different study if I had interviewed women at a university with a stronger "publish or perish" ethos across all departments. In such cases, it is likely that the pre-tenure women professors would have had less flexibility to pursue an interdisciplinary or practice-based research agenda. Because I did not ask my 
participants about their reasoning for joining their current university, I cannot say if the tenure requirements factored into their decision to work at this particular institution.

If mainstream journals are serious about increasing the gender and racial balance of their publications, they cannot wait for women to start banging down their doors. Because women tend to submit fewer articles to prestigious journals than men, the editors of these journals need to intentionalize their efforts to recruit and publish nonhomogenous authors (Heath-Stout, 2020). In her study of race and gender balance in archeological journals, Heath-Stout (2020) describes how only one prestigious journal had bucked the trend of predominantly publishing white cis-gendered men. The Journal of Archaeological Research not only solicits the majority of its articles, rather than waiting for scholars to submit manuscripts, the editors also rarely reject reviewed articles outright. Instead, "authors receive clear revision instructions and reminders to resubmit, leading to a high publication rate for manuscripts that are submitted and reviewed" (Heath-Stout, 2020, p.421). The direct solicitation of manuscripts (from both men and women) likely gives many who would not have otherwise considered submitting to this journal assurance that this publication values their work. Such efforts on the part of editors may be necessary for people from non-dominant groups to understand that their work will be carefully considered on its scholarly merits, and they will not have to suffer the emotional toll not only of rejection, but also epistemological dismissal.

\section{Myth \#2: Women are Stymied by the Written Style of Academic Publication}

The second myth related to women's work has to do with how women scholars express themselves through writing. Based on much of the feminist literature around 
writing and women's voice, I entered this study looking for a distinct written style that women would be able to point to in their prose. This style, I thought, would be more personal, or perhaps more reflective than the writing commonly expected in androcentric circles. I had also expected my participants to report some frustration with the language of distance, the lack of personal pronouns, or perhaps the lack of reflexivity in their writing. The most surprising discovery for me was that the women I spoke with were not that concerned about whether they were visible as actors in their academic prose. While many clearly saw themselves in their research practices, they saw the text, itself, as more of a communicative tool to articulate their arguments about their scholarly work. In addition to a general lack of concern about personal voice in the prose, the women in this study had pursued research interests that allowed them to write in a style that was comfortable to them. The qualitative researchers comfortably used the first person in their prose, and the quantitative researchers generally shied away from it.

This finding contradicts theories put forth by many feminist researchers, who argue that the voice used to communicate research is heavily masculinized and that the enforcement of such a voice diminishes the ability of women scholars to authentically participate in academic thought. I would like to argue that although academic language is certainly a unique style of communication, borne out of Western androcentric values of communication, the implication that we would be unable to mold such language to our needs diminishes our agency and intellect. Two of the women in this study, Oksana and Rene, not only learned English as an additional language, but also learned academic English, which is arguably yet another language all together. Several other women 
described using different voices for different types of audiences, indicating that they have a firm control over the written means of communication. The implication here is that women can and do draw on a range of "repertoires" in their scholarly communication. Repertoire is a term that is commonly used in sociolinguistics to describe how communicative practices can be creative and dynamic, yet still governed by grammatical and social constraints (Busch, 2012; Gumperz, 1972). Like intersectionality, which refers to the multiple and overlapping nature of identity, repertoires form a "heteroglossic whole, which...encompasses the co-presence of different discourses, codes, and voices" (Busch, 2012, p.520). The women in this study are neither made up of one part nor of one voice. They are dynamic and creative, with the ability to intentionally select from different repertoires to communicate with their target audiences.

In light of the dynamism and flexibility of written repertoires, the feminist argument that distant, objective language obscures a writer's authentic voice paints a narrow picture of authenticity. The women in this study were deeply, authentically passionate about their work and did not feel as though this authenticity was misrepresented in their published writing. Requirements that determine whether or not a voice is truly authentic do not always apply for all women scholars and may actually support the dualism of androcentric mythology. Indeed, claims asserting that women need to build relationships with their readers before presenting an argument or prefer to use personal pronouns in their prose are binary representations of womanhood that may not reflect the communicative preferences of all women scholars. Such binaries 
perpetuate myths of what is masculine and what is feminine, without considering that scholars may feel comfortable along a continuum of socialized values.

Despite their ability to learn and excel in academic reprertoires, most of the women in this study did not have direct instruction in their writing practice. If they were lucky, they had an advisor who would provide them with sustained, constructive feedback on their prose, working with them to explicate the mechanisms of effective academic communication. If not, these women had to learn on their own, through reading examples or instructional manuals, through joining writing groups, or throwing themselves headfirst into a stressful cycle of trial and error. Direct, sustained disciplinary writing instruction in graduate school would help alleviate some of the anxiety of trying to learn the rules of communication on one's own. Such instruction would also help dismantle recursive hierarchical systems by giving everyone the same access to the same tools of communication.

\section{Myth \#3: Perfectionism is a Pathology}

The final myth I would like to interrogate in this section is the pathologization of perfectionism. Because perfectionism is commonly associated with women, it is often thought of as a drain on productivity, a quality that harms, rather than helps a research agenda. The women in my study would likely agree with this assessment. They were, in general, quite critical of their own perfectionist tendencies, especially when they felt as though these tendencies slowed down their scholarly work. However, one of the reasons these women are so successful is likely because of their ability to produce work that does not flounder under a heavily critical eye. Assuming that perfectionism is a pathology 
associates it with labored scholarship, rather than a mechanism for survival in a society that judges the work of women, especially BIPOC women or multilingual women more harshly than that of white men. The idea of labored scholarship, in turn, is contrasted with the scholarship of white men, which is more often viewed as shining with natural or raw talent.

If women are not viewed as being potential "diamonds in the rough," do they miss out on valuable mentorship opportunities where more experience scholars seek to expose their hidden potential? I believe this is a likely prospect. Research already shows that men in graduate school and as novice academics are often paired more frequently with mentors than women, and particularly BIPIOC women (Guarino \& Borden, 2017; Kelly \& McCann, 2014; Welton et al., 2014). This could be a result of same gender or racial affinities, but it could also be related to perceptions of scholarly potential. According to Dua (2007), students possessing traits commonly associated with women (such as emotional instability or "neediness") are less likely to be selected for mentoring relationships than are those seen as being more confident or self-sufficient. Dua recommends that, in order to counter such relationships, women need to pro-actively seek out mentors with whom they would likely work well. This suggestion illustrates an unfortunate paradox: women are expected to be emotionally sensitive, yet they are often preemptively punished for this trait. However, if they act with more agency, women are likely to be seen as "pushy" or "aggressive" and, as a result, punished for stepping outside their gendered norm. 
The duality in which many women find themselves with regard to socialized expectations can be illustrated by a comparison in a recent article from the $\mathrm{BBC}$. In this article, Ruggeri (2018) enumerates the myriad ways that perfectionism can destroy one's health and potential for success. To illustrate these pitfalls, she compares two sports stars: Cristiano Ronaldo, a white European male soccer star and Serena Williams, a black American woman tennis star. Ronaldo is quoted as saying that he strives for excellence over perfection, whereas Williams is portrayed as "a self-described perfectionist who destroys racquets and casts blame when things go wrong-outbursts which have cost her the game" (para. 18). Aside from perpetuating the "angry black woman" stereotype, what the article misses in this example is how the path to success for each star has been forged. While Ronaldo follows in the path of a number of famous white European soccer stars, Williams has had to carve out a path of her own. If Serena Williams had been anything less than perfect in her professional trajectory, she would not have been permitted to engage in a sport that has traditionally not been open to black bodies. It is unlikely that women will stop feeling the need to be perfect any time soon, especially since many are still fighting for a place at the academic table. However, a more nuanced understanding of how and why perfectionism manifests in women's scholarly practice could normalize this experience for many women.

In addition to serving as a mechanism for success in a culture that still holds deep racist and sexist values, perfectionist tendencies also point to an intense level of care. We can see this care in how my participants write and rewrite a draft so they can flawlessly communicate their message. We can also see care in how these scholars hold their 
students to high standards while supporting their emotional and academic growth. Instead of referring to women's work through a lens of perfectionism, perhaps we should reframe such tendencies as a "culture of care" in order to highlight the intentionality that women bring to their scholarship. In light of care, it is also important for women scholars to be cared for through supportive relational networks, people they can be "not perfect" with. These relationships take time and trust; in addition, they may not be easily accessible within one's department, especially if the department is overwhelmingly made up of older white men. If universities and departments facilitate interdisciplinary writing or research groups for women and non-gender-conforming folk, they may be able to connect with others who share similar anxieties and experiences. Sharing their experiences outside their department may provide a like-minded group of peers who would not necessarily be on one's tenure committee, allowing for greater freedom to be vulnerable without risking one's reputation.

\section{Future Research}

There are a range of ways in which the findings from this study could be expanded and broadened. One direction could be to investigate more nuance in the difference in research practices between professorial ranks. It was clear from my interviews that tenured professors have more freedom to pursue their research interests without the pressure of the tenure clock. What is still unclear is whether these pursuits would interfere with their promotion to full professor. If the women in this study feel that pursuing the next level of promotion would compromise their research vision, would they choose to remain associate professors instead? Research in this vein could also seek to 
better understand women's research trajectories over time. Do women's research agendas become more subversive as they establish a more secure platform from which to generate knowledge?

Another area of research could investigate the relationship between mentoring and research productivity for mentors. Mentoring was a small part of this study, yet it has a strong research tradition, especially with regard to junior faculty and graduate students. However, this study did not deeply investigate the ways that mentoring can be reciprocal, or how it could benefit both the mentor and the mentee. Future research could investigate how positive mentoring relationships provide bi-directional support, rather than viewing this relationship as unidirectional. Research in this area could also investigate ways of acknowledging the importance of disciplinary breadth, rather than just depth in terms of research publication. This type of research could provide a foundation of support for women who work closely with mentees or women who pursue more interdisciplinary topics. Some questions to pursue could include: what practical changes could departments make in their promotion and tenure (or hiring) criteria that would support an interdisciplinary scholarly agenda? Would these changes lead to greater diversity in hiring and promotion?

Finally, it is important to reconsider research's relationship with perfectionism, and investigate this topic not from a deficit lens, but as a coping strategy. While we know that perfectionist tendencies are correlated with a range of physical and mental health risks, it is important to consider where perfectionism originates from and whether it is perfectionism, itself, or the stress of trying to prove oneself in a society that perpetuates 
notions of scarcity as a way of denying access to those who are not seen as legitimate participants. What more could we understand about perfectionism based on an understanding of this tendency through a more nuanced lens?

\section{Conclusions}

When I began this study, I was seeking to better understand how women academics speak through their writing. Specifically, I was interested in sites of resistance or replication of academic norms, in women's own publication practice or in the ways that they mentored their students. For me, as a linguist by training and language teacher by profession, this meant a focus on the prose itself (words, sentence structure). Much of the literature I had focused on as I developed this topic discussed how the linguistic preferences of androcentric prose limits women's voices, preventing us from expressing our full selves and limiting the range of ideas we are able to describe. Based on this literature, I had expected language to be a primary site of resistance or reproduction for my participants in their scholarship and mentoring practices. However, the language itself did not appear to be an area of contention for the women in this study. In fact, most women I spoke with neither felt restricted by requirements of academic prose nor the desire to challenge written conventions in their writing style. They reported similar experiences with their mentees. The women I interviewed passed down expectations of academic writing to their students and reported that their graduate students generally seemed eager to learn these expectations.

This finding (or non-finding) surprised me at first, but on further consideration, I began to wonder whether the mastery of academic prose and the explicit teaching of it to 
students is a form of subversion, itself. The perfectionism that the women in this study described using in their writing and research practices helped them get their work in front of their intended audiences, despite a range of barriers imposed by gatekeepers. In addition, these women's practice of explicitly mentoring their students in the academic practices through detailed, yet supportive feedback helps novices develop the tools they need to challenge systems from within. Because of the insular nature of academia, it may not be possible to challenge established ways of doing, thinking, and being from the outside. Instead, it may be necessary for subverters to act more as "tempered radicals" as they pass through the well-guarded gates of academic knowledge production. As Jennifer Nansubuga Makumbi's quote at the beginning of this chapter reminds us, resistance is not always a splashy act of glory. Sometimes, it is quiet; sometimes, it is a small refusal or a passing act of kindness. But bit by bit, and day by day, the work of women is providing both insights and alternatives to academic androcentrism. A re-framing of women's subversive tactics in the production of knowledge is one contribution of this study to the academic literature. In addition to exploring what individual acts of subversion might be, the narratives of the women I interviewed invite us to think more deeply about how this subversion happens by uncovering the mechanisms of resistance and the depth of labor required for new voices to enter scholarly conversations.

Another assumption that I carried when I began this dissertation was centered around the dearth of women's publication, in comparison to men. I was interested in learning more about why women publish less than men, with the belief that if women could achieve publication parity, they would want to; it was just a matter of learning what 
barriers stood in their way. Coupled with this assumption is the argument that relational work distracts from academic scholarship, and that mentoring or teaching cannot contribute to a professor's academic trajectory. However, Feminist Standpoint theorists might assert that questions arising from these assumptions are based on an androcentric world view. Instead of asking “why do women publish so little?” perhaps we should be asking "why do men need to publish so much?" Instead of asking "how can we help women say 'no' to mentoring requests?" we should be asking "how can we better reward scholarship that arises out of mentoring relationships?" The reframing of these questions is another contribution of this study. I would like to argue here that the problem with publication does not arise from women's deficiencies, but rather from a system that is only capable of understanding research from an androcentric perspective which conflates "more" with "better" and "research" with "individual brilliance."

Narratives around what and how much women should publish still dominate academic thought, and women are consistently held up against the white male expectations of frequent, focused publication practices. This model is perpetuated by capitalist assumptions of scarcity, where publication outlets and academic posts are commodities to be fought over, secured, and horded. It is challenging to create a subversive research practice in this environment, yet many women do so. They publish in top-tier journals, master the narrative styles of their own disciplines and others, all the while putting forth a research agenda that challenges common assumptions around disciplinary thought and research practices. 
In concluding this dissertation, is difficult to figure out where to start. This research project has spanned nearly two years, from writing a proposal to polishing this final product. In thinking back over this experience, I am flooded with a range of emotions. I am remembering the generosity of my participants, their determination, and their academic excellence; I am thinking about how they have carved out a space for themselves while wrestling with a number of challenges and roadblocks throughout their academic trajectories. I am also reflecting on the lessons that I have learned about my own research practice over these past two years. As a prospective graduate of a doctoral program, I too have felt the need to establish myself as a scholar, to finish the year with an emerging publication record and a clear scholarly agenda. I feel this pressure in light of universities with shrinking budgets, student populations, and number of full-time faculty positions, and I wonder if I will be able to carve out a space for my own voice in this challenging academic landscape.

However, I may have already done so. In my introduction, I described the disconnect I felt between my written voice and my research practice, but in writing this dissertation, I have felt these two parts come into better alignment. This may be because, for the first time, I am drawing on my own lived experience as a tool for understanding and exploring topics, not shying away from the self as an instrument for inquiry. As I pursue a line of scholarship that includes my whole academic self, I have found both writing and the accompanying research practice to come more naturally. This experience relates to what many of my participants told me about the reasons why they do research. For the women in this study, their research came from a personal drive to make sense of a 
complex world and to contribute to a richer public conversation. They brought together the personal, the political, and the scholarly, using their research to better understand their own positions in this world. In doing so, they practiced slow, meticulous research, resulting in scholarship that they were proud of. In androcentric terms, such intractable mingling of ourselves, this messy world, and our research practice is an act of subversion, but for many of us, it may be the clearest path forward. 


\section{References}

Ackerman, J. (1995). Postscript: The assimilation and tactics of Nate. In C. Berkenkotter \& T. N. Huckin, Genre knowledge in disciplinary communication: Cognition, culture, power (pp. 117-144). LErlbaum Associates.

Aiston, S. J., \& Jung, J. (2015). Women academics and research productivity: An international comparison. Gender and Education, 27(3), 205-220.

https://doi.org/10.1080/09540253.2015.1024617

ATLAS.ti (8.4). (2020). [Computer software]. Scientific Software Development GmbH. https://atlasti.com/

Austin, A. E. (2002). Preparing the next generation of faculty: Graduate school as socialization to the academic career. The Journal of Higher Education, 73(1), 94122. https://doi.org/10.1080/00221546.2002.11777132

Austin, A. E., \& Wulff, D. H. (2004). Paths to the professoriate: Strategies for enriching the preparation of future faculty (1st ed.). Jossey-Bass.

Bagilhole, B. (1994). Being different is a very difficult row to hoe: Survival strategies of women academics. In S. Davies, C. Lubelska, \& J. Quinn (Eds.), Changing the subject: Women in higher education. Taylor \& Francis.

Bancroft, S. (2013). Capital, kinship, and white privilege: Social and cultural influences upon the minority doctoral experience in the sciences. Multicultural Education, 20(2), 10-16.

Bazerman, C. (1988). Shaping written knowledge: The genre and activity of the experimental article in science. University of Wisconsin Press. 
Benevento, N., Greco, A., Pasqueralle, T., Rodriguez, C., Russo, F., Spendley, A., Sullivan, K., Sun, Y., \& Wharton, R. (2017). Who publishes more books in U.S. English departments, men or women? Publishing Research Quarterly, 33(4), 357-372. https://doi.org/10.1007/s12109-017-9548-X

Berkenkotter, C., Huckin, T. N., \& Ackerman, J. (1988). Conventions, conversations, and the writer: Case study of a student in a Rhetoric Ph.D. program. Research in the Teaching of English, 22(1), 9-44.

Bernstein, R. (2015, April 29). PLOS ONE ousts reviewer, editor after sexist peer-review storm. Science Insider. https://www.sciencemag.org/news/2015/05/plos-oneousts-reviewer-editor-after-sexist-peer-review-storm

Bertrand Jones, T., Wilder, J., \& Osborne-Lampkin, L. (2013). Employing a Black feminist approach to doctoral advising: Preparing Black women for the professoriate. Journal of Negro Education, 82(3), 326-338. https://doi.org/10.7709/jnegroeducation.82.3.0326

Bhavnani, K.-K. (2004). Tracing the contours: Feminist research and feminist objectivity. In S. N. Hesse-Biber \& M. L. Yaiser (Eds.), Feminist perspectives on social research. Oxford University Press.

Biber, D., Johansson, S., Leech, G., Conrad, S., \& Finegan, E. (1999). Longman grammar of spoken and written English. Longman.

Blanton, L. L. (2003). Narrating one's self: Public-personal dichotomies and a (public) writing life. In S. Vandrick \& C. P. Casanave (Eds.), Writing for scholarly publication: Behind the scenes in language education (pp. 131-145). Routledge. 
Bourdieu, P. (1979). Distinction: A social critique of the judgement of taste. Harvard University Press.

Bourdieu, P. (1987). What makes a social class? On the theoretical and practical existence of groups. Berkeley Journal of Sociology, 3, 1-17.

Bourdieu, P. (1988). Homo academicus. Stanford University Press.

Bourdieu, P., \& Passeron, J. C. (1977). Reproduction in education, society, and culture ( $2^{\text {nd }}$ ed.). SAGE Publications.

Box-Steffensmeier, J. M., Cunha, R. C., Varbanov, R. A., Hoh, Y. S., Knisley, M. L., \& Holmes, M. A. (2015). Survival analysis of faculty retention and promotion in the social sciences by gender. PLOS ONE, 10(11), e0143093. https://doi.org/10.1371/journal.pone.0143093

Buchanan, N. T. (2020). Researching while Black (and female). Women \& Therapy, 43(1-2), 91-111. https://doi.org/10.1080/02703149.2019.1684681

Busch, B. (2012). The linguistic repertoire revisited. Applied Linguistics, 33(5), 503-523. https://doi.org/10.1093/applin/ams056

Campbell, R., \& Wasco, S. M. (2000). Feminist approaches to social science: Epistemological and methodological tenets. American Journal of Community Psychology, 28(6), 773-791. https://doi.org/10.1023/A:1005159716099

Canagarajah, A. S. (2002). A geopolitics of academic writing. University of Pittsburgh Press. 
Canagarajah, A. S. (2003). A somewhat legitimate and very peripheral participation. In S. Vandrick \& C. P. Casanave (Eds.), Writing for scholarly publication: Behind the scenes in language education. Routledge.

Casanave, C. P. (1990). The role of writing in socializing graduate students into an academic discipline in the social sciences [Ph.D., Stanford University]. https://search.proquest.com/pqdtglobal/docview/303855322/abstract/7198DB4B4 E854BE6PQ/1

Casanave, C. P. (2002). Writing games: Multicultural case studies of academic literacy practices in higher education. Lawrence Erlbaum Associates.

Casanave, C. P. (2003). Narrative braiding: Constructing a multistrand portrayal of self as writer. In S. Vandrick \& C. P. Casanave (Eds.), Writing for scholarly publication: Behind the scenes in language education (pp. 131-145). Routledge.

Casanave, C. P. (2008). Learning participatory practices in graduate school: Some perspective-taking by a mainstream educator. In X. M. Li \& C. P. Casanave (Eds.), Learning the literacy practices of graduate school: Insiders' reflections on academic enculturation. University of Michigan Press.

Casanave, C. P. (2019). Performing expertise in doctoral dissertations: Thoughts on a fundamental dilemma facing doctoral students and their supervisors. Journal of Second Language Writing, 43, 57-62. https://doi.org/10.1016/j.jslw.2018.02.005

Casanave, C. P., \& Vandrick, S. (2003). Writing for scholarly publication: Behind the scenes in language education. Lawrence Erlbaum Associates. 
Charmaz, K. (2012). Writing feminist research. In S. N. Hesse-Biber (Ed.), Handbook of feminist research: Theory and praxis $\left(2^{\text {nd }} \mathrm{d}\right.$.). SAGE Publications.

Charmaz, K. (2014). Constructing grounded theory (2nd ed.). Sage.

Cheryan, S., \& Markus, H. R. (2020). Masculine defaults: Identifying and mitigating hidden cultural biases. Psychological Review, 127(6), 1022-1052. https://doi.org/10.1037/rev0000209

Collins, P. H. (1986). Learning from the outsider within: The sociological significance of Black feminist thought. Social Problems, 33(6), S14-S32. https://doi.org/10.2307/800672

Collins, P. H. (1990). Black feminist thought: Knowledge, consciousness, and the politics of empowerment. Unwin Hyman.

Crenshaw, K. (1989). Demarginalizing the intersection of race and sex: A Black feminist critique of antidiscrimination doctrine, feminist theory and antiracist politics. In J. James \& T. D. Sharpley-Whiting (Eds.), The Black feminist reader. Blackwell.

Curry, M. J. (2016). More than language: Graduate student writing as "disciplinary becoming.” In S. Simpson, N. A. Caplan, M. Cox, \& T. Philips (Eds.), Supporting graduate student writers: Research, curriculum, and program design (pp. 78-96). University of Michigan Press.

Delgado Bernal, D., \& Villalpando, O. (2002). An apartheid of knowledge in academia: The struggle over the "legitimate" knowledge of Faculty of Color. Equity \& Excellence in Education, 35(2), 169-180. https://doi.org/10.1080/713845282 
Delpit, L. D. (2006). Other people's children: Cultural conflict in the classroom. New Press.

DeVault, M. L. (1990). Talking and listening from women's standpoint: Feminist strategies for interviewing and analysis. Social Problems, 37(1), 21.

DeVault, M. L., \& Gross, G. (2012). Feminist qualitative interviewing: Experience, talk, and knowledge. In S. N. Hesse-Biber (Ed.), Handbook of feminist research: Theory and praxis (2 $2^{\text {nd }}$ ed., pp. 206-236). SAGE Publications.

DiFuccia, M., Pelton, J., \& Sica, A. (2007). If and when sociology becomes a female preserve. The American Sociologist, 38(1), 3-22. https://doi.org/10.1007/s12108007-9001-2

Dotson, K. (2011). Tracking epistemic violence, tracking practices of silencing. Hypatia, 26(2), 22. https://doi.org/doi:10.1111/j.1527-2001.2011.01177.x

Dressen-Hammouda, D. (2008). From novice to disciplinary expert: Disciplinary identity and genre mastery. English for Specific Purposes, 27(2), 233-252. https://doi.org/10.1016/j.esp.2007.07.006

Dua, P. (2007). Feminist mentoring and female graduate student success: Challenging gender inequality in higher education. Sociology Compass, 1(2), 594-612. https://doi.org/10.1111/j.1751-9020.2007.00042.x

Duff, P. A. (2010). Language socialization into academic discourse communities. Annual Review of Applied Linguistics, 30, 169-192. http://dx.doi.org/10.1017/S0267190510000048 
Esposito, J., Lee, T., Henderson, K. L.-T., Mason, A., Outler, A., Jackson, J. R., Washington, R., \& Whitaker-Lea, L. (2017). Doctoral students' experiences with pedagogies of the home, pedagogies of love, and mentoring in the academy. Educational Studies, 53(2), 155-177.

https://doi.org/10.1080/00131946.2017.1286589

Evans-Winters, V., \& Esposito, J. (2018). Researching the bridge called our backs: The invisibility of 'us' in qualitative communities. International Journal of Qualitative Studies in Education, 31(9), 863-876.

https://doi.org/10.1080/09518398.2018.1478152

Farkas, A. H., Bonifacino, E., Turner, R., Tilstra, S. A., \& Corbelli, J. A. (2019).

Mentorship of women in academic medicine: A systematic review. Journal of General Internal Medicine, 34(7), 1322-1329. https://doi.org/10.1007/s11606019-04955-2

Fine, M. (1992). Disruptive voices: The possibilities of feminist research. University of Michigan Press.

Fleischman, S. (1998). Gender, the personal, and the voice of scholarship: A viewpoint. Signs: Journal of Women in Culture and Society, 23(4), 975-1016. https://doi.org/10.1086/495298

Fujioka, M. (2008). Dissertation writing and the (re)positioning of self in a "Community of Practice.” In C. P. Casanave \& X. M. Li (Eds.), Learning the literacy practices of graduate school: Insiders' reflections on academic enculturation. University of Michigan Press. 
Fulkerson, T. J., \& Tushingham, S. (2019). Who dominates the discourses of the past? Gender, occupational affiliation, and multivocality in North American archaeology publishing. American Antiquity, 84(3), 379-399. https://doi.org/10.1017/aaq.2019.35

Gardner, S. K. (2013). Women faculty departures from a striving institution: Between a rock and a hard place. The Review of Higher Education, 36(3), 349-370. https://doi.org/10.1353/rhe.2013.0025

Ginther, D. K., \& Kahn, S. (2006). Women's careers in academic social science: Progress, pitfalls, and plateaus [Working Paper]. http:// people.bu.edu/skahn/GintherKahn\%20SocSci\%20c hapter.pdf

Golde, C. M. (2000). Should I stay or should I go? Student descriptions of the doctoral attrition process. The Review of Higher Education, 23(2), 199-227. https://doi.org/10.1353/rhe.2000.0004

Gómez Cama, M., Larrán Jorge, M., \& Andrades Peña, F. J. (2016). Gender differences between faculty members in higher education: A literature review of selected higher education journals. Educational Research Review, 18, 58-69. https://doi.org/10.1016/j.edurev.2016.03.001

Gonzales, L. D. (2014). Framing faculty agency inside striving universities: An application of Bourdieu's theory of practice. The Journal of Higher Education, 85(2), 193-218. https://doi.org/10.1080/00221546.2014.11777324 
Gonzales, L. D. (2018). Subverting and minding boundaries: The intellectual work of women. The Journal of Higher Education, 89(5), 677-701. https://doi.org/10.1080/00221546.2018.1434278

Gonzales, L. D., \& Terosky, A. L. (2016). From the faculty perspective: Defining, earning, and maintaining legitimacy across academia. Teachers College Record, 44.

Gonzales, L. D., \& Terosky, A. L. (2020). On their own terms: Women's pathways into and through academe. Journal of Diversity in Higher Education, 13(3), 274-287. http://dx.doi.org.proxy.lib.pdx.edu/10.1037/dhe0000128

Gopaul, B. (2015). Inequality and doctoral education: Exploring the "rules" of doctoral study through Bourdieu's notion of field. Higher Education, 70(1), 73-88. https://doi.org/10.1007/s10734-014-9824-Z

Gray, G. (2017). Academic voice in scholarly writing. The Qualitative Report, 22(1), $179-196$.

Griffin, K. A. (2020). Institutional barriers, strategies, and benefits to increasing the representation of women and men of color in the professoriate: Looking beyond the pipeline. In L. W. Perna (Ed.), Higher Education: Handbook of Theory and Research (Vol. 35, pp. 277-349). Springer International Publishing. https://doi.org/10.1007/978-3-030-31365-4_4

Griffin, K. A., \& Reddick, R. J. (2011). Surveillance and sacrifice: Gender differences in the mentoring patterns of Black professors at predominantly White research 
universities. American Educational Research Journal, 48(5), 1032-1057. https://doi.org/10.3102/0002831211405025

Guarino, C. M., \& Borden, V. M. H. (2017). Faculty service loads and gender: Are women taking care of the academic family? Research in Higher Education, 58(6), 672-694. https://doi.org/10.1007/s11162-017-9454-2

Gumperz, J. J. (1964). Linguistic and social interaction in two communities. American Anthropologist, 66(6/2), 137-153. https://doi.org/10.1525/aa.1964.66.suppl_3.02a00100

Haraway, D. (1988). Situated knowledges: The science question in feminism and the privilege of partial perspective. Feminist Studies, 14(3), 575. https://doi.org/10.2307/3178066

Harding, S. G. (1991). Whose science? Whose knowledge?: Thinking from women's lives. Cornell University Press.

Harding, S. G. (2004). Rethinking standpoint epistemology: What is "strong objectivity"? In S. N. Hesse-Biber \& M. L. Yaiser (Eds.), Feminist perspectives on social research. Oxford University Press.

Hartstock, N. C. M. (1983). The feminist standpoint: Developing the ground for a specifically feminist historical materialism. In S. G. Harding \& M. B. Hintikka (Eds.), Discovering reality. Feminist perspectives on epistemology, metaphysics, methodology, and philosophy of science. Kluwer Academic Publishers. 
Hatch, T., \& Skipper, A. (2016). How much are PhD students publishing before graduation?: An examination of four social science disciplines. Journal of Scholarly Publishing, 47(2), 171-179. https://doi.org/10.3138/jsp.47.2.171

Heath-Stout, L. E. (2020). Who writes about archaeology? An intersectional study of authorship in archaeological journals. AMERICAN ANTIQUITY, 85(3), 20.

Hedgecock, J. S. (2008). Lessons I must have missed: Implicit literary practices in graduate education. In C. P. Casanave \& X. M. Li (Eds.), Learning the literacy practices of graduate school: Insiders' reflections on academic enculturation. University of Michigan Press.

Hesse-Biber, S. N. (2017). The practice of qualitative research (3rd ed.). SAGE Publications.

Hesse-Biber, S. N., Leavy, P., \& Yaiser, M. L. (2004). Feminist approaches to research as a process: Reconceptualizing epistemology, methodology, and method. In S. N. Hesse-Biber \& M. L. Yaiser (Eds.), Feminist perspectives on social research. Oxford University Press.

Hesse-Biber, S. N., \& Piatelli, D. (2012). The feminist practice of holistic reflexivity. In S. N. Hesse-Biber (Ed.), Handbook of feminist research: Theory and praxis (Second edition., pp. 557-582). SAGE Publications.

Hesse-Biber, S. N., \& Yaiser, M. L. (2004). Feminist perspectives on social research. Oxford University Press. 
Hilário, C. M., Martínez-Ávila, D., Grácio, M. C. C., \& Wolfram, D. (2018). Authorship in science: A critical analysis from a Foucauldian perspective. Research Evaluation, 27(2), 63-72. https://doi.org/10.1093/reseval/rvx041

Holmes, S. L., Land, L. D., \& Hinton-Hudson, V. D. (2007). Race still matters: Considerations for mentoring Black women in academe. Negro Educational Review, 58(1/2), 105-129.

hooks, b. (1984). Feminist theory: From margin to center ( $1^{\text {st }}$ ed.). South End Press. hooks, b. (1994). Teaching to transgress: Education as the practice of freedom. Routledge.

Huber, L. P. (2009). Disrupting apartheid of knowledge: Testimonio as methodology in Latina/o critical race research in education. International Journal of Qualitative Studies in Education, 22(6), 639-654. https://doi.org/10.1080/09518390903333863

Humble, Á. M., Solomon, C. R., Allen, K. R., Blaisure, K. R., \& Johnson, M. P. (2006). Feminism and mentoring of graduate students. Family Relations, 55(1), 2-15. https://doi.org/10.1111/j.1741-3729.2006.00352.x

Hur, H., Andalib, M. A., Maurer, J. A., Hawley, J. D., \& Ghaffarzadegan, N. (2017). Recent trends in the U.S. Behavioral and Social Sciences Research (BSSR) workforce. PLoS ONE, 12(2). https://doi.org/10.1371/journal.pone.0170887

Hyland, K. (2015). Academic publishing: Issues and challenges in the construction of knowledge. Oxford University Press. 
Hyland, K. (2016). Academic publishing and the myth of linguistic injustice. Journal of Second Language Writing, 31, 58-69. https://doi.org/10.1016/j.jslw.2016.01.005

Ivanič, R. (1998). Writing and identity: The discoursal construction of identity in academic writing. John Benjamins.

Jones, D. R. (2016). A proposed systems model for socializing the graduate writer. Studies in Higher Education, 43(1), 1-17. https://doi.org/10.1080/03075079.2016.1160276

Kamler, B. (2010). Revise and resubmit: The role of publication brokers. In C. Aitchison, B. Kamler, \& A. Lee (Eds.), Publishing pedagogies for the doctorate and beyond. Routledge.

Kelly, B. T. (2019, March 29). Though more women are on college campuses, climbing the professor ladder remains a challenge. https://www.brookings.edu/blog/brown-center-chalkboard/2019/03/29/thoughmore-women-are-on-college-campuses-climbing-the-professor-ladder-remains-achallenge/

Kelly, B. T., \& McCann, K. I. (2014). Women faculty of color: Stories behind the statistics. The Urban Review, 46(4), 681-702. https://doi.org/10.1007/s11256014-0275-8

Kim, K. M. (2015). Post/graduate feedback in second language writing: The feedback network on the dissertation proposal. In C. Badenhorst \& C. Guerin (Eds.), Research literacies and writing pedagogies for masters and doctoral writers (pp. 238-256). Brill. 
Kubota, R. (2003). Striving for original voice in publication?: A critical reflection. In S. Vandrick \& C. P. Casanave (Eds.), Writing for scholarly publication: Behind the scenes in language education (pp. 53-60). Routledge.

Lave, J., \& Wenger, E. (1991). Situated learning: Legitimate peripheral participation. Cambridge University Press.

Le Guin, U. K. (1989). Dancing at the edge of the world: Thoughts on words, women, places. Gollancz.

Leggatt-Cook, C. (2011). An uncertain balance: Negotiating theory, politics and love in academic writing. Feminism \& Psychology, 21(3), 393-410.

https://doi.org/10.1177/0959353510370029

Li, X. M. (2008). Learning to write a thesis with an argumentative edge. In C. P. Casanave \& X. M. Li (Eds.), Learning the literacy practices of graduate school: Insiders' reflections on academic enculturation. University of Michigan Press.

Liang, S., \& Fu, Y. (2020). Otter Voice Meeting Notes (2.1.1) [Computer software]. https://otter.ai

Lillis, T., \& Curry, M. J. (2006). Professional academic writing by multilingual scholars: Interactions with literacy brokers in the production of English-medium texts. Written Communication, 23(1), 3-35. https://doi.org/10.1177/0741088305283754

Lillis, T., \& Curry, M. J. (2018). Trajectories of knowledge and desire: Multilingual women scholars researching and writing in academia. Journal of English for Academic Purposes, 32, 53-66. https://doi.org/10.1016/j.jeap.2018.03.008 
Lillis, T., \& Turner, J. (2001). Student writing in higher education: Contemporary confusion, traditional concerns. Teaching in Higher Education, 6(1), 57-68. https://doi.org/10.1080/13562510020029608

Linabary, J. R., \& Hamel, S. A. (2017). Feminist online interviewing: Engaging issues of power, resistance and reflexivity in practice. Feminist Review, 115(1), 97-113. https://doi.org/10.1057/s41305-017-0041-3

Lincoln, Y. S., \& Guba, E. G. (1986). But is it rigorous? Trustworthiness and authenticity in naturalistic evaluation. New Directions for Program Evaluation, 1986(30), 7384. https://doi.org/10.1002/ev.1427

Lorde, A. (2007). Sister outsider: Essays and speeches (Rev. ed.). Crossing Press.

Lundine, J., Bourgeault, I. L., Glonti, K., Hutchinson, E., \& Balabanova, D. (2019). “I don't see gender": Conceptualizing a gendered system of academic publishing. Social Science \& Medicine, 235, 112388. https://doi.org/10.1016/j.socscimed.2019.112388

Madill, A., \& Gough, B. (2008). Qualitative research and its place in psychological science. Psychological Methods, 13(3), 254-271. https://doi.org/10.1037/a0013220

Margolis, E., \& Romero, M. (1998). “The department Is very male, very white, very old, and very conservative": The functioning of the hidden curriculum in graduate sociology departments. Harvard Educational Review, 68(1), 1-33. https://doi.org/10.17763/haer.68.1.1q3828348783j851 
Mato, D. (2011). There is no 'universal' knowledge, intercultural collaboration is indispensable. Social Identities, 17(3), 409-421. https://doi.org/10.1080/13504630.2011.570978

Mayer, S. J., \& Rathmann, J. M. K. (2018). How does research productivity relate to gender? Analyzing gender differences for multiple publication dimensions. Scientometrics, 117(3), 1663-1693. https://doi.org/10.1007/s11192-018-2933-1

McElhinny, B., Hols, M., Holtzkener, J., Unger, S., \& Hicks, C. (2003). Gender, publication and citation in sociolinguistics and linguistic anthropology: The construction of a scholarly canon. Language in Society, 32(3), 299-328. https://doi.org/10.1017/S0047404503323012

McFarland, J., Hussar, B., de Brey, C., Snyder, T., Wang, X., Wilkinson-Flicker, S., Gebrekristos, S., Zhang, J., Rathbun, A., Barmer, A., Mann, F. B., Hinz, S., Nachazel, T., Smith, W., \& Ossolinski, M. (2017). The condition of education 2017 (NCES 2017-144; p. 386). U.S. Department of Education. https://nces.ed.gov/pubs2017/2017144.pdf

McMillan Cottom, T., \& Gay, R. (2020, February 25). Hear to slay (No. 39). https://luminary.link/xMW4BUF1Ifb

Merrick, E. (1999). “Like chewing gravel": On the experience of analyzing qualitative research findings using a feminist epistemology. Psychology of Women Quarterly, 23(1), 47-57. https://doi.org/10.1111/j.1471-6402.1999.tb00340.x 
Meyerson, D., \& Tompkins, M. (2007). Tempered radicals as institutional change agents: The case of advancing gender equity at the University of Michigan. Harvard Journal of Law and Gender, 30(2), 303-322.

Mitchell, K. M. (2017). Academic voice: On feminism, presence, and objectivity in writing. Nursing Inquiry, 24(4), e12200. https://doi.org/10.1111/nin.12200

Mohanty, C. (2003). "Under Western Eyes” revisited: Feminist solidarity through anticapitalist struggles. Signs, 28(2), 499-535. https://doi.org/10.1086/342914

Mott, C., \& Cockayne, D. (2017). Citation matters: Mobilizing the politics of citation toward a practice of 'conscientious engagement.' Gender, Place \& Culture, 24(7), 954-973. https://doi.org/10.1080/0966369X.2017.1339022

Mountz, A. Bonds, A., Mansfield, B., Loyd, J., Hyndman, J., Walton-Roberts, M., ... \& Curran, W. (2015). For slow scholarship: A feminist politics of resistance through collective action in the neoliberal university. ACME: An International Journal for Critical Geographies, 14(4), 1235-1259.

Nelson, N., \& Castelló, M. (2012). Academic writing and authorial voice. In M. Castelló \& C. Donahue (Eds.), University writing: Selves and texts in academic societies (1st ed.). Emerald.

O’Meara, K. (2007). Striving for what? Exploring the pursuit of prestige. In J. C. Smart (Ed.), Higher Education: Handbook of Theory and Research (Vol. 22, pp. 121179). Springer Netherlands. https://doi.org/10.1007/978-1-4020-5666-6_3

O’Meara, K., Kuvaeva, A., Nyunt, G., Waugaman, C., \& Jackson, R. (2017). Asked more often: Gender differences in faculty workload in research universities and the 
work interactions that shape them. American Educational Research Journal, 54(6), 1154-1186. https://doi.org/10.3102/0002831217716767

Orphan, C. (2018, July 25). Why regional comprehensive universities are vital parts of U.S. higher education. Scholars Strategy Network. https://scholars.org/brief/whyregional-comprehensive-universities-are-vital-parts-us-higher-education

Paasi, A. (2005). Globalisation, academic capitalism, and the uneven geographies of international journal publishing spaces. Environment and Planning, 37(5), 769789. https://doi.org/10.1068/a3769

Paré, A. (2010). Slow the presses: Concerns about premature publication. In C. Aitchison, B. Kamler, \& A. Lee (Eds.), Publishing pedagogies for the doctorate and beyond. Routledge.

Planty, M., Kena, G., \& Hannes, G. (2009). The condition of education 2009 in brief (NCES 2009-082). U.S. Department of Education. https://nces.ed.gov/programs/digest/d08/tables/dt08_249.asp

Potgieter, F., \& Smit, B. (2009). Finding academic voice: A critical narrative of knowledge-making and discovery. Qualitative Inquiry, 15(1), 214-228. https://doi.org/10.1177/1077800408322792

Prior, P. (1998). Writing/disciplinarity: A sociohistoric account of literate activity in the academy. Lawrence Erlbaum Associates.

Prior, P., \& Bilbro, R. (2012). Academic enculturation: Developing literate practices and disciplinary identities. In M. Castelló \& C. Donahue (Eds.), University writing: 
Selves and texts in academic societies (pp. 19-32). Emerald Group Publishing Limited.

Rautman, A. E. (2012). Who gets published in American Antiquity? SAA Archaeological Record, 12(2), 25-26.

Rice, K. G., Lopez, F. G., Richardson, C. M. E., \& Stinson, J. M. (2013). Perfectionism moderates stereotype threat effects on STEM majors' academic performance. Journal of Counseling Psychology, 60(2), 287-293. http://dx.doi.org.proxy.lib.pdx.edu/10.1037/a0032052

Roberts, N. A., \& Plakhotnik, M. S. (2009). Building social capital in the academy: The nature and function of support systems in graduate adult education. New Directions for Adult and Continuing Education, 122, 43-52. https://doi.org/10.1002/ace.333

Ruggeri, A. (2018, February 20). The dangerous downsides of perfectionism. $B B C$. https://www.bbc.com/future/article/20180219-toxic-perfectionism-is-on-the-rise Saldaña, J. (2016). The coding manual for qualitative researchers ( $3^{\text {rd }}$ ed.). SAGE. Sánchez-Martín, C., \& Seloni, L. (2019). Transdisciplinary becoming as a gendered activity: A reflexive study of dissertation mentoring. Journal of Second Language Writing, 43, 24-35. https://doi.org/10.1016/j.jslw.2018.06.006

Sandler, B. H., \& Hall, R. M. (1986). The campus climate revisited: Chilly for women faculty, administrators, and graduate students (No. ED282462; Project on the Status and Education of Women). Association of American Colleges. https://files.eric.ed.gov/fulltext/ED282462.pdf 
Scimago Journal \& Country Rank. (2020). Scimago Institutions Rankings.

https://www.scimagojr.com/

Sefcovic, E. M. I., \& Bifano, D. T. (2004). Creating a rhetorical home for feminists in the "Master's House" of the academy: Toward a gendered taxonomy of form and content. Women and Language: WL; Urbana, 27(1), 53-62.

Settles, I. H., Jones, M. K., Buchanan, N. T., \& Dotson, K. (2020). Epistemic exclusion: Scholar(ly) devaluation that marginalizes faculty of color. Journal of Diversity in Higher Education. http://dx.doi.org.proxy.lib.pdx.edu/10.1037/dhe0000174

Shvidko, E., \& Atkinson, D. (2019). From student to scholar: Making the leap to writing for publication. In P. Habibie \& K. Hyland (Eds.), Novice writers and scholarly publication: Authors, mentors, gatekeepers (pp. 155-175). Springer International Publishing. https://doi.org/10.1007/978-3-319-95333-5_9

Smith, D. E. (1987). The everyday world as problematic: A feminist sociology. Northeastern University Press.

Souto-Manning, M., \& Ray, N. (2007). Beyond survival in the ivory tower: Black and Brown women's living narratives. Equity \& Excellence in Education, 40(4), 280290. https://doi.org/10.1080/10665680701588174

Speakman, R. J., Hadden, C. S., Colvin, M. H., Cramb, J., Jones, K. C., Jones, T. W., Lulewicz, I., Napora, K. G., Reinberger, K. L., Ritchison, B. T., Edwards, A. R., \& Thompson, V. D. (2018). Market share and recent hiring trends in anthropology faculty positions. PLOS ONE, 13(9), e0202528. https://doi.org/10.1371/journal.pone.0202528 
Sprague, J. (2016). Feminist methodologies for critical researchers: Bridging differences ( $2^{\text {nd }}$ ed.). Rowman \& Littlefield.

Sprague, J., \& Kobrynowicz, D. (2004). A feminist epistemology. In S. N. Hesse-Biber \& M. L. Yaiser (Eds.), Feminist perspectives on social research. Oxford University Press.

Spray, E., \& Hunt, J. W. (2015). Measuring the academic literacies beliefs and researcher identity of research students. Journal of Learning Development in Higher Education, 667(8).

Stockdill, B. C., \& Danico, M. Y. (2012). Transforming the ivory tower: Challenging racism, sexism, and homophobia in the academy. University of Hawaii Press.

Survey of Earned Doctorates. (2016). US National Science Foundation.

https://www.nsf.gov/statistics/2018/nsf18304/datatables/tab23.htm

Swales, J. (1996). Occluded genres in the academy: The case of the submission letter. In E. Ventola \& A. Mauranen (Eds.), Academic writing: Intercultural and textual issues (pp. 45-58). John Benjamins Publishing.

Tardy, C. M. (2005). “It's like a story": Rhetorical knowledge development in advanced academic literacy. Journal of English for Academic Purposes, 4(4), 325-338. https://doi.org/10.1016/j.jeap.2005.07.005

Tardy, C. M., \& Matsuda, P. K. (2009). The construction of author voice by editorial board members. Written Communication, 26(1), 32-52.

https://doi.org/10.1177/0741088308327269 
Teeuwsen, P., Ratković, S., \& Tilley, S. A. (2014). Becoming academics: Experiencing legitimate peripheral participation in part-time doctoral studies. Studies in Higher Education, 39(4), 680-694. https://doi.org/10.1080/03075079.2012.729030

Terosky, A. L. (2019). Wings of an actor: The role of relationships in women scholars' intellectual trajectories. The Review of Higher Education, 43(1), 25-52. https://doi.org/10.1353/rhe.2019.0089

Thein, A. H., \& Beach, R. (2010). Mentoring doctoral students towards publication within scholarly communities of practice. In C. Aitchison, B. Kamler, \& A. Lee (Eds.), Publishing pedagogies for the doctorate and beyond. Routledge.

Pew Charitable Trust (2019). Two decades of change in federal and state higher education funding: Recent trends across levels of government. . https://pew.org/2M7okiZ

Vandrick, S. (2003). On beginning to write at 40. In S. Vandrick \& C. P. Casanave (Eds.), Writing for scholarly publication: Behind the scenes in language education (pp. 53-60). Routledge.

Webb, C. (1992). The use of the first person in academic writing: Objectivity, language and gatekeeping. Journal of Advanced Nursing, 17(6), 747-752. https://doi.org/10.1111/1365-2648.ep8532499

Weber, L. (2004). Conceptual framework for understanding race, class, gender and sexuality. In S. N. Hesse-Biber \& M. L. Yaiser (Eds.), Feminist perspectives on social research. Oxford University Press. 
Welton, A. D., Mansfield, K. C., \& Lee, P.-L. (2014). Mentoring matters: An exploratory survey of educational leadership doctoral students' perspectives. Mentoring \& Tutoring: Partnership in Learning, 22(5), 481-509.

https://doi.org/10.1080/13611267.2014.983330

Wenger, E. (1998). Communities of practice: Learning, meaning, and identity. Cambridge University Press.

Williams, R. B. (2011). Citation systems in the biosciences: A history, classification and descriptive terminology. Journal of Documentation, 67(6), 995-1014.

http://dx.doi.org.proxy.lib.pdx.edu/10.1108/00220411111183564

Winkle-Wagner, R., \& McCoy, D. L. (2016). Entering the (postgraduate) field: Underrepresented students' acquisition of cultural and social capital in graduate school preparation programs. The Journal of Higher Education, 87(2), 178-205. https://doi.org/10.1353/jhe.2016.0011

Wolgemuth, J. R., \& Harbour, C. P. (2008). A man's academy? The dissertation process as feminist resistance. NASPA Journal About Women in Higher Education, 1(1), 183-203. https://doi.org/10.2202/1940-7890.1010 


\section{Appendix A: Solicitation Email}

SUBJECT HEADING: Interview Request for EdD Dissertation

Dear $* * *$

I am an EdD student in the College of Education here at Portland State University. For my dissertation, I am researching how women professors participate in academic research and publication in the social sciences. I am reaching out to you to see if you would be interested and available in being interviewed for this study. I have attached a file with an overview of the project and expected time commitment from the participants.

Please let me know if you are interested in participating, or if you are not, would you have any suggestions for other people in your department who I could contact?

Thank you for your time and consideration.

Best,

Linnea Spitzer 


\section{Appendix B: Solicitation Email Attachment}

Thank you for your interest in participating in this study. Here an overview of the topic and information about the potential time-commitment.

\section{Overview of the study:}

In this study, I am seeking to understand how women faculty have learned and interpreted the norms of academic communication, and how they either perpetuate or subvert these norms through their academic work and through their mentoring practices. By focusing on academic writing for publication, I hope to better understand how women faculty in the social sciences create space for their scholarly identities in their research practice and how they mentor the next generation of scholars in the practice of scholarship. The purpose of this study is to explore how women understand, describe, and produce scholarly work. More specifically, this study will explore how women faculty have learned and interpreted the norms of academic communication, and how they either perpetuate or subvert these norms through their academic work and through their mentoring practices.

\section{Time Commitment:}

For this study, I will be asking for three interviews, 60-90 minutes each in Spring, Summer, and/or Fall 2020. I will time these interviews based on the availability of my participants.

Thank you for considering participation in this study. 


\section{Appendix C: Interview Protocols}

\section{Interview 1.}

Protocol prior to beginning the interview:

1. Thank the interviewee for participation

2. Provide an overview of the study

3. Review consent form, note measures to protect confidentiality, ask for pseudonym

4. Ask participant if she has any questions

5. Ask for permission to begin recording

Interview Questions:

1. Could you talk a little bit about your research?

a. (prompt, if necessary) Why are you interested in this topic?

2. How would you define good writing in your discipline?

a. (follow-up, if necessary) What are some of the rules of writing in your discipline?

3. Do you consider yourself a good writer? Why or why not?

4. Can you describe how you were taught about writing in graduate school?

a. (prompt) Who taught you?

b. (prompt) What did you learn?

5. Can you describe one of your early experiences with publication?

6. What did you learn about writing as you started publishing research? 
7. What do publishers expect in terms of written language from articles in your discipline?

8. Scholarly publications often expect writers to write from a position of distance, both in terms of voice (like using the third person or maintaining an objective "disinterested tone") and in terms of explicit reference to personal connection to the research. Some woman scholars have found that these parameters constrain their ability to represent themselves in their research. In your scholarly writing, do you find ways to express yourself or your voice?

a. (follow-up) If yes, in what ways? If no, do you find other ways to express your connection with your work?

9. For our next interview, I would like to review 2-3 of your publications, ones that you feel are the best representations of your work. I would like to review these with you, so we can talk about how you see yourself and your voice represented in your written work. Would you be willing to send me a copy of these publications?

\section{Interview 2.}

Protocol prior to beginning the interview:

1. Summarize conversation from previous interview,

2. Ask follow-up questions,

3. Ask if she has anything to add. 
Interview Questions:

1. For each paper we review: Can you tell me a little about your experience writing this paper?

a. Why this topic?

b. What was the process of drafting like?

c. What was the process of revising based on reviewer or editorial feedback like?

d. Is there anywhere you see yourself or your voice represented in the text of this article? Could you underline or highlight it and tell me about why this represents you?

i. In what way do you think this represents your voice?

ii. Why did you make the choice to include this wording here?

2. Is there anything regarding how you see yourself represented in your research that we haven't covered today that you would like to talk about?

3. In our next interview, I would like to talk about how you work with your graduate students, including students in your classes and your advisees on their writing practice.

\section{Interview 3.}

Protocol prior to beginning the interview:

1. Summarize conversation from previous interview,

2. Ask follow-up questions,

3. Ask if she has anything to add. 
Interview Questions:

1. What do you tell your graduate students and advisees about good writing in your discipline?

2. Do your students ever feel seem constrained by the expectations of writing in your discipline?

a. Do you see these expectations as constraining?

b. (follow up) How do you help them through this?

3. Do you think that the writing your students do in their graduate programs is similar to or different from the writing they might do professionally? In what ways is it similar or different?

4. Where do you think your messaging to your students around writing comes from?

5. Do you follow your own advice to students in your writing practice?

a. (prompt) If yes, in what ways? If now, why not?

6. Are there any "rules" around academic writing that you intentionally ignore, or that you tell your students to ignore?

7. What do the next generation of women scholars need to understand about publishing in your discipline?

8. Is there anything regarding mentoring that we haven't covered today that you would like to talk about? 